\title{
Investigation of Water Leakage Through Direct Tension Cracks in Reinforced Concrete Panels
}

By

Seyyednezameddin Bozorgzadeh

B.Sc., Azad University of Iran, Tehran Central Branch, 2009

\author{
A Thesis \\ Presented to Ryerson University \\ in Partial Fulfillment of the \\ Requirements for the Degree of \\ Master of Applied Science \\ in the Program of \\ Civil Engineering
}

Toronto, Ontario, Canada, 2012

(C)Seyyednezameddin Bozorgzadeh 2012 



\section{AUTHOR'S DECLARATION FOR ELECTRONIC SUBMISSION OF A THESIS}

I hereby declare that I am the sole author of this thesis. This is a true copy of the thesis, including any required final revisions, as accepted by my examiners. I authorize Ryerson University to lend this thesis to other institutions or individuals for the purpose of scholarly research

Seyyednezameddin Bozorgzadeh

I further authorize Ryerson University to reproduce this thesis by photocopying or by other means, in total or in part, at the request of other institutions or individuals for the purpose of scholarly research. I understand that my thesis may be made electronically available to the public.

Seyyednezameddin Bozorgzadeh 

Investigation of Water Leakage Through Direct Tension Cracks in Reinforced Concrete Panels

Master of Applied Science 2012

Seyyednezameddin Bozorgzadeh

Civil Engineering

Ryerson University

\begin{abstract}
In this study the leakage of pressurized water through direct tension cracks in reinforced concrete (RC) panels is investigated experimentally. The results of the experiment can contribute to the field from different aspects since not many experimental studies of this kind have been reported in the literature. In this experimental program, three RC panels are subjected to direct tension force in order to form a major crack. The leakage test is then performed on the cracked specimens and the leakage of water through the crack is measured for different crack widths. The collected data consists of reinforcement strains, crack widths and the leakage rate through the cracks. Related theoretical models are compared against the experiment results. These results indicate that the leakage of water through a crack depend on the pressure of the water, cube of the crack width and crack width gradient.
\end{abstract}





\section{Acknowledgements}

The author wishes to express his gratitude to his supervisor Dr. Reza Kianoush whom without his continuous guidance, suggestions and support this study could not be accomplished. The experimental studies would not have been possible without the support of laboratory lead technical officer Nidal Jalouk and technical officer Domenic Valle. The author would also acknowledge valuable discussions with Dr. Armin Ziari on the subject. 



\section{Contents}

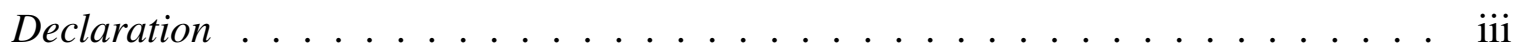

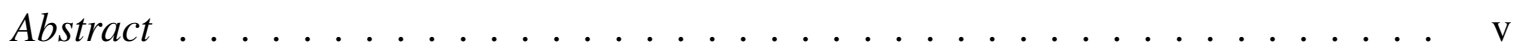

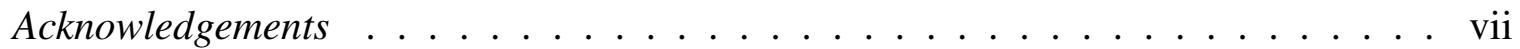

List of Tables . . . . . . . . . . . . . . . . . . . xi

List of Figures . . . . . . . . . . . . . . . . . . . . . xiii

List of Symbols . . . . . . . . . . . . . . . . . . . xvii

$\begin{array}{lll}1 & \text { Introduction } & 1\end{array}$

1.1 General . . . . . . . . . . . . . . . . . . . . . 1

1.2 Objectives and Scope $\ldots \ldots \ldots \ldots$. . . . . . . . . . . . . . 2

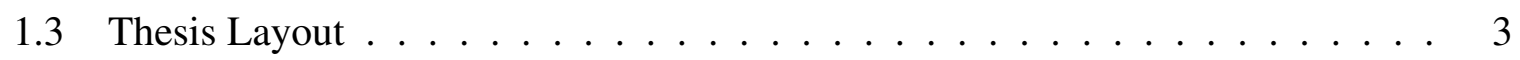

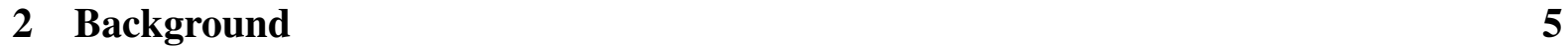

2.1 General . . . . . . . . . . . . . . . . . . . 5

2.2 Direct Tension Cracking _. . . . . . . . . . . . . . . . . . 7

2.3 Permeability of Cracks in Concrete . . . . . . . . . . . . . . . . . 9

2.3 .1 Cracks and Water Tightness . . . . . . . . . . . . . . . . . 9

2.3 .2 Basic Flow Equations $\ldots \ldots$. . . . . . . . . . . . . . 10

2.3 .3 Permeability Coefficient . . . . . . . . . . . . 12

2.3 .4 Roughness Factor . . . . . . . . . . . . . . . . . . . 13

2.3 .5 Effective Crack Width . . . . . . . . . . . . . . 16

2.4 Self-healing of Cracks $\ldots \ldots \ldots \ldots$

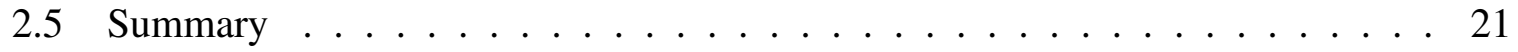




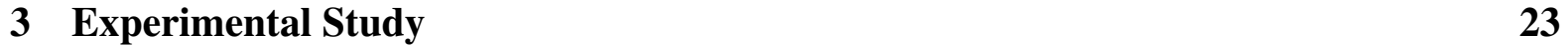

3.1 Introduction . . . . . . . . . . . . . . . . . . 23

3.2 Experimental Study $\ldots \ldots \ldots \ldots$. . . . . . . . . . . . . . . . . 24

3.2 .1 Test Specimens . . . . . . . . . . . . . . . . . . . . 24

3.2 .2 Casting and Curing . . . . . . . . . . . . . . . . . 25

3.2 .3 Material Properties . . . . . . . . . . . . . . . . 26

3.2 .4 Test setup . . . . . . . . . . . . . . . . . . 30

3.2 .5 Test Procedure and Instrumentation $\ldots \ldots$. . . . . . . . . . . . 37

4 Test Results and Discussion $\quad 43$

4.1 General . . . . . . . . . . . . . . . . . . . 43

4.2 Phase I . . . . . . . . . . . . . . . . . . . . . . . . 43

$4.2 .1 \quad$ Specimen S150 . . . . . . . . . . . . . . . . . . . . . 44

4.2 .2 Specimen S250 . . . . . . . . . . . . . . . . . . . . 45

$4.2 .3 \quad$ Specimen S200 . . . . . . . . . . . . . . . . . . . . . . 48

4.3 Phase II . . . . . . . . . . . . . . . . . . . . 53

$4.3 .1 \quad$ Specimen S250 . . . . . . . . . . . . . . . . . . 54

$4.3 .2 \quad$ Specimen S200 . . . . . . . . . . . . . . . . . 56

4.4 Phase III . . . . . . . . . . . . . . . . . . . . . . 58

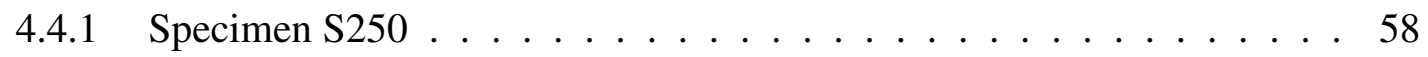

4.4 .2 Specimen S200 . . . . . . . . . . . . . . . . . . 63

4.5 Leakage Test Results Analysis . . . . . . . . . . . . . . . . . . . . 65

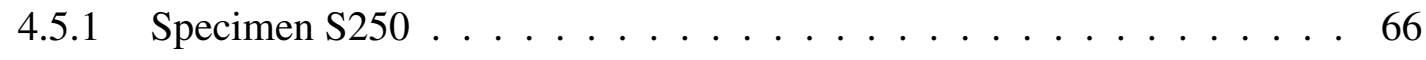

4.5 .2 Specimen S200 . . . . . . . . . . . . . . . . . . . . . 69

\begin{tabular}{lll}
\hline Conclusions & 75
\end{tabular}

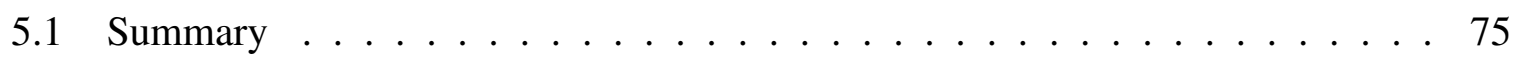

5.2 Conclusions . . . . . . . . . . . . . . . . . . 76

5.3 Recommendations for Future Research . . . . . . . . . . . . . . 77

\begin{tabular}{ll}
\hline References & 79
\end{tabular} 


\section{List of Tables}

2.1 Guide to reasonable crack widths in reinforced concrete under service load $(\mathrm{ACI} 224-\mathrm{R}) \ldots \ldots \ldots \ldots \ldots$

2.2 Roughness Factor from BIDEPE Test $\ldots \ldots \ldots \ldots \ldots$

3.1 Specimen Information . . . . . . . . . . . . . . . . . 25

3.2 Concrete Compressive Strength $\ldots \ldots \ldots$

4.1 Theoretical Cracking Load . . . . . . . . . . . . . . . . . . . . . . . . 44

4.2 Leakage Test Crack Widths (mm), S250 . . . . . . . . . . . . . . . . 61

4.3 Measured Leakage for Different Crack Widths, S250 . . . . . . . . . . . . 61

4.4 Measured Leakage for Different Crack Widths, S200 . . . . . . . . . . . . . . 64

$4.5 \quad$ Crack Widths used for Leakage Test in millimeter, S200 . . . . . . . . . . 72

$4.6 \quad$ Leakage per meter length, $\mathbf{S} 250$. . . . . . . . . . . . . . . . . . . . . 74

$4.7 \quad$ Leakage per meter length, S200 . . . . . . . . . . . . . . . . . . . . 74 



\section{List of Figures}

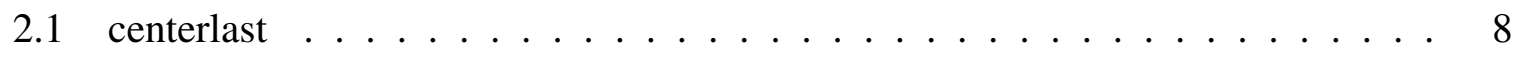

2.2 Effective Crack width, source: Akhavan et. al(2012) . . . . . . . . . . . . 17

3.1 RC panel Sections . . . . . . . . . . . . . . . . . . . . 25

3.2 Casting and Curing of Specimens . . . . . . . . . . . . . . . . 26

3.3 Steel Strain Gage installation . . . . . . . . . . . . . . . . . . . . . 27

3.4 Strain Gage Locations on Rebars $\ldots \ldots \ldots$

3.5 Concrete Tests . . . . . . . . . . . . . . . . . . . . . . . . . . . . . . . . . 29

3.6 Rebar Tensile Stress-Strain Curve . . . . . . . . . . . . . . . . . . 30

3.7 Rebars fixed to the RC beam by welding a nut . . . . . . . . . . 31

3.8 Setup Plan View . . . . . . . . . . . . . . . . . . . . . . . . . . 32

3.9 Reinforcement layout of RC distributing beam $\ldots \ldots \ldots 33$

3.10 Details of reinforcing bars used in RC distributing beam . . . . . . . . . 34

3.11 South view of the setup - RC beam on roller supports $\ldots \ldots \ldots$. . . . . 35

3.12 Test Setup, Phase I $\ldots \ldots \ldots$

3.13 Side Rubber Pad . . . . . . . . . . . . . . . . . . . . . . 37

3.14 Gum Rubber used between the chamber and concrete surface . . . . . . . . . . 38

3.15 Phase I, Surface LVDTs . . . . . . . . . . . . . . . . . . . . . . . . 39

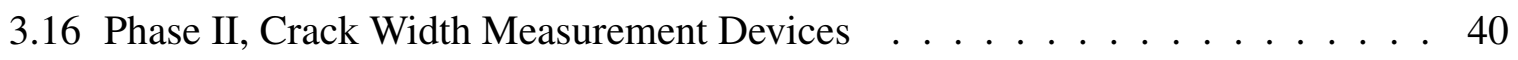

3.17 Pressure Gauge . . . . . . . . . . . . . . . . . . . . . 41

3.18 Leakage Test . . . . . . . . . . . . . . . . . . . . . . 41

4.1 Sample S150 Corner Cracks . . . . . . . . . . . . . . . . . . . . 45

4.2 Schematic Figure of Cracks on Specimen S250 . . . . . . . . . . . . . 46

4.3 Rebar Strain-Tensile Load, S250, Phase I $\ldots \ldots \ldots \ldots$ 
4.4 Crack widths recorded by LVDTs, S250, Phase I $\ldots \ldots \ldots \ldots$

$4.5 \quad$ LVDT Readings, S250,Phase I $\ldots \ldots \ldots \ldots \ldots \ldots$

4.6 LVDT Readings, S250, Phase I _ . . . . . . . . . . . . . . . 51

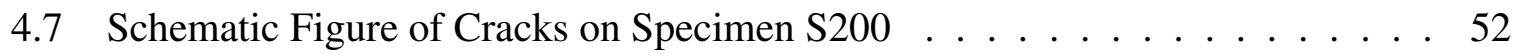

4.8 LVDT Readings, S200, Phase I . . . . . . . . . . . . . . . 53

4.9 Rebar Strain-Tensile Load, S200, Phase I $\ldots \ldots \ldots \ldots \ldots$

4.10 Crack Width, S250, Phase II … . . . . . . . . . . . . . 55

4.11 Rebar Strains, S250, Phase II $\ldots \ldots \ldots \ldots$

4.12 Crack Width, S200, Phase II … . . . . . . . . . . . . . 57

4.13 Strain-Tensile Load, S200, Phase II _ . . . . . . . . . . . . . . . 57

4.14 Top Crack Width (Outside of the Chamber),S250, Phases II and III . . . . . . 59

4.15 Bottom Crack Width, S250, Phases II and III $\ldots \ldots \ldots \ldots$

4.16 Rebar Strains, S250, Phase II and Phase III … . . . . . . . . 60

4.17 Crack Widths vs. Tensile Load, S250, Phase III . . . . . . . . . . . . 60

4.18 Leakage Flow vs. Top Crack Width, S250 . . . . . . . . . . . . . . . 62

4.19 Leakage Flow vs. Bottom Crack Width, S250 … . . . . . . . . . . 62

4.20 Crack Widths, S200, Phase III ． . . . . . . . . . . . . . . . 63

4.21 Leakage Flow vs. Top Crack Width, S200 … . . . . . . . . . . . . . 64

4.22 Leakage Flow vs. Bottom Crack Width, S200 . . . . . . . . . . . . . 65

4.23 Leakage vs. Bomhard Effective Crack Width, S250 . . . . . . . . . . . 67

4.24 Leakage vs. Akhavan Effective Crack Width, S250 . . . . . . . . . . . 67

4.25 Leakage vs. Water Head, S250, Crack Width of $0.15 \mathrm{~mm} \ldots \ldots$. . . . . 69

4.26 Roughness Factor, S250 . . . . . . . . . . . . . . . . . . . . 70

4.27 Leakage vs. Effective Crack Width, S200 … . . . . . . . . . . . . 71

4.29 Crack Width Ratio . . . . . . . . . . . . . . . . . . . . . . . . . . 72

4.28 Roughness Factor, $\mathbf{S} 200 \ldots \ldots \ldots$ 


\section{List of Symbols}

$\bar{k} \quad$ non-dimensional permeability coefficient

$\Delta h \quad$ change in water head

$\Delta P \quad$ total pressure loss

$\mu \quad$ fluid viscosity

$v \quad$ kinematic viscosity

$\rho \quad$ fluid density

$\rho_{s} \quad$ percentage of longitudinal steel reinforcement

$\sigma \quad$ splitting tensile strength of concrete

$\sigma_{c t} \quad$ tensile stress of concrete

$\varepsilon_{s 2} \quad$ steel strain at the crack

$\varepsilon_{s E 1} \quad$ steel strain at the point of zero slip at pre-stabilized cracking

$\varepsilon_{S E 2} \quad$ steel strain at crack at the cracking load level

$\varepsilon_{s E} \quad$ steel strain at the point of zero slip

$\xi \quad$ roughness factor

$A_{e} \quad$ transformed cross sectional area

$A_{s} \quad$ longitudinal reinforcement area 
$E_{c} \quad$ concrete modulus of elasticity

$E_{s} \quad$ steel modulus of elastisity

$e_{z} \quad$ unit vector in the upward vertical direction

F $\quad$ body force per unit mass

$f_{c}^{\prime} \quad$ compressive strength of concrete

$f_{y} \quad$ yield stress of steel

$f_{c t} \quad$ tensile strength of concrete

$g$ gravitational acceleration, $\left(9.81 \mathrm{~m} / \mathrm{s}^{2}\right)$

$h \quad$ wall thickness

$i \quad$ hydraulic gradient

$J \quad$ volumetric flow

$k \quad$ coefficient of permeability

$l \quad$ crack length

$l_{t} \quad$ transmission length

$l_{s, \max }$ length over which slip occurs between steel and concrete in the vicinity of a crack (two times transmission length)

$m \quad$ number of columns in a crack

$N_{r} \quad$ cracking load

$p \quad$ pressure

$P_{c r} \quad$ cracking load

$Q \quad$ leakage flow

$Q_{r} \quad$ flow in a rough-wall crack 
$Q_{s} \quad$ flow in a smooth-wall crack

$Q_{1, T} \quad$ flow for the first row of elements

$Q_{p 1} \quad$ leakage flow due to pressure $p_{1}$

$S_{\max } \quad$ maximum crack spacing

$U \quad$ velocity vector

w $\quad$ crack width

$w_{\text {avg. }} \quad$ average crack width

$w_{\text {Bottom }}$ bottom crack width

$w_{e f f} \quad$ effective crack width

$w_{\text {top }} \quad$ top crack width 



\section{Chapter 1}

\section{Introduction}

\subsection{General}

Concrete cracking is inevitable due to its inherent low tensile strength. Cracking occurs when the concrete tensile stress in a member reaches the tensile strength of the concrete. Appropriate provisions must be undertaken to prevent or control the cracks according to type of crack and the structure. The following are some of the main causes of cracking in hardened concrete:

- Structural Loading including design loads, overloads and fatigue.

- Volume Instability can be caused by drying shrinkage, thermal changes or creep.

- Physio-Chemical effects like AAR/ASR/DEF, steel corrosion and freeze-thaw cycles.

Reinforced concrete (RC) is suited for environmental structures that are involved in storage or transmission of liquids such as reservoirs, sewage tanks, etc. Since these Liquid Containing Structures (LCS) are more vulnerable to adverse effects of crack formation, crack control is essential in these types of structures. Cracking will affect both durability and functionality of the structure by facilitating corrosion of the reinforcement and also may result in flow of the liquid in or out of the structure. To ensure serviceability and durability, the crack widths must be controlled and limited to specific values.

Due to their functionality, the design of LCS is governed by serviceability limit states. Among those, the leakage limit states mostly govern over other serviceability limit states like deflection. In prestressed concrete containers, leakage is totally prevented since the structure 
is designed to remain uncracked under service loads. On the other hand, the cracks must be limited to specific widths to control the leakage in RC containers.

Among different types of cracks, the ones induced in direct tension are more vulnerable to allow for the leakage of liquid in/out of the structure. These cracks penetrate through the wall of the container and create a thru path for the liquid. For instance, a vertical section of a circular tank has to carry the tensile ring force produced by the internal hydrostatic pressure of the liquid. Structural members such as floor and roof slabs, walls and tunnel linings also may be subjected to direct tensile stresses as a result of restraint volume change. Current codes of practice do not differentiate between direct tension cracks and other types of cracks. In case of leakage limit states, these cracks must be treated with more caution in comparison with other types of the cracks.

In order to determine appropriate crack width limitations, knowledge of water flow through the cracks is essential. A model from rock mechanics has been employed in the previous studies to predict the flow through the crack. This model, known as the Poiseuille flow, assumes laminar flow through a smooth parallel-sided slot. Concrete cracks have a rough inner surface and thus, the flow through them has a much lower rate compared to smooth gaps. A correction factor (known as roughness or tortuosity factor) is used to account for the crack morphology. A high deviation of the roughness factor is reported from previous studies. The reported values are either empirical or from experiments mostly performed on small-scale plain concrete specimens. As a result, the field still lacks an inclusive model capable of predicting the flow through cracked concrete.

\subsection{Objectives and Scope}

The main objective of this study is to provide some insight into the problem of water leakage through direct tension cracks. With this intention, an experimental study is carried out to investigate the subject. Three full-scale RC panels specimens are cracked in direct tension. The cracks are then subjected to pressurized fluid to measure the rate of leakage through them. A load-controlled setup is used to apply the tensile force on the the specimens in order to initiate a major crack and also to change the crack widths afterwards. The research is focused on the leakage of water through the cracks. The main expected outcomes of this research are the rates of water leakage through the cracks and the roughness factors for the cracks. The 
validity of analytical models are also evaluated and compared against the experimental results.

\subsection{Thesis Layout}

The current chapter is a brief introduction to the subject. A literature review on direct tension cracking and permeability of concrete cracks is presented in Chapter 2. Cracking behavior of reinforced concrete in direct tension is briefly covered since it was required to crack the test specimens in order to conduct the leakage test. Previous research on permeability of cracked concrete are summarized. Governing flow equations, roughness factors and effective crack widths are then discussed.

Chapter 3 introduces the designed experimental study. Following the test specimens and material properties, the test setup is explained. The test procedure is then described in details. This investigation consists of three related phases which are described individually.

Chapter 4 reports the results of the experimental study and the discussions on these results. The results of each phase are reported for all specimens. The results of the leakage test are discussed in more details. Comparisons with previous studies and new findings are included in this chapter as well. Chapter 5 begins with a short summary of the research. It is followed by the conclusions and finally recommendations for the future work. 



\section{Chapter 2}

\section{Background}

\subsection{General}

Reinforced concrete (RC) is widely used in the construction industry. Because of the low tensile strength of the concrete, formation of cracks under very low tensile forces is inevitable. Aesthetic problems, reduced durability and serviceability are among undesirable effects of cracking on RC structures. The effects of cracking are more severe on reinforced concrete environmental structures. Some of these structures like reservoirs, sewage tanks and nuclear power plants are engaged in transmission or storage of liquids and thus, liquid tightness is considered to be their main functionality. Uncracked concrete can be assumed as tight for most of the cases. But concrete usually cracks at very low tensile stresses and permeability of cracked concrete is exponentially larger than that of uncracked concrete. High permeability will result in leakage of water in or out of the structure, reduced serviceability and even endangers safety in some conditions.

In order to protect reinforced concrete structures from the above mentioned adverse effects of cracking, crack widths must not exceed certain limitations. The maximum crack width that may be considered not to ruin the appearance of a structure depends on various factors including position, length, and surface texture of the crack as well as the illumination in the surrounding area. According to Park and Paulay (1975), crack widths in the range $0.25 \mathrm{~mm}$ to $0.38 \mathrm{~mm}$ may be acceptable for aesthetic reasons.

The crack width that will not endanger the corrosion of the reinforcement strongly depends on the environment of the structure. Due to the harsh environmental conditions of Liquid Con- 
taining Structures (LCS), these crack width limitations are of special importance. Table 2.1 shows the different crack widths that ACI 224 (2001) recommends according to the exposure condition of the structure. On the basis of these limitations, ACI 318 (2008) employs the distribution of tension steel in order to limit the crack widths. Some crack width limitations are also recommended by ACI 350 (2006) specifically for flexural cracks in environmental engineering concrete structures. According to this code flexural crack widths should be limited to $0.23 \mathrm{~mm}$ and $0.27 \mathrm{~mm}$ for severe and normal exposure respectively.

Table 2.1: Guide to reasonable crack widths in reinforced concrete under service load (ACI 224-R)

\begin{tabular}{|c|c|}
\hline Exposure Condition & Crack Width $(\mathbf{m m})$ \\
\hline Dry air or protective membrane & 0.41 \\
\hline Humidity, moist air, soil & 0.30 \\
\hline De-icing chemical & 0.18 \\
\hline Seawater spray, wetting and drying & 0.15 \\
\hline Water retaining structures & 0.10 \\
\hline
\end{tabular}

In order to set appropriate crack width limitations for leakage limit states, proper understanding of liquid transmission through the crack is essential. Current methods used to estimate the rate of leakage through concrete cracks lack the necessary accuracy. Previous researchers have used a model from rock mechanics that assumes laminar flow between two smooth parallel-sided surfaces. A correction factor is then used to account for the roughness of the inner crack surface. The reported roughness factors in the literature have a significantly high variation and no fixed values are determined yet.

A brief review of direct tension cracking is presented in what follows. The basic flow equations are introduced and the mentioned model from rock mechanics is derived. Few relative experiments found in literature are summarized. Crack width gradients are discussed and a brief introduction to self-healing of the cracks is presented. A summary of the key information is provided at the end of this chapter. 


\subsection{Direct Tension Cracking}

A basic model is used with reference to ?? (CEB) in order to gain a general understanding of cracking behavior of reinforced concrete. Concrete cracks when the tensile stress in a member reaches the tensile strength of the concrete. The simplest structural element that can be used to investigate the direct tension cracking in reinforced concrete is a single embedded rebar. This element can be subjected to concentric direct tension force by pulling the extruded rebar from both ends.

Different stages of cracking for the tie element are: i) prior to cracking, ii) crack formation(prestabilized cracking), iii) stabilized cracking and iv) post-stabilized cracking. The applied tensile load will transfer from the rebar to the surrounding concrete through the bond stresses. The variation of strain distribution for each stage is illustrated in Fig. 2.1.

Fig 2.1a shows the stage prior to cracking. The steel strain has its maximum value at the two ends where the concrete strain is equal to zero. Moving inside from the loaded ends, the stress is transfered to the concrete and thus, the strain in the steel decreases while the concrete strain increases. The difference between the two strains is accommodated by the slip mechanism at the interface of the concrete and steel. The mathematical relations of the bond and slip mechanism are out of the scope of this study. The two strains will become equal to each other at the point of zero slip at some distance from the loaded end, so called the transmission length $\left(l_{t}\right)$. Cracking takes place only inside the zero slippage region. It can be simply concluded that cracks could not be spaced smaller than the transmission length.

The first crack forms at the point of zero slippage where the stress in the concrete reaches the tensile strength of concrete. This stage is shown in Fig. 2.1b. At the cracked section the whole stress will be transfered to the steel rebar and the stress in the concrete will be equal to zero. Comparing to the state of the tie element prior to the cracking, it can be recognized that the cracked section has the same properties as each of the loaded ends. As a result, by increasing the tensile load the second crack will form in a similar manner as the first one in between the first crack and the loaded ends.

The process of cracking continues up to a certain magnitude of tensile load where the spacing of the cracks would be smaller than the transmission length. Hence, increasing the load will not lead to formation of new cracks and a stable state is reached. The stabilized cracking is illustrated in Fig. 2.1c. Increasing the tensile load will result in increase of the crack widths at this level. 
a)

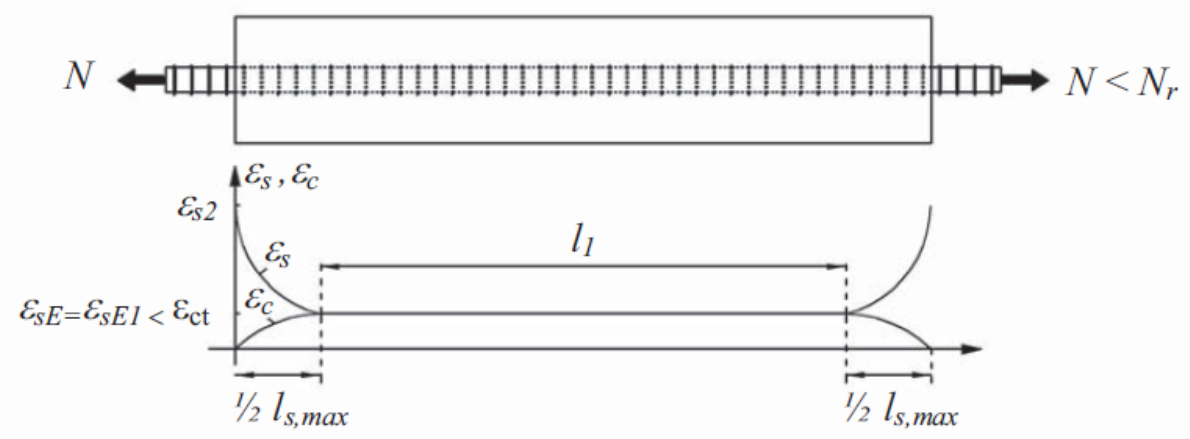

b)

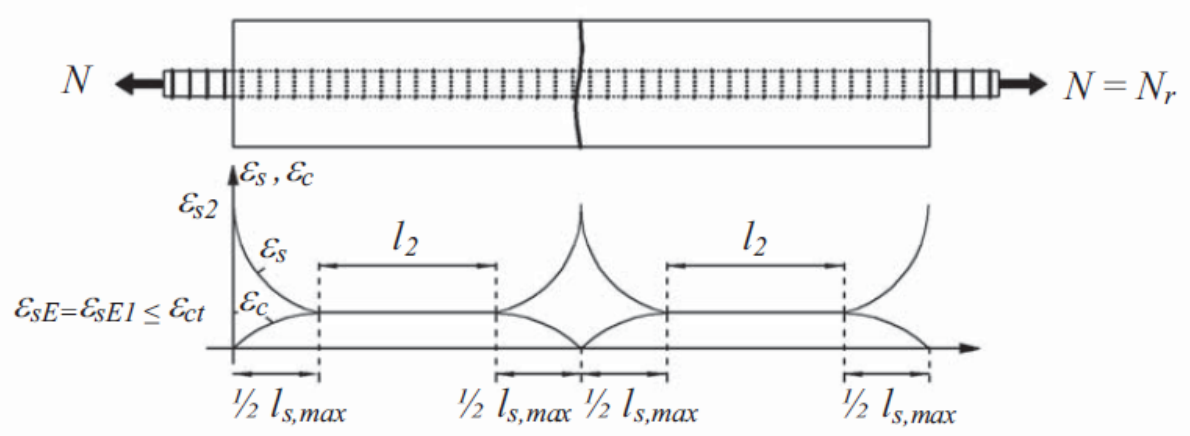

c)
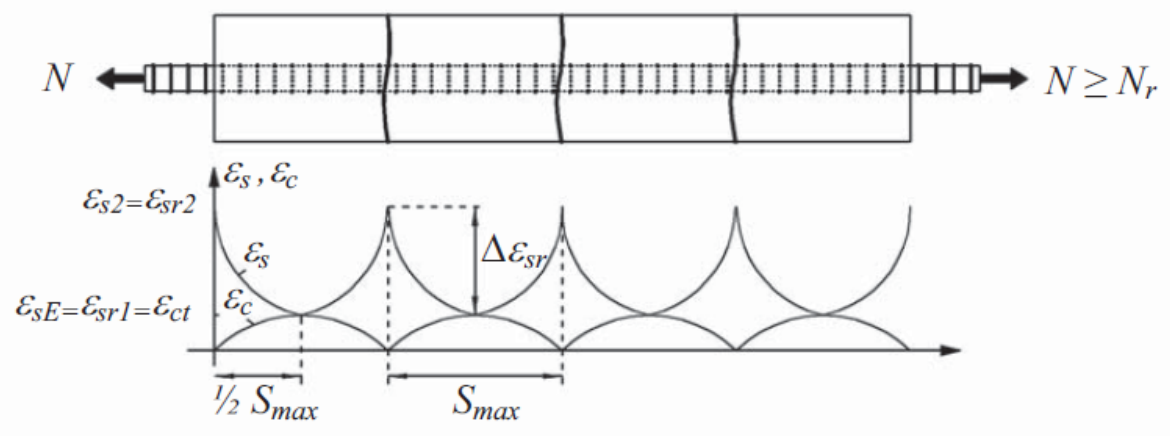

d)

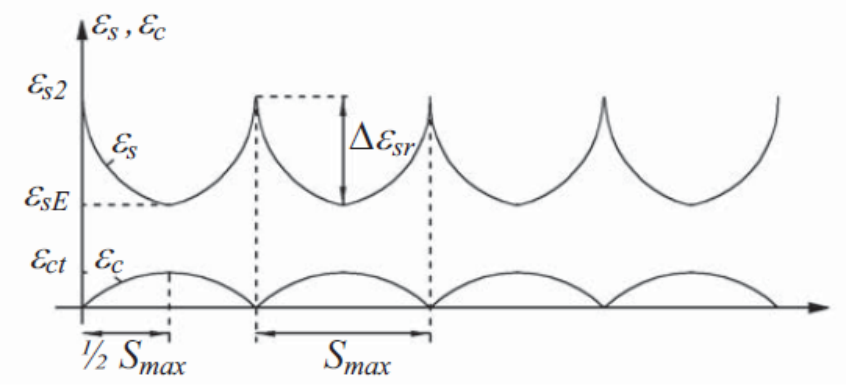

Figure 2.1: Strain distribution in a RC tie element, a) prior to cracking, b) crack formation c) stabilized cracking, d) post-stabilized cracking 


\subsection{Permeability of Cracks in Concrete}

\subsubsection{Cracks and Water Tightness}

Tightness of concrete is of major importance in the field of engineering practice due to durability concerns in general and serviceability for LCS in particular. Durability of the structure strongly depends on the possibility for the aggressive agent to travel through the concrete. Corrosion of steel reinforcement, freeze and thaw cycles and alkali-aggregate reactions are examples of this case. In case of LCS, liquid tightness is the main functionality of the structure and if violated, the serviceability will be reduced and even the safety of the structure might be compromised. That is the case for water or sewage containments, nuclear power plants, etc.

Research has shown that presence of cracks, both at micro and macro scales, affects the transfer properties of concrete. Kermani (1991) reported a very high variation in permeability of concrete samples loaded in compression. Prior to formation of a major crack, sample's initial permeability of $4 \times 10^{-14}[\mathrm{~m} / \mathrm{s}]$ was increased about 1000 times, due to development of micro cracks. Wang and Karr (1997) tested concrete disks, fractured using a splitting tensile test. They correlated the crack opening displacement (COD) with the permeability coefficient of a crack. Their results showed little effect of CODs smaller than 50 microns on permeability of the sample while for CODs between 50 to 200 microns the permeability increased rapidly.

Extensive research on the water permeability of crack-free concrete has shown that in general, the saturated water permeability of concrete is a function of its porosity, pore connectivity, and the square of a threshold pore diameter. In presence of macro cracks almost all of the flow happens through them and the flow through the matrix can be neglected. In such situations the crack geometry (length/width/roughness) plays an important role in permeability of the material. Limited research has been done on the flow of fluids through cracked concrete and the field still lacks a reliable prediction model. The most popular model used to quantify the liquid flow through a concrete crack is one originally developed in Rock Mechanics. This model, known as Poiseuille flow, assumes laminar flow through a smooth parallel-sided slot and uses a reduction factor to account for roughness of the crack wall. The validity of this model has been identified by different researchers, but a wide range of roughness factors has been reported. The Poiseulle flow model, roughness factor and relevant studies will be discussed in detail in this section. 


\subsubsection{Basic Flow Equations}

Generally, motion of a fluid is described by Navier-Stokes equations. The flow of an incompressible Newtonian viscous fluid can be written as:

$$
\frac{\partial p}{\partial t}+(u . \nabla) u=F-\frac{1}{\rho} \nabla p+\frac{\mu}{\rho} \nabla^{2} p
$$

Where $U=\left(u_{x}, u_{y}, u_{z}\right)$ is the velocity vector, $F$ is the body force per unit mass, $\rho$ is the fluid density, $\mu$ is the fluid viscosity and $p$ is the pressure. The Navier-Stokes equations embody the principle of conservation of linear momentum, along with a linear constitutive relation that relates the viscous stresses to the element strain rates and the coefficient of viscosity. The Term $\frac{\partial p}{\partial t}$ represents the acceleration of a fluid particle: the velocity may change with time. The $(u . \nabla) u$ term is called the "advective acceleration" and represents the acceleration that a particle may have, even in a steady-state flow field, by virtue of moving to a location at which there is a different velocity. $F, \frac{1}{\rho} \nabla p$ and $\frac{\mu}{\rho} \nabla^{2} p$ on the right side of Eq. 2.1 represent applied body force, the pressure gradient, and the viscous forces respectively.

Usually the force due to gravity is the only considerable applied body force; $F=g . e_{z}$ where $g$ is the gravitational acceleration and $e_{z}$ is the unit vector in the upward vertical direction. For uniform density, gravity can be eliminated from the equations by defining a reduced pressure $\hat{p}=p+\rho g z($ Phillips (1991) $)$

$$
F-\frac{1}{\rho} \nabla p=-g e_{z}-\frac{1}{\rho} \nabla p=-\frac{1}{\rho}\left(\nabla p+\rho g e_{z}\right)=-\frac{1}{\rho} \nabla \hat{p}
$$

Finally the Navier-Stokes equations can be written for the steady-state of flow. The term $\frac{\partial u}{\partial t}$ drops out:

$$
\mu \nabla^{2}-\rho(u . \nabla) u=\nabla p
$$

Note that for simplicity of notation term $\mathrm{p}$ is used instead of the reduced pressure $\mathrm{P}$.

Eq. 2.3 consists of three equations and four unknowns, namely pressure and three velocity components. Incompressible continuity relation provides the forth equation required to close the system. The compressibility of water is roughly $5 \times 10^{-10} / \mathrm{Pa}$ (Batchelor (1967)), so a pressure change of $10 \mathrm{MPa}$ would alter the density by only 0.5 percent; the assumption of incompressibility is therefore reasonable. For an incompressible fluid, conservation of volume 
provides the continuity equation:

$$
\nabla . u=\frac{\partial u_{x}}{\partial x}+\frac{\partial u_{y}}{\partial y}+\frac{\partial u_{z}}{\partial z}=0
$$

The set of four coupled partial differential equations must be augmented by the no-slip boundary conditions, which state that at the interface between a solid and a fluid, the velocity of the fluid must be equal to that of the solid. This implies that at the surface of the fracture, all components of the fluid velocity must be zero.

The simplest model that represents a crack for hydrological purposes is that of two smooth, parallel walls separated by a uniform aperture, $w$. For this specific geometry, the Navier-Stokes equations can be solved exactly to yield a parabolic velocity profile between the two walls of the crack. Presence of the advective component of acceleration causes the Navier-Stokes equations to be non-linear and difficult to solve. For the case of steady flow between parallel plates the advective component of acceleration vanishes identically. Aligning the $x$-axis with the pressure gradient, the $y$-axis perpendicular to the pressure gradient within the plane of the fracture, and the $\mathrm{z}$-axis normal to the fracture plane, with the fracture walls located at $z= \pm \frac{w}{2}$. The solution to Eq. 2.3 and 2.4 is a Poiseuille parabola (Jaeger and Zimmerman (2007)):

$$
u_{x}=-\frac{1}{2 \mu} \frac{\partial p}{\partial x}\left[\left(\frac{w}{2}\right)^{2}-z^{2}\right], u_{y}=0, u_{z}=0
$$

The three dimensional (volumetric) flow can be calculated by integrating the velocity:

$$
Q_{x}=l \int_{-\frac{h}{2}}^{+\frac{h}{2}} u_{x} d z=-\frac{l}{2 \mu} \frac{\partial p}{\partial x} \int_{-\frac{h}{2}}^{+\frac{h}{2}}\left[\left(\frac{w}{2}\right)^{2}-z^{2}\right] d z=-\frac{l w^{3}}{12 \mu} \frac{\partial p}{\partial x}
$$

Where $l[\mathrm{~m}]$ is the length of the crack in $y$ direction, $w$ is the crack width $[\mathrm{m}], \mu\left[N s / \mathrm{m}^{2}\right]$ is the viscosity of the fluid and $\frac{\partial p}{\partial x}\left[\mathrm{~N} / \mathrm{m}^{3}\right]$ is the pressure change between inlet and outlet of the crack. The term $l w^{3} / 12$ is known as the crack transmissivity and is sometimes stated as $w^{3} / 12$ for unit length of the crack. This result is also known as the "cubic law" since the transmissivity is proportional to the cube of aperture.

For a single crack, if we state the pressure in terms of water head, the term $\frac{\partial p}{\partial x}$ in Eq. 2.6 will represent the hydraulic gradient of the crack. Also for consistency of units the viscosity term should change to kinematic viscosity and the flow through the crack can be written as: 


$$
Q=-\frac{g l}{12 v} \frac{\Delta h}{h} w^{3}
$$

Where $g\left[\mathrm{~m} / \mathrm{s}^{2}\right]$ is the gravitational acceleration, $\Delta h[\mathrm{~m}]$ is the change in water head, $h[\mathrm{~m}]$ is the thickness of the wall, and $v\left[\mathrm{~m}^{2} / \mathrm{s}\right]$ is the kinematic viscosity of the fluid and the term $\frac{\Delta h}{h}$ represents the hydraulic gradient.

Eq. 2.7 is only exact for smooth-parallel wall openings which is not the case for most of the fracture surfaces. The surface of crack walls in concrete is rough . This will result in a much lower flow than that calculated by Eq. 2.7. Experiments have shown that it is possible to modify the Poiseuille flow by multiplying a reduction factor $(\xi)$ accounting for the crack morphology. This factor, named as turtuosity or roughness factor by different authors, will be discussed in section 2.3.4. Eq. 2.7 can be completes as:

$$
Q=-\xi \frac{g l}{12 v} \frac{\Delta h}{h} w^{3}
$$

The other assumption in Eq. 2.7 is that the two walls of the crack are parallel and thus the crack width is constant. In contrast, actual cracks have a highly variable profile both at the surface and through the crack. So an equivalent crack width must replace the constant value of w in Eq. 2.7 in a way that results in the same flow as in the actual crack width. The effective crack widths will be discussed later in this chapter.

\subsubsection{Permeability Coefficient}

Darcy's law describes the flow of a fluid through a porous medium. In its most basic form, and for the case of laminar flow, it relates the water flow rate to the pressure gradient:

$$
J=\frac{Q}{w l}=-\frac{k}{v} \frac{\partial p}{\partial x}
$$

Where $\mathbf{J}[\mathrm{m} / \mathrm{s}]$ is the volumetric flow and $\mathrm{k}\left[\mathrm{m}^{2}\right]$ is the permeability coefficient . The Poiseuille flow can be re-written in analogy with Darcy's law and alternatively represented in terms of permeability coefficient of the crack.

$$
Q=-\xi \frac{g l}{12 v} \frac{\Delta h}{h} w^{3}=-\frac{k}{v} \frac{\partial p}{\partial x} w l
$$




$$
k=\xi \frac{w^{2}}{12}
$$

\subsubsection{Roughness Factor}

As mentioned before, Eq. 2.7 is only valid for parallel openings with a smooth surface. Experiments show much lower flow rates than that calculated by Eq. 2.7. This is due to turtuosity of the inner crack surfaces. A roughness (tortuosity) factor, accounting for crack morphology, is used to reduce the calculated flow.

$$
Q_{r}=\xi Q_{s}=\xi \frac{g l}{12 v} \frac{\Delta h}{h} w^{3}
$$

Where $Q_{r}$ is the flow of the natural-rough crack, $Q_{s}$ is the flow of the smooth wall crack and $\xi$ is the roughness factor. Several experimental configurations have been used by researchers to measure the flow of fluids through cracked concrete. Different loading conditions (compression, tension or bending) have been used on natural or artificial cracks (joint). However, research on permeability of cracked concrete has been limited and the results from previous studies suggest different values with a high variation for the roughness factor. Some of these experiments will be discussed below.

\section{Bomhard}

Bomhard (1986) provided equations to calculate the leakage rate through both cracked and uncracked concrete walls with thickness of $h$. His proposed equation for water flow through a crack follows the cubic law:

$$
Q=\frac{\bar{k}}{v} w_{e f f}^{3} l \frac{\Delta h}{h}
$$

Where $\bar{k}$ is the non-dimensional permeability coefficient and $w_{\text {eff }}$ is the effective crack width and will be discussed in $\S 2.3 .5$. Bomhard stated that $\bar{k}$ has to be less than 0.01 which corresponds to laminar flow. He also compared the leakage through uncracked concrete, cracks and joints 100 times wider than cracks and found the leakage ratio of $1: 10^{4}: 10^{10}$, respectively. 


\section{Imhof-Zeitler}

Imhof-Zeitler (1996) tested $200 \mathrm{~mm}$ thick specimens under a water head of 1.4 meter for 72 hours and developed the following model for flow rate through penetration cracks:

$$
Q=\frac{g}{A v / \rho}\left[1+\frac{\Delta h}{h}\right] w l
$$

Where A $\left[1 / m^{2}\right]$ is a friction coefficient, $\rho$ is the density of liquid. According to experimental results, Imhof-Zeitler proposed two values for the friction factor based on the crack width:

$$
\begin{aligned}
& A=\frac{12}{w^{2}} \frac{4}{c w^{1.6}} \frac{80}{14 i-20} * 10^{6}, \quad w>0.1 \mathrm{~mm} \\
& A=\frac{12}{w^{2}} \frac{4}{0.82 c w^{0.6} \sqrt{v / \rho}} * 10^{6}, \quad w<0.1 \mathrm{~mm}
\end{aligned}
$$

Where $i$ is the hydraulic gradient. Bomhard assumed a value of $c$ equal to 1 for water and 1.89 for other liquids. He multiplied Eq. 2.16 by 1.43 for reinforcement ratio greater than $0.3 \%$

\section{Tsukamoto and Wörner}

Tsukamoto (1991) investigated the variation of permeability of reinforced concrete and fiber-reinforced concrete in plates under controlled displacements. They used different fluids such as water, methanol, petrol, motor oil, etc. Their results show no difference between the fluids if the fluid viscosity is taken into account. The measurements were smaller than the theoretical prediction and varied by a multiplicative coefficient which increases linearly with the crack width. For instance, this coefficient was 0.05 for $\mathrm{w}=0.2 \mathrm{~mm}$ in reinforced concrete for instance.

\section{Archambault}

Archambault G. and Ladanyi (1992) tested a specimen made of jointed squared blocks of bricks, containing two sets of orthogonal cracks under a biaxial compression. Their tests show the decrease of permeability with the compression which is due to reduction of the joint aperture. Their setup made it possible to focus on anisotropy (angles of the sets of fractures) of permeability. They showed that anisotropy is a function of the stress state, i.e., the com- 
pressive stress closes the cracks differently according to their orientation. Their results are exclusive since their material did not represent the behavior of the actual material.

\section{Marchal and Beaudoux}

Marchal and M. (1992) used a different model for predicting the flow (Carman-Kozeny model). They measured the flow passing through a crack created by splitting and compared it to a theoretical prediction. They found that the effect of tortuosity is to divide the theoretical flow (plane crack) by a tortuosity factor of 75 which is comparable to that exhibited on rocks. Results form Breysse and Lasne (1994) confirm these conclusions qualitatively.

\section{Edvardsen}

Edvardsen (1996) conducted water permeability tests on small concrete specimens having a single crack induced in tension. The following were the varying parameters in his test:

- Crack width $(0.1,0.2,0.4 \mathrm{~mm})$

- Crack Length $(200,300$ and $400 \mathrm{~mm})$

- Water pressure head (ranging from 2.5 to $20 \mathrm{~m}$ )

- Hydraulic gradient (ranging from 6.25 to 50)

- Water Hardness

- Cement (Portland cement,slag cement and sulphate resistant cement)

- Aggregate (granite,limestone and basalt) and Filler (limestone dust and fly-ash)

Edvardsen reported a large distribution of measured flow due to the large variability of measured crack widths. Despite the variability of the results the validity of cubic law was confirmed. He suggested a mean value of $\xi=0.25$ by regression analysis of test results.

\section{Breysse and Gerard}

Breysse D. (1997), using an iterative procedure and with the aid of non-linear finite-element computations, designed an original specimen to measure the flow under tensile loading of a 
mortar. Their specimen, named BIPEDE, consisted of a concrete disk with two steel plates glued on it's both sides. The concrete disk had a diameter of $110 \mathrm{~mm}$ and thickness of 40 $\mathrm{mm}$. The steel plates of $2 \mathrm{~mm}$ contained a circular hole of radius $27.5 \mathrm{~mm}$ at the middle to allow the fluid penetrate within the concrete. BIPEDE samples allowed for controlling the mechanically induced level of damage as well as avoiding any global specimen instability due to strain-softening or brittle failure. It also made it possible to obtain a diffused damage zone where cracks can be considered as spread. Table 2.2 shows the values of roughness factor $\xi$ evaluated from BIPEDE measurements.

Table 2.2: Roughness Factor from BIDEPE Test

\begin{tabular}{|r|r|r|r|r|r|}
\hline $\mathbf{w}(\mu \mathbf{m})$ & 4.4 & 5.5 & 6.9 & 12.1 & 22 \\
\hline$\xi$ & 0.0045 & 0.023 & 0.117 & 0.216 & 0.36 \\
\hline
\end{tabular}

\subsubsection{Effective Crack Width}

The term $w$ in Eq. 2.8 refers to the crack width assuming the crack width is constant everywhere. In reality crack widths often vary along length and depth of the crack. Due to tortuosity, crack's actual length is larger than its nominal length and crack wall surfaces are rough. These features reduce the permeability of the crack causing the measured flow to be much smaller than that calculated by Poiseulle flow. Most of the previous studies mentioned in $\$ 2.3 .4$ do not take the crack width gradient into account and only relate the inlet crack width to the flow. Bomhard (1986) recommended using an effective crack width based on inner and outer crack widths of the tank wall. Akhavan and Rajabipour (2012) proposed a more complete model for computing an effective crack width $\left(w_{\text {eff }}\right)$ by taking the crack width gradient both along the surface length and through the dept of the crack.

Bomhard (1986) represented an equation for calculating an effective crack width. In his equation he differs between inner $\left(w_{1}\right)$ and outer $\left(w_{2}\right)$ crack widths and calculates the effective crack width as:

$$
w_{\text {eff }}=\sqrt[3]{2 \frac{\left(w_{1} w_{2}\right)^{2}}{w_{1}+w_{2}}}
$$

Akhavan et al. (2012) used a digitized crack profile to calculate an effective thru crack 
width that would result in the same permeability coefficient (Eq. 2.11) as the actual variable crack. Their work is based on a technique originally suggested by Dietrich and Teutsch (2005) for fractured rocks. The variable crack profile is discretized into a series of local parallel plates, which are further combined into a global parallel plate. Figure 2.2 shows the method for calculation of the effective crack width adopted from Akhavan et al. (2012). The crack is in the $x-y$ plane. $\mathrm{X}, \mathrm{Y}$ and $\mathrm{Z}$ directions represent the direction of the flow (crack depth), diametric direction parallel to the crack and diametric direction perpendicular to the crack plane respectively. If $w_{i j}$ represents the crack width for the $i$ th element in $\mathrm{X}$ direction and $j$ th element in direction Y, the first row of elements can be represented by $w_{1 j}$. For the first row of elements, the flow rate is described by Darcy's law:

$$
Q_{1, T}=\sum_{j=1}^{n} Q_{1 j}=\frac{1}{\mu} \sum_{j=1}^{n} l_{1 j} w_{1 j} K_{1 j} \frac{\Delta p_{1 j}}{h_{1 j}}
$$

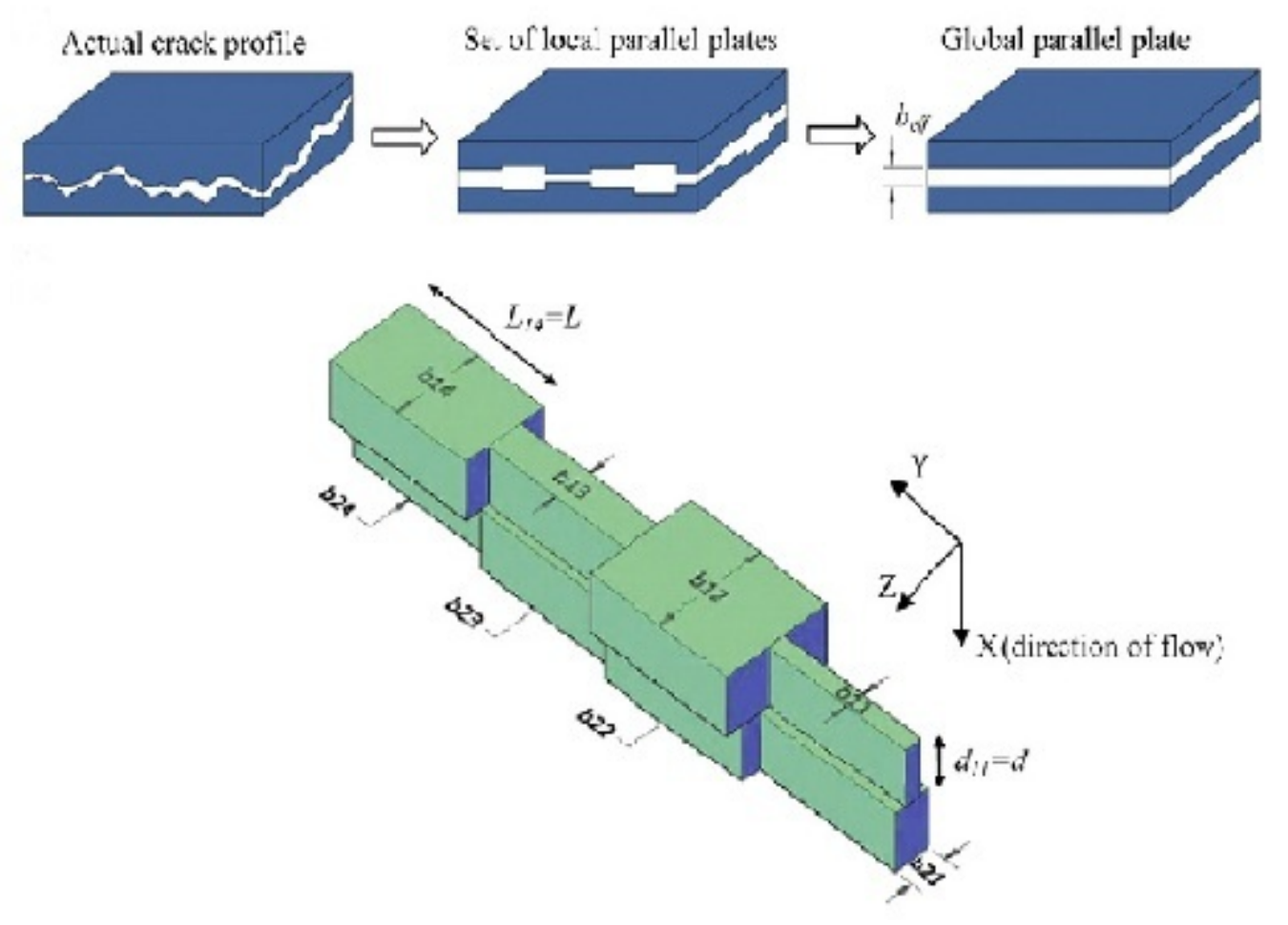

Figure 2.2: Effective Crack width, source: Akhavan et. al(2012)

Where $n$ is the number of elements in each row, $K=\frac{w_{1 j}^{2}}{12}$ is the permeability coefficient, $h_{1 j}$ 
is the element thickness and $\Delta p_{1 j}$ is the pressure loss for each element. By choosing constant values for elements' length and thickness $(l$ and $h)$ and assuming one-dimensional flow ( $\Delta p_{11}=$ $\left.\Delta p_{12}=\Delta p_{1}\right)$, the flow will be:

$$
Q_{1, T}=\frac{1}{12 \mu} \frac{\Delta p_{1}}{h} l \sum_{j=1}^{n} w_{1 j}^{3}
$$

In the above equation the term $\sum_{j=1}^{n} w_{1 j}^{3}$ can be replaced by a single crack width which would result in the same flow:

$$
\begin{gathered}
b_{1, e f f}=\sqrt[3]{\frac{1}{n} \sum_{j=1}^{n} w_{1 j}} \\
Q_{1, T}=\frac{1}{12 \mu} \frac{\Delta p_{1}}{h} l w_{1, e f f}^{3}
\end{gathered}
$$

By using a similar procedure, an effective crack width can be calculated in X direction, through the depth of the crack. For a column of $m$ crack elements with length, width, and thickness of $l, w_{i, e f f}$ and $h$ :

$$
\begin{gathered}
Q_{1, T}=Q_{2, T}=\ldots=Q_{i, T}=Q_{T} \\
\frac{1}{12 \mu} \frac{\Delta p_{1}}{h} \frac{n l}{m} w_{1, \text { eff }}^{3}=\frac{1}{12 \mu} \frac{\Delta p_{2}}{h} \frac{n l}{m} w_{2, e f f}^{3}=\ldots=\frac{1}{12 \mu} \frac{\Delta p_{i}}{h} n l w_{i, e f f}^{3}=\frac{1}{12 \mu} \frac{\Delta p_{i}}{h} \frac{n l}{m} w_{\text {eff }}^{3}
\end{gathered}
$$

Where $Q_{T}$ is the total flow rate, $\Delta P=\Delta P_{1}+\Delta P_{2}+\ldots+\Delta P_{m}$ is the total pressure loss across the specimen, and $m$ is the number of rows. Eq. 2.23 can be simplified as the following:

$$
\begin{gathered}
\Delta P_{i}=\Delta P_{1}\left(\frac{w_{1, e f f}}{w_{i, e f f}}\right)^{3} \\
\Delta P=\sum_{i=1}^{m} \Delta p_{i}=m \Delta P_{1} w_{1, e f f}^{3}\left(\frac{1}{w_{e f f}}\right)^{3}
\end{gathered}
$$

Akhavan et al. then calculate the effective thru crack width as: 


$$
\sqrt[3]{\frac{m}{\sum_{i=1}^{m}\left(\frac{1}{w_{1, e f f}}\right)^{3}}}
$$

\subsection{Self-healing of Cracks}

A noticeable number of environmental engineering structures are fabricated using reinforced concrete. Besides its numerous advantages, concrete cracks at very low tensile stresses. These stresses can have various sources some of which are structural loading, shrinkage, thermal effects, creep, etc. Uncracked concrete can be assumed as tight for LCS but after cracking concrete becomes permeable up to a certain degree. The permeability of the concrete depends on the type and geometry (width, tortuosityi, length, etc.) of the crack. Direct tension cracks have shown to be more critical than any other types of cracks since they provide a thru path for the liquid in or out of the structure.

Experimental studies have shown that cracks have the ability to seal themselves. Self healing of cracks, also known as autogenous healing, is one phenomenon acting to reduce durability problems caused by the cracks. Self-healing process can take place only in presence of water. This process consists of chemical reactions of compounds exposed at the cracked surfaces. The crystals produced from these reactions form a layer on each inner wall of the crack. Accretion of the crystallization on both surfaces of a crack can re-establish the continuity of the material eventually. In extreme cases complete sealing may be achieved.

There are two hypothesis on the autogenous healing of the cracks. First, the hydration of un-hydrated clinker available in the micro-structure of hardened concrete can fill the crack to a certain order. The second one implies that the precipitation of calcium carbonate crystals $\left(\mathrm{CaCO}_{3}\right)$ can contribute to the formation of the sediment material. The first hypothesis is vitally dependent of presence of water. The latter requires presence of dissolved $\mathrm{CO}_{2}$ in the leaking water. Mechanical blocking, obstruction of narrow crack areas with ultra-fine material, swelling, silting up of cracks and deposition of debris can also contribute to healing.

Current codes of practice take the self-healing of the cracks into account in their design guidelines for a serviceable reinforced concrete water containment. According to ACI 224 (2001) the healing phenomenon will not occur for active cracks which are subjected to movement. It also states that in order to achieve a self-healed crack the flow of water has to be extremely slow so that it would not dissolve and wash away the lime deposit. ACI 224 (2001) 
requires complete evaporation at the exposed face. However previous studies including the one by Ziari and Kianoush (2009a b) have shown that the concrete self healing process might take place even when positive flow of water exists through cracks. Saturation of the crack and the adjacent concrete with water in addition to the age of the crack are considered effective on the autogenous healing of the crack. Even a single cycle of drying and re-immersion will reduce the healing strength. Delayed healing also results in less restoration of strength than does immediate correction.

The following is a highlight of the studies carried out with the subject of self-healing of concrete cracks.

\section{Hearn}

Hearn and C.T. (1997) conducted permeability tests on mortars with $78 \%$ of hydrated clinker to investigate the role of un-hydrated cement in self-healing of the cracks. He investigated the chemical effects, like continuing hydration, dissolution and deposition of soluble species. The inflow and outflow both were subjected to chemical analysis. The findings of this study pointed out a significant increase in $\mathrm{Ca}^{2+}$ ions concentration in the outflow, which indicates dissolution-deposition of calcium carbonate $\mathrm{CaCo}_{3}$.

\section{Edvardsen}

Edvardsen (1999) conducted permeability tests on small-scale concrete specimens each with a single tensile crack. His results indicate a quick reduction in the leakage. Edvardsen explained the phenomenon by the crystallization of calcium carbonate $\mathrm{CaCo}_{3}$. He also showed that cracks with initial effective widths of 200 microns after sufficiently long water exposure can completely seal after five to seven weeks.

\section{Reinhardt and Joos}

Reinhardt and Joos (2003) investigated the effects of crack width and temperature on the decrease of the flow rate. Narrow cracks showed a faster healing than wider ones and a higher temperature resulted in quicker self-healing process. Furthermore, cracks of the width less than $0.10 \mathrm{~mm}$ in high performance concrete (HPC) samples can be closed by self-healing processes under certain condition.

The above mentioned studies mostly investigate the transfer properties of the concrete. Some other tests are performed to investigate the role of autogenous healing on mechanical 
properties of concrete. Jacobsen et al. (1996) performed experiments on concrete cubes damaged by rapid freeze and thaw cycles. Test specimens were then placed in water. Deterioration and healing were measured through the evolutions of the compressive strength and the resonance frequencies giving the dynamic modulus of elasticity. Resonance frequencies and compressive strengths were both decreased during freeze/thaw cycles and self-healing gave a substantial recovery of the frequency but only a small recovery of the compressive strength. He explained this small recovery by the fact that cracks were not fully filled with the newly formed crystals.

\subsection{Summary}

Cracking is inevitable in RC structures. In LCS cracking will result in leakage of the liquid in/out of the structure and the serviceability of the structure will be reduced. The rate of leakage depends on the crack geometric properties such as its length, width, morphology, etc. Codes of practice recommend limiting the crack widths to control the amount of leakage. A model based on laminar flow between two parallel smooth-sided plates is widely used to predict the leakage through the crack. A multiplicative roughness factor is then used to reduce the calculated flow. This factor has a high variation in the literature.

- As a linear function of crack width (Tsukamoto (1991))

- $0.04 \leq \xi \leq 0.53$ (Meichner, 1992)

- constant mean value of 0.25 (Edvardsen, 1996)

- constant mean value of 0.1 by (Gerard,1996)

- Range of $0.0045 \leq \xi \leq 0.36$ depending on the crack width (Breysse and Gerard, 1997)

In presence of water, cracks have shown an ability to heal themselves. The duration, crack widths and water pressures at which this phenomenon happens vary in the literature. It is important to mention that the content of liquid containing structures is not always water and also in some cases, the required time period to achieve the self healing can not be tolerated. 



\section{Chapter 3}

\section{Experimental Study}

\subsection{Introduction}

Bomhard (1986) states that water tightness can be achieved by one or more of three methods: limiting concrete tensile stress, specifying a minimum depth of compression zone or limiting crack width. He considers the first method as an unsuitable measure due to variability of concrete tensile strength. A sufficient depth of compression zone will result in closure of the crack on the compression side and a reliable watertightness will be reached. Distribution of tension steel is used in practice to limit the crack width in RC members.

There are some occasions in which reinforced concrete sections must carry purely tensile forces. For instance, a vertical section of a cylindrical shape tank is subjected to the tensile ring force produced by internal pressure. In comparison with flexural cracks, the direct tension induced cracks are more critical since there is no compression zone and the opening penetrates the whole depth of the section. Hence, the crack width must be limited to control the leakage. ACI Committee 224R (2001) recommends a maximum crack width of $0.1 \mathrm{~mm}$ for water retaining structures. However it does not exclude direct tension cracks from other types. 0.23 $\mathrm{mm}$ and $0.27 \mathrm{~mm}$ limitations are also recommended by ACI 350 (2006) specifically for flexural cracks in environmental engineering concrete structures for severe and normal exposure respectively.

For setting appropriate crack width limitations, knowledge of cracks permeability is essential. Limited research has been done on permeability of concrete sections with major cracks and the field still lacks a reliable model to predict the flow. A model from rock mechanics is 
the most popular flow prediction model used for concrete cracks. The model assumes laminar flow through a smooth parallel-sided slot. A reduction factor is then used to account for the crack tortuosity and roughness. Different values of the roughness factor with high variability are reported in the literature. Most of these purely empirical values are based on small scale plain concrete samples.

This experimental study aims to examine the permeability of a major crack in a full-scale RC panel representing a wall segment of a circular tank. This chapter presents a description of the test specimens and set-up in addition to a detailed test procedure. The test consists of three different phases: crack initiation, reloading and leakage test.

- Phase I: Test specimens are subjected to direct tension force until a major crack is formed and then unloaded.

- Phase II: Samples are reloaded to find the relation between the external load and the crack width.

- Phase III: The crack is subjected to pressurized water and the rate of leakage through the crack is measured for different water pressures at different crack widths.

\subsection{Experimental Study}

\subsubsection{Test Specimens}

The test specimens in this experimental study represent segments of a circular tank wall. The vertical section of a typical circular tank is subjected to direct tension force due to the internal pressure of the liquid inside. A specimen configuration is selected to simulate the real-life situation. All three specimens are 1 meter long and 1 meter wide while they have different depths (thickness) of $150 \mathrm{~mm}, 200 \mathrm{~mm}$ and $250 \mathrm{~mm}$. Reinforcement ratios of $0.8 \%$ and $0.64 \%$ were used in these specimens similar to reinforcement ratios used in practice. Table 3.1 and Fig. 3.1 show the specimen details. The longitudinal reinforcement are extended out of the panel on each side. These extensions are used to apply the direct tension force to the specimen. 
Table 3.1: Specimen Information

\begin{tabular}{|c|c|c|c|c|}
\hline No. & Specimen Name & Thickness $(\mathbf{m m})$ & Rebar Size & $\rho_{s}(\boldsymbol{\%})$ \\
\hline 1 & S150 & 150 & $20 \mathrm{M}$ & 0.8 \\
\hline 2 & S200 & 200 & $15 \mathrm{M}$ & 0.8 \\
\hline 3 & S250 & 250 & $15 \mathrm{M}$ & 0.64 \\
\hline
\end{tabular}

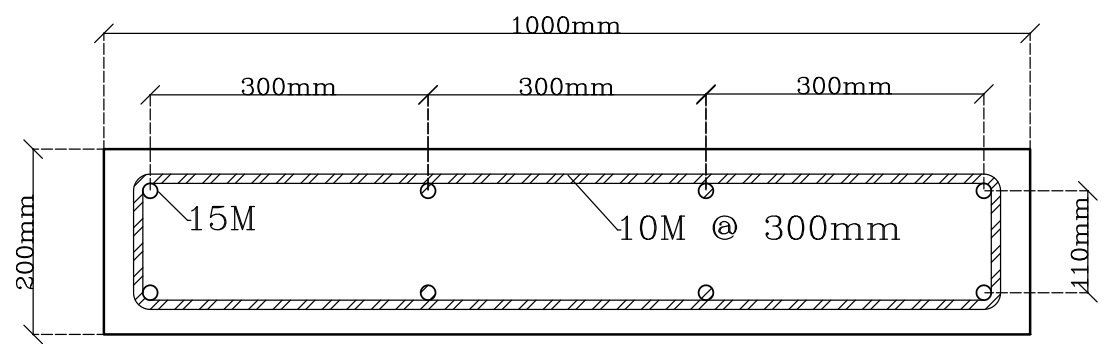

a) $\$ 200$

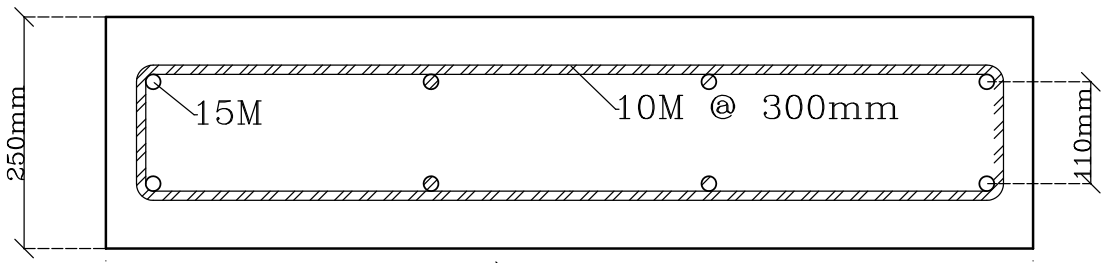

b) $\$ 250$

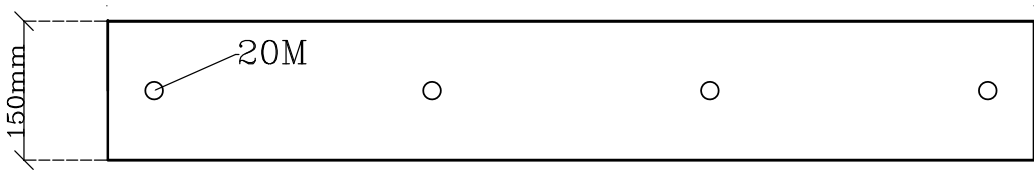

c) $\mathrm{S} 150$

Figure 3.1: RC panel Sections

\subsubsection{Casting and Curing}

Wooden forms were used for all specimens. Holes were drilled on the two opposite sides of the form to allow the extruded rebars out of the panel as shown in Fig. 3.2. Steel strain gages were installed at various locations on longitudinal reinforcement. A small surface on each rebar was ground at the location of each strain gage to create a smooth surface. The surface was cleaned by alcohol and a smooth piece of cloth from any grease or dust. Relative chemicals were then 
applied to the surface and the strain gages were glued at their locations. Water proof paste was applied around each strain gage and then covered by aluminum tape to ensure a water and damage proof condition. Fig. 3.3. and Fig. 3.4 show the details of strain gage installation and the location of strain gages on the rebars respectively. Form oil was applied on the whole inner surface of the forms. After all the preparations specimens were cast flat on the floor. Concrete cylinders were also cast and placed next to the panels.

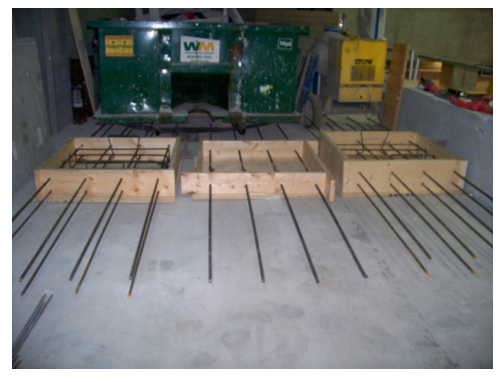

(a) Form Work Prior to Casting

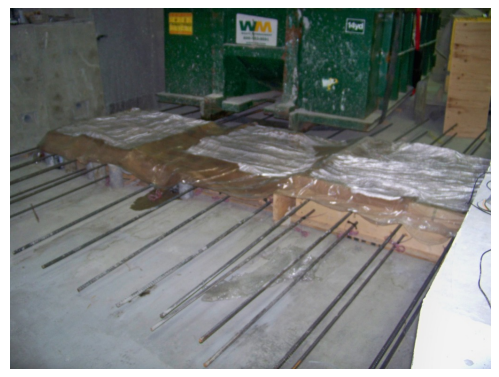

(c) Specimen Curing

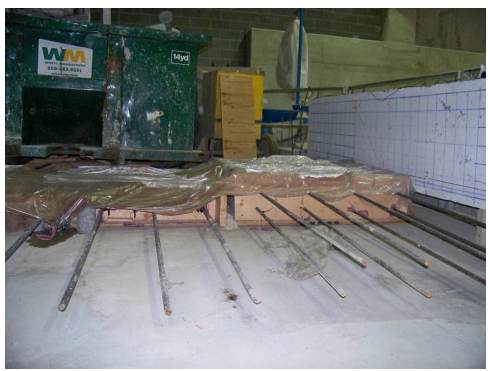

(b) Specimen Curing

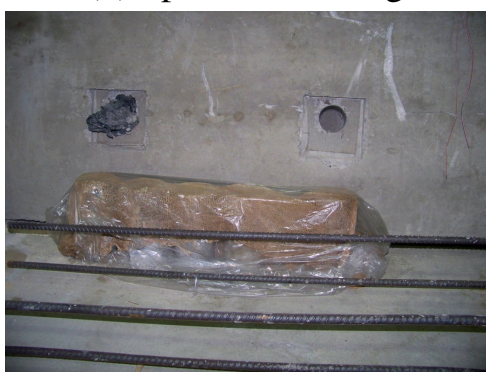

(d) Cylinder Curing

Figure 3.2: Casting and Curing of Specimens

After casting some time was given to the specimens for the partial set and then the exposed surfaces were troweled. The specimens and cylinders were all covered with wet burlap and plastic sheets after a few hours. The specimens were kept wet for a week. The sides of the forms were then removed and specimens were again covered with wet burlap and plastic sheets. Concrete cylinders were also stripped and kept wet. Wet curing continued for three more weeks until the concrete was 28 days old.

\subsubsection{Material Properties}

Normal density concrete provided by a local supplier was used. All three specimens were cast in place from the same batch of concrete. Compressive strength test was conducted in accor- 


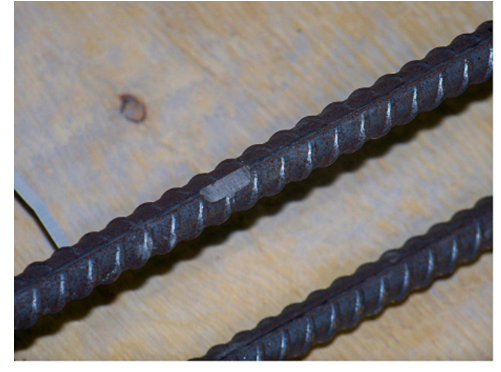

(a) Surface preparation

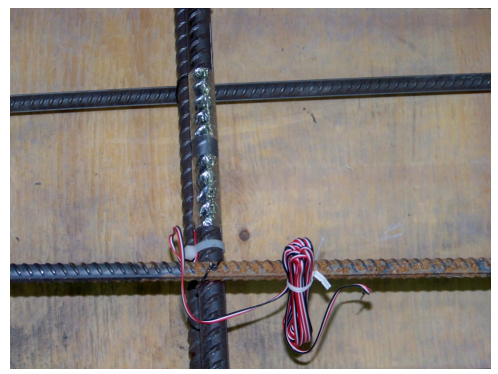

(c) Aluminum Tape on the Gage

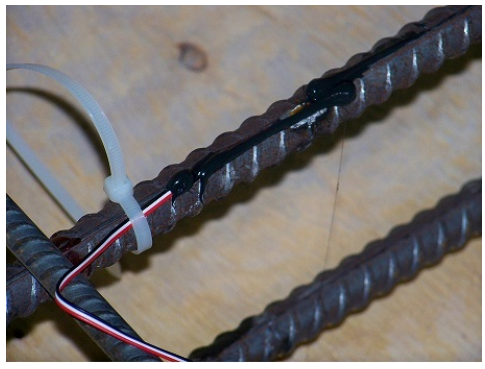

(b) Water Proof Paste

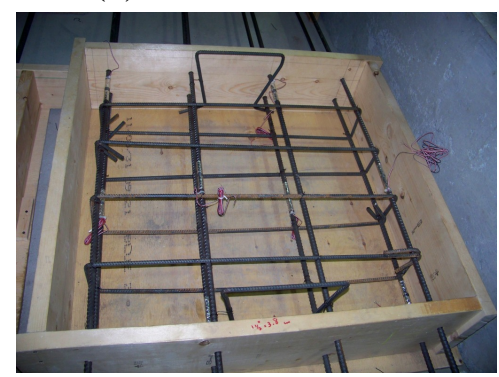

(d) Strain Gage Arrangement

Figure 3.3: Steel Strain Gage installation

dance with ASTM C39/C39M (2005). Although the mix had a specified 28-days compressive strength of $35 \mathrm{MPa}$, the concrete compressive strength was about $47 \mathrm{MPa}$. Table 3.2 shows the result of compression test on $100 \mathrm{~mm}$ by $200 \mathrm{~mm}$ cylinders. Knowing the compressive strength of concrete, the modulus of elasticity $\left(E_{c}\right)$ and the modulus of rupture $\left(f_{c t}\right)$ of concrete can be estimated according to ACI 209R (2008):

$$
\begin{aligned}
& E_{c}=0.043 \sqrt{\gamma_{c}^{3} \cdot f_{c}^{\prime}}=0.043 \sqrt{2300^{3} * 47}=32517 \quad \mathrm{MPa} \\
& f_{c t}=0.0069 \sqrt{\gamma_{c} \cdot f_{c}^{\prime}}=0.0069 \sqrt{2300 * 47}=2.27 \quad \mathrm{MPa}
\end{aligned}
$$

The splitting tensile strength test was performed on 28-days cylinders according to ASTM C496/C496M (2004). From an average load of $101 \mathrm{kN}$ recorded for three samples, a tensile strength of 3.3 $\mathrm{MPa}$ was calculated for the concrete:

$$
\sigma=\frac{2 P}{\pi . l . d}=\frac{2 * 101.53 * 10^{3}}{\pi * 100 * 200}=3.315 \quad M P a
$$




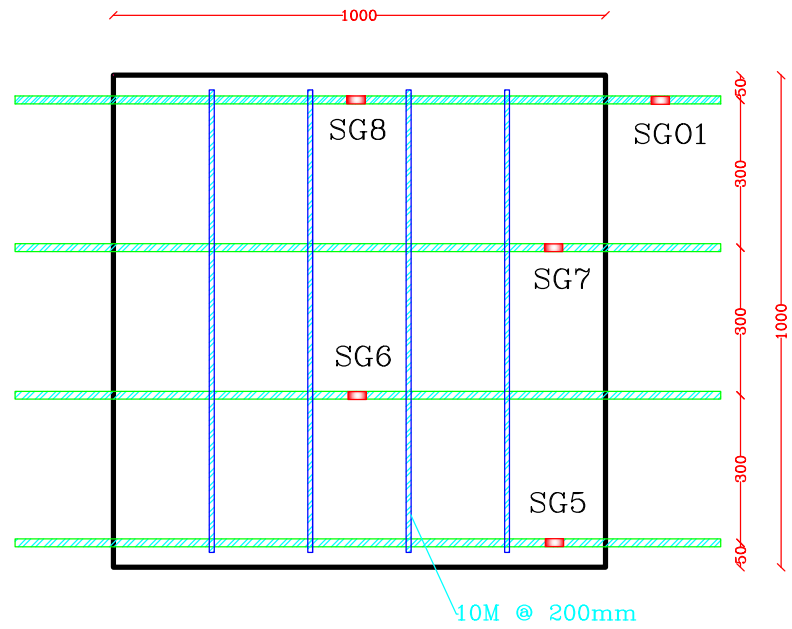

(a) Top Layer

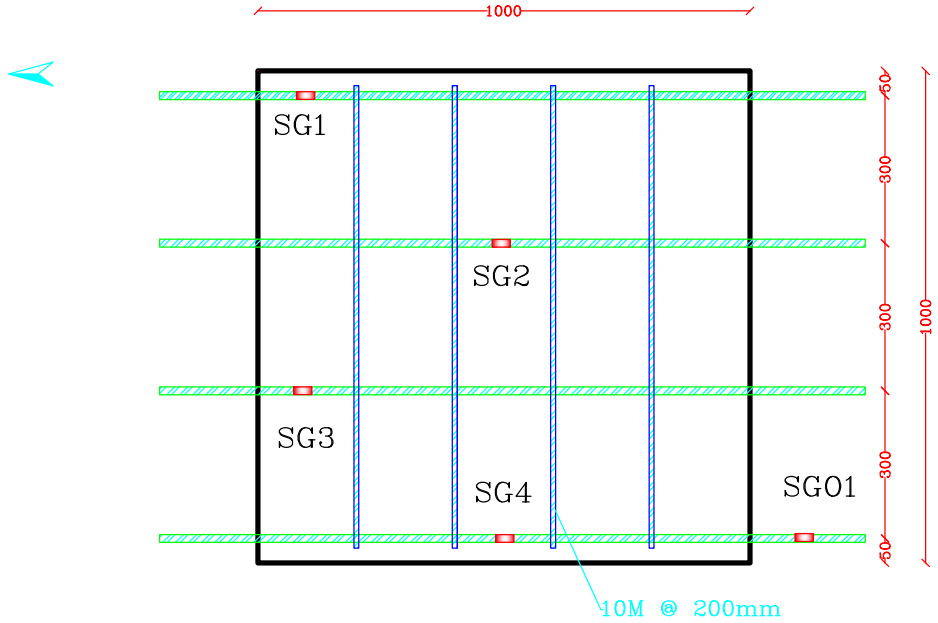

(b) Bottom Layer

Figure 3.4: Strain Gage Locations on Rebars 
Table 3.2: Concrete Compressive Strength

\begin{tabular}{|c|c|c|c|}
\hline Time (Day) & Sample & $\begin{array}{c}\text { Cylinder Compressive } \\
\text { Strength (MPa) }\end{array}$ & $\begin{array}{c}\text { Mean Compressive } \\
\text { Strength (MPa) }\end{array}$ \\
\hline \multirow{3}{*}{7} & 1 & 32.14 & \multirow{2}{*}{31.62} \\
\cline { 2 - 3 } & 2 & 33.54 & \multirow{2}{*}{4} \\
\cline { 2 - 3 } & 3 & 29.18 & \multirow{2}{*}{40.23} \\
\hline \multirow{3}{*}{14} & 1 & 42.69 & \multirow{2}{*}{4} \\
\cline { 2 - 3 } & 2 & 41.15 & \multirow{2}{*}{4.16} \\
\cline { 2 - 3 } & 3 & 36.86 & \\
\hline \multirow{3}{*}{28} & 1 & 48.71 & 46.94 \\
\cline { 2 - 3 } & 2 & 45.84 & \\
\cline { 2 - 3 } & 3 & &
\end{tabular}

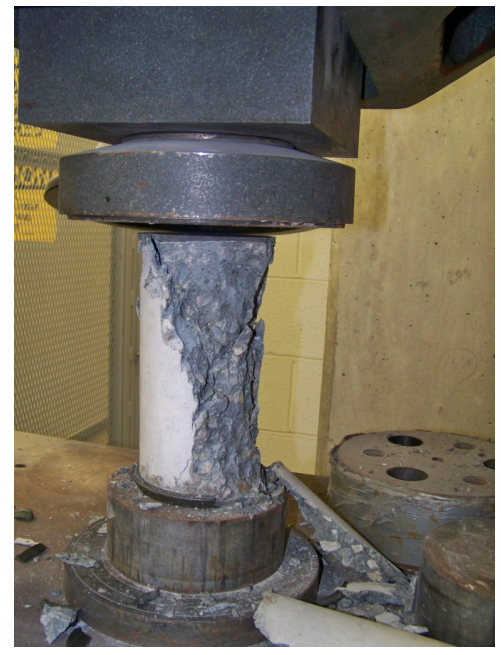

(a) Compressive Strength Test

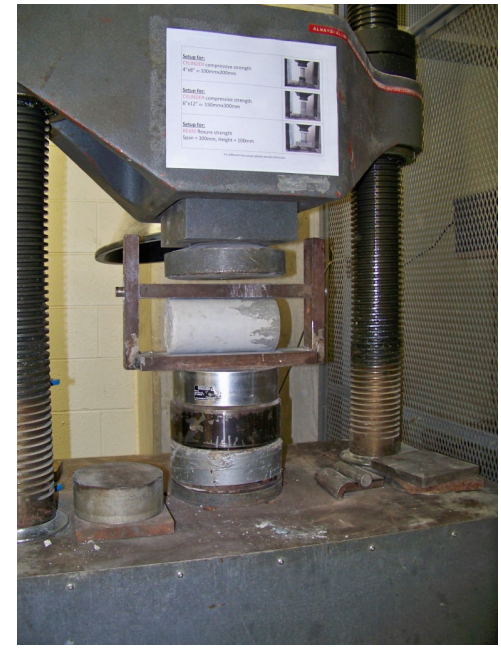

(b) Splitting Test

Figure 3.5: Concrete Tests

Grade 400 steel rebars were used in this experiment. No. 20 and No. 15 deformed rebars were used for longitudinal reinforcement and No. 10 rebars were used for temperature and shrinkage reinforcement. Figure 3.6 shows the stress-strain curve for the $15 \mathrm{M}$ rebar. The uniaxial tension test results match the analytical strain-stress curve. Modulus of elasticity of $E_{s}=200000 \mathrm{MPa}$ and yielding stress of $f_{y}=400 \mathrm{MPa}$ are used for calculations. 


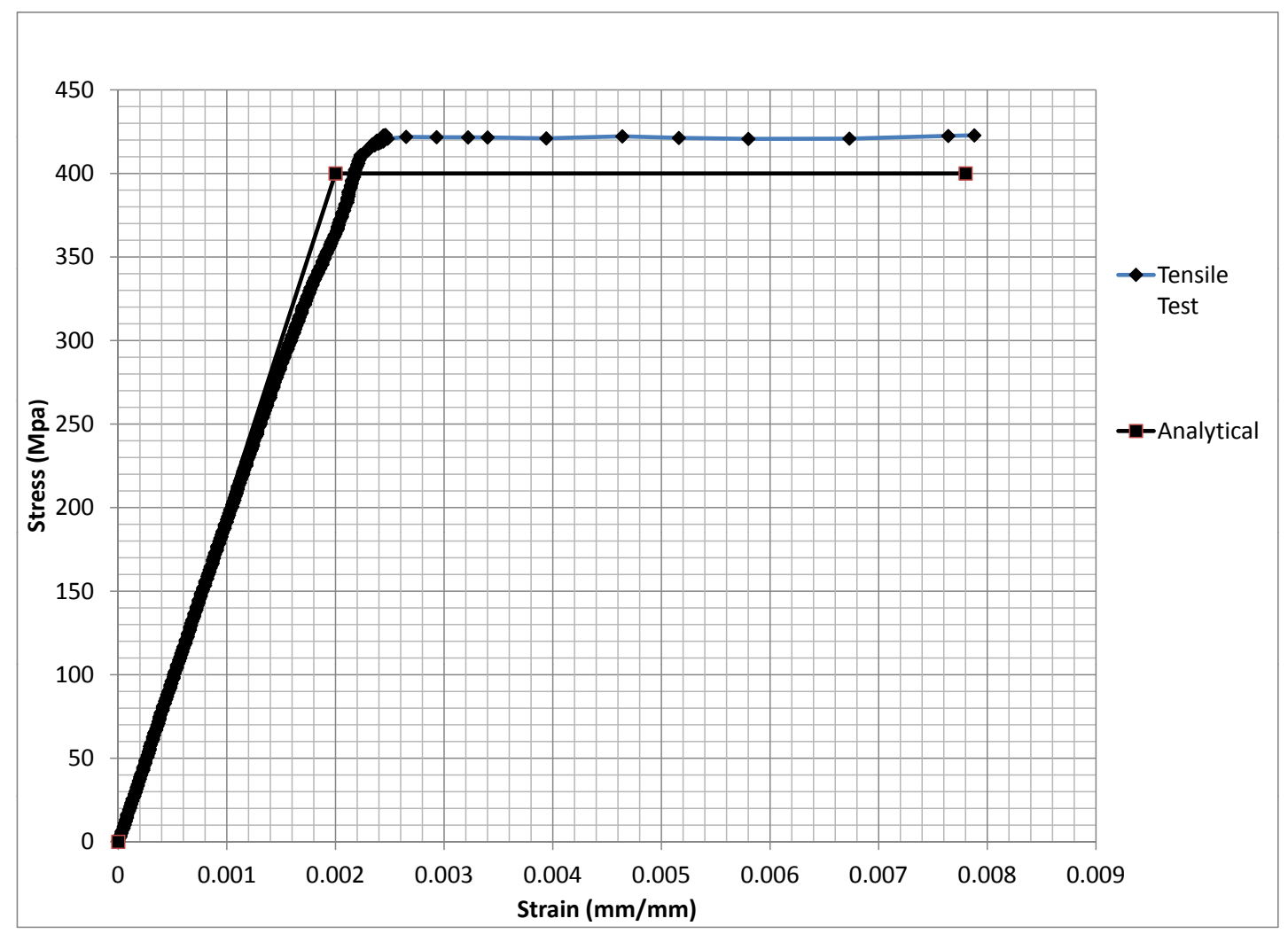

Figure 3.6: Rebar Tensile Stress-Strain Curve

\subsubsection{Test setup}

Phase I, Direct Tension Cracking: Direct tension force was applied to the RC panels throughout the extruded longitudinal reinforcement until a major crack penetrated the whole depth of the specimen. The sample was unloaded after formation of the crack. A distinctive setup was chosen to allow applying the tensile force by pulling the extruded rebars. The extended rebars were fixed to a rigid wall at the north side and pulled against it from the south side. The fixation was done by welding a steel nut to the rebar as shown in Fig 3.7. Fig. 3.8 shows the plan view of the setup. Two RC beams were used at both north and south ends to uniformly distribute the force between the rebars. These beams were previously designed for similar experiments. Fig. 3.9 and 3.10 show the details of distributing RC beams. Each RC beam has been designed to work as a deep beam, i.e., the forces were primarily transferred through compression struts 
and tesion ties.

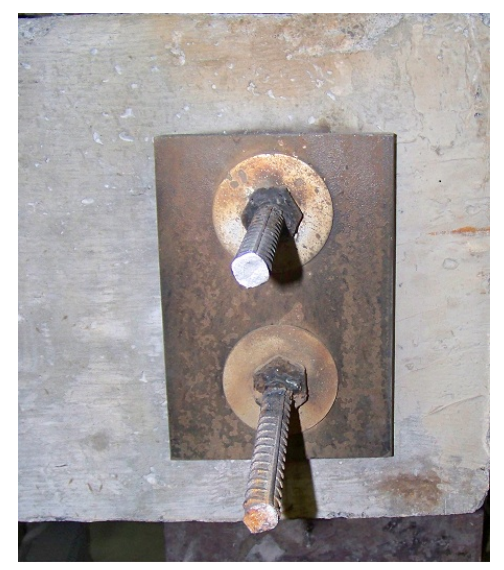

Figure 3.7: Rebars fixed to the RC beam by welding a nut

The tensile force was applied by means of two identical manual hydraulic jacks. The jacks pushed a W310x283 steel I-beam against the rigid wall via large diameter solid steel rounds. The I-beam transfered the loads from the jacks to two points on the southern RC beam. The northern $\mathrm{RC}$ beam was fixed to the rigid wall at two similar points to ensure deep beam behavior. Two pairs of C150x19 short beams were used for this purpose. The panel was supported at four corners. The RC panel, I-Beam and southern RC beam were all placed on rollers to ensure free sliding boundary condition in the $\mathrm{N}-\mathrm{S}$ direction.

During the first test it was observed that the southern RC beam was lifted up from its support. Therefore, a frame was assembled and fixed to the rigid floor in a way to prevent the $\mathrm{RC}$ beam from lifting up while allowing it to slide freely in the direct tension axis. This frame is shown in Fig 3.11. Fig. 3.12 shows different parts of the setup for Phase I.

Phase II, Reloading: The same test setup as in PhaseI was used to reload the sample up to $80 \%$ of the cracking load in order to find the relationship between external load and crack widths at the surface of the crack. The specimen was unloaded at the end of this phase as well. 


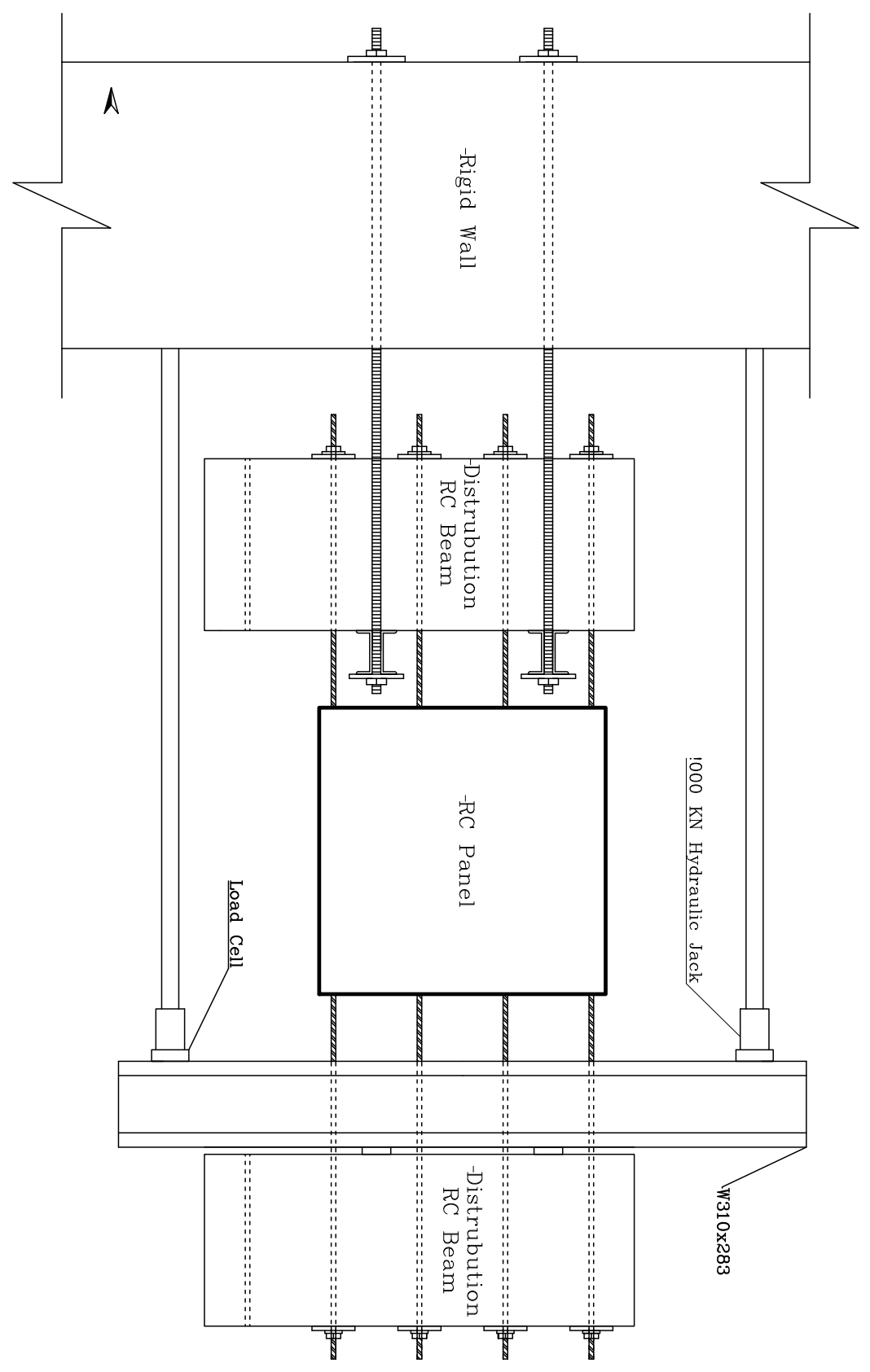

Figure 3.8: Setup Plan View 

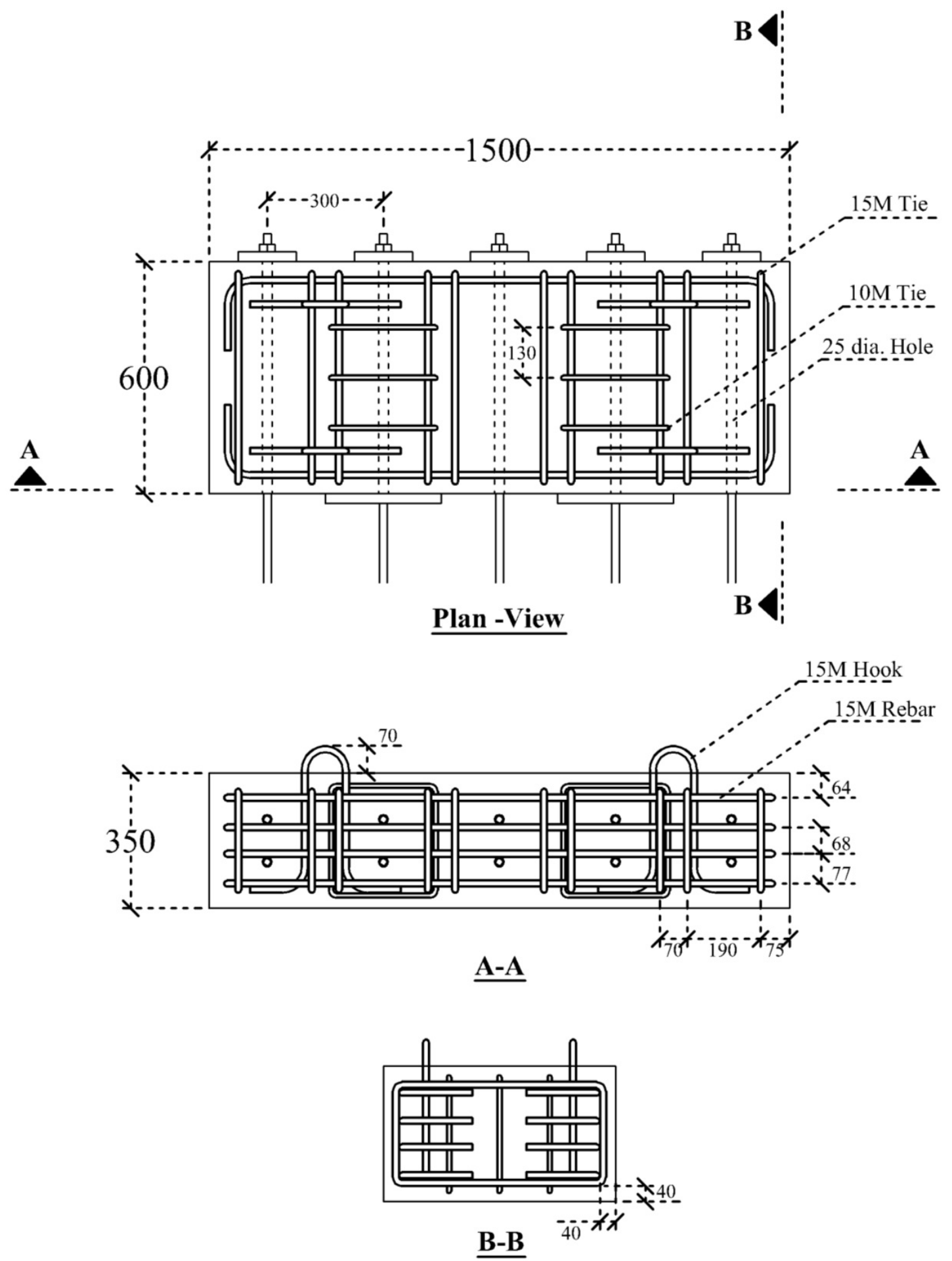

Figure 3.9: Reinforcement layout of RC distributing beam 


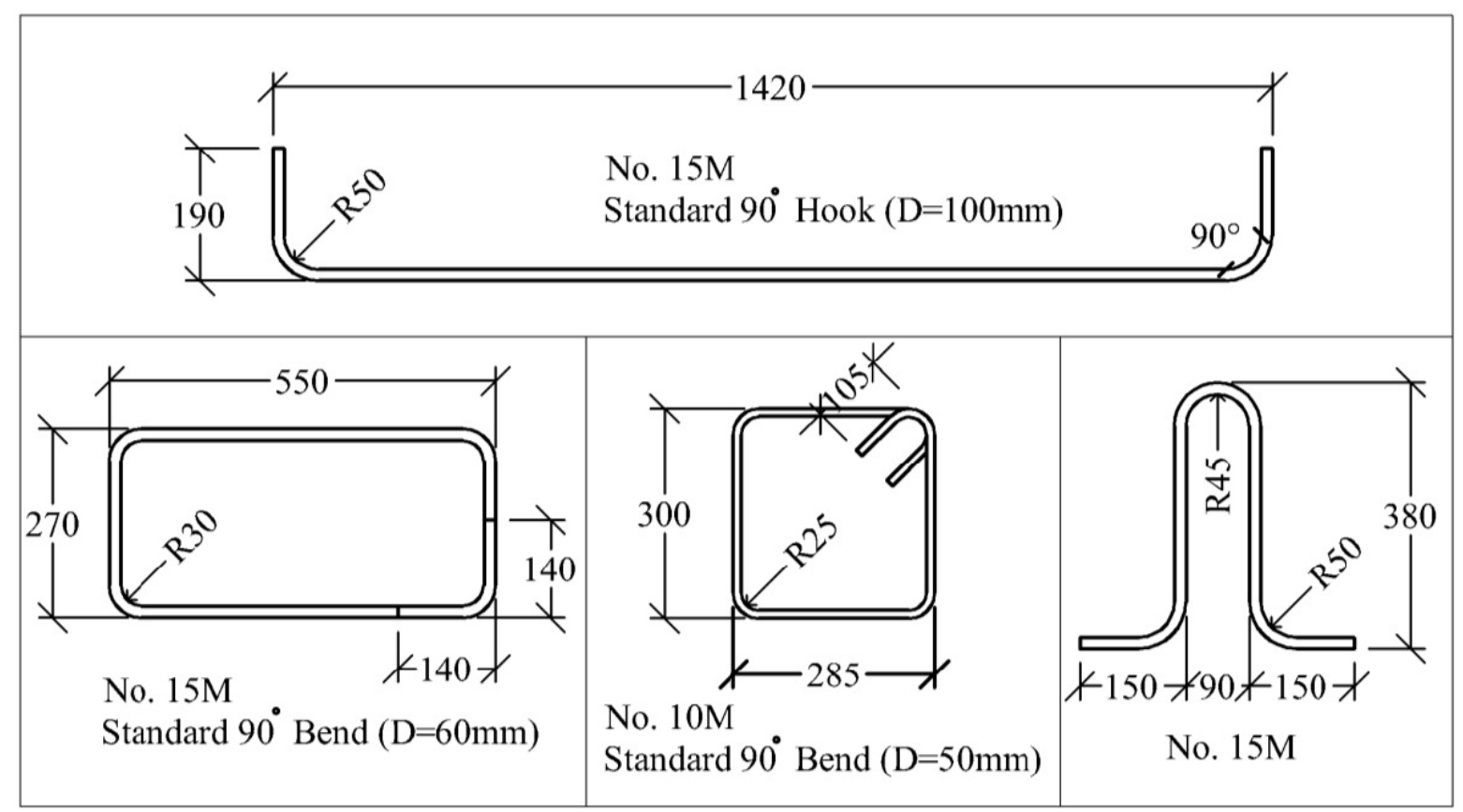

Figure 3.10: Details of reinforcing bars used in RC distributing beam

Phase III, Leakage: This stage was the most challenging of all phases. The purpose of PhaseIII was to measure the rate of water leakage through the crack. The water pressure and the crack width were the variables in the leakage test. Therefore, a pressurized water chamber was required to be attached and sealed to the surface of the concrete on top of the crack while it would not resist the applied direct tension force at all. The other issue was to expose the whole length of the crack to pressurized water. In case of a water chamber installed only on a proportion of the crack at top, the water would travel a diagonal path through the crack to reach the bottom surface, i.e., the crack would leak from a length larger than the length exposed to water.

A unique setup was chosen to overcome the above mentioned issues. A water chamber that was fabricated from $5 \mathrm{~mm}$ thick steel sheet. Two pieces of gum rubber sheet, each $25 \mathrm{~mm}$ thick , were attached to the sides of the sample at the location of the crack for the chamber lips to rest on. With this arrangement, the tank edges would not cover any part of the crack.

Fig. 3.13 shows the procedure of attaching the gum rubber sheet to the side of the sample. First, a thin layer of epoxy was applied to the side surface of the sample in order to create a smooth surface. This layer did not cover the crack. A thick layer of water resistant silicone 


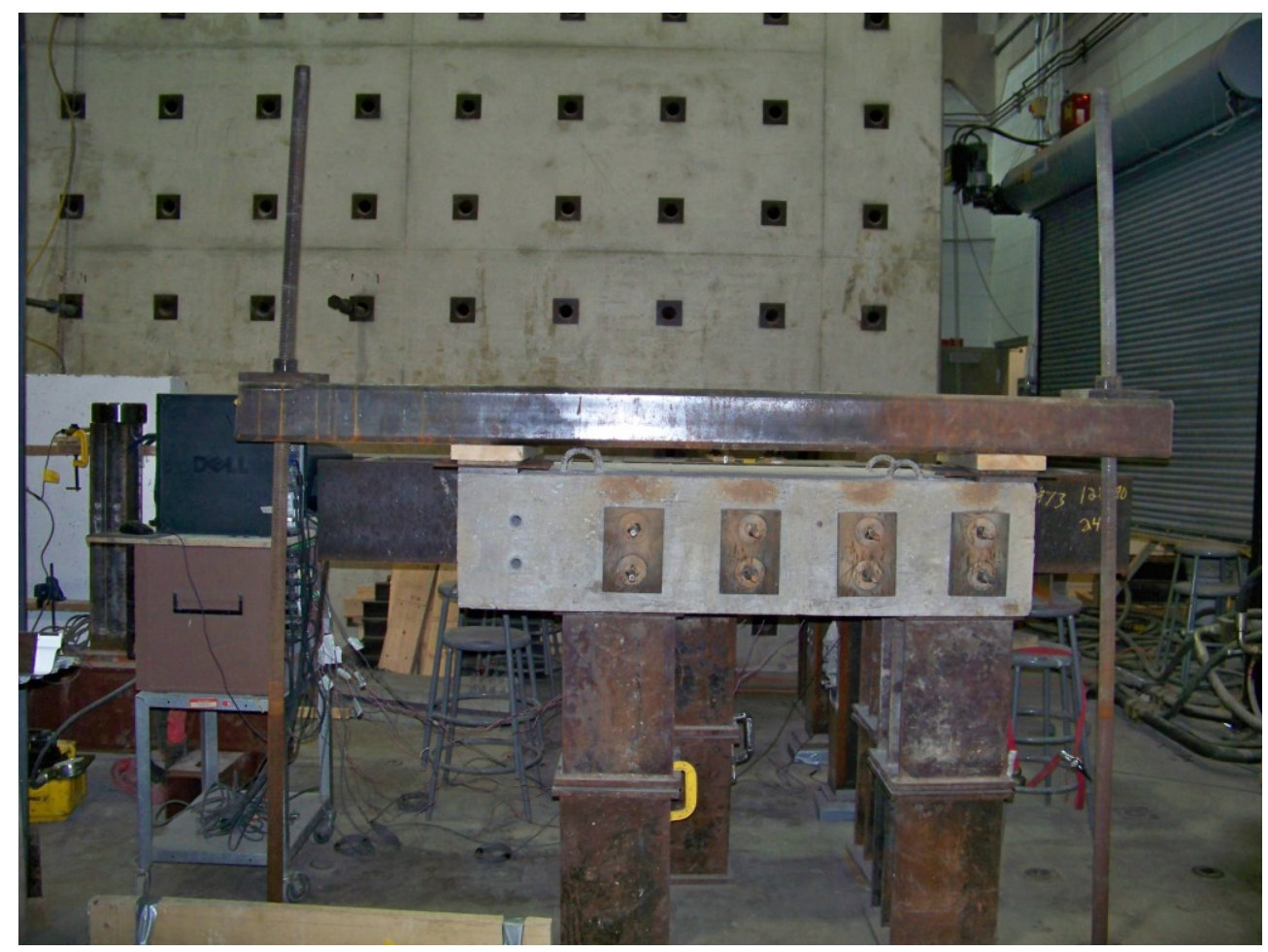

Figure 3.11: South view of the setup - RC beam on roller supports

was then applied to the side surface of the sample. The gum rubber sheet was then attached to the sample using small anchor bolts. Steel washers and nuts were used to tighten the the rubber pad to the surface.

As shown in Fig. 3.13a a thin epoxy layer was also applied to the surface of the concrete panel to create a smooth contact surface for the edges of the chamber. A layer of water proof silicon was applied on top of the epoxy and a layer of the gum rubber, as shown in Fig. 3.14 was placed between the edge of the chamber and the concrete surface.

A thick layer of silicone was applied on the inner surface of the chamber lips and given enough time to cure. The chamber was then placed on the RC panel on top of the crack. It was held down by two 50mmx76mmx1200mm HSS beams along the length of the chamber from top and two $50 \mathrm{~mm} \times 76 \mathrm{mmx} 1200 \mathrm{~mm}$ HSS beams in the same direction beneath the specimen. The top and bottom HSS beams were tightened together at each end by a $19 \mathrm{~mm}$ steel threaded rod to resist the uplift pressure. Spacers were provided between the bottom HSS and specimens to allow flow of any leaked water. The thick rubber pad between the chamber and the specimen, separated the chamber from the specimen in a way that it would not resist any of the direct 


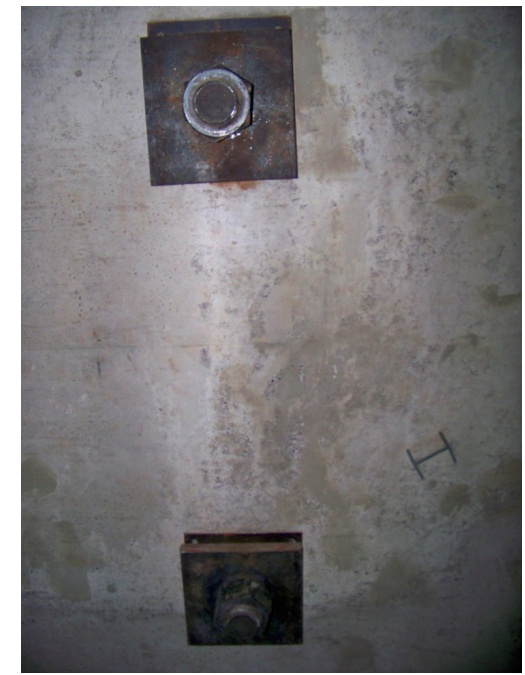

(a) Fixation of Distribution RC to Rigid wall

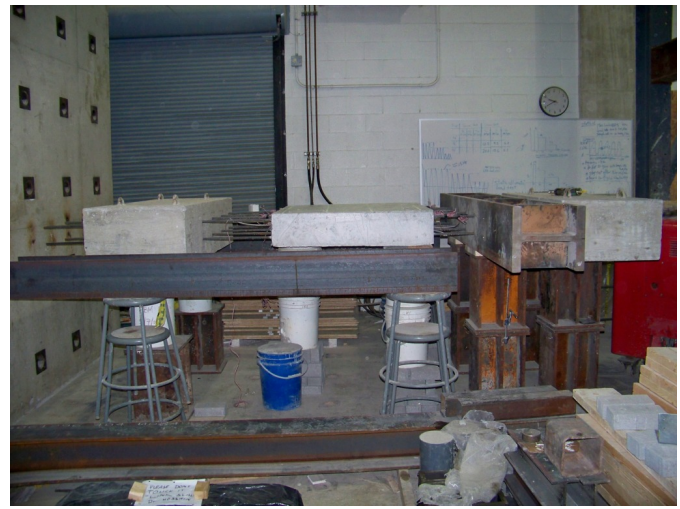

(c) Side View

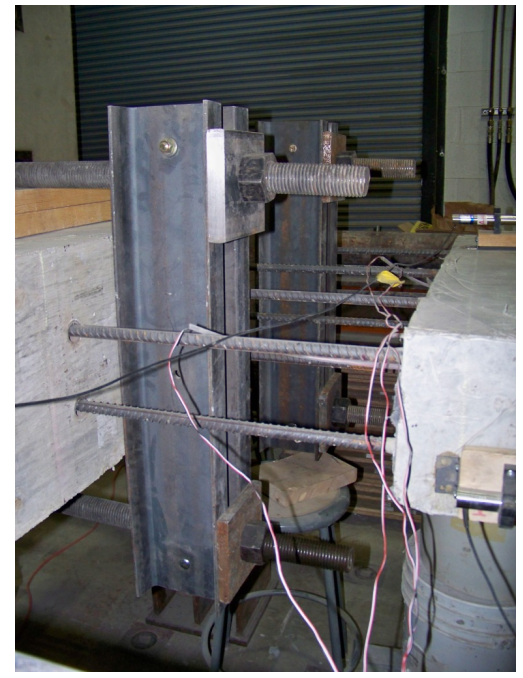

(b) Fixation of Threaded Rod to Rigid Wall

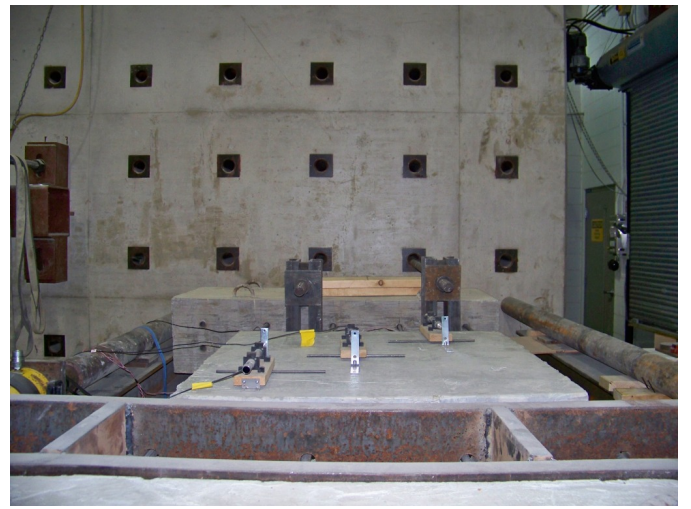

(d) Front view

Figure 3.12: Test Setup, Phase I 


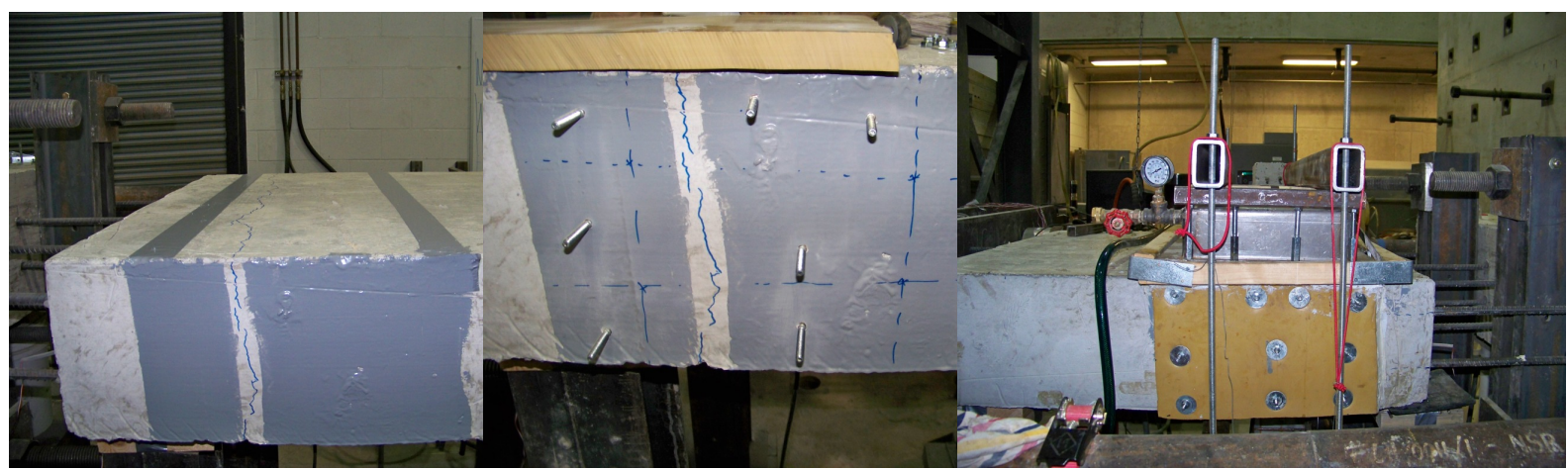

(a) Epoxied surface

(b) Anchor bolts

(c) Rubber pad

Figure 3.13: Side Rubber Pad

tension force.

In oder to pressurize the water inside the chamber and control the pressure, a pressure regulator and a pressure gage were installed at the inlet and the outlet of the chamber respectively. The inlet was connected to city water and the outlet valve was kept open. The outlet valve was closed as soon as water started flowing out from the outlet. The pressure regulator was then used to adjust the water pressure of the chamber.

The specimen was reloaded incrementally up to the cracking load. The water leakage was measured at different crack widths for different water pressures. The leaked water was gathered by an open-top rainspout section, sloping down towards a container placed on a digital scale. The weight of the gathered water was measured over time to find the rate of water leakage through the crack.

\subsubsection{Test Procedure and Instrumentation}

\section{Phase I}

Two identical hydraulic jacks were operated by manual pumps. Two compression load cells were connected to the jacks to show the applied loads during loading and also record it overt time. Reinforcing rebars of the RC panels were instrumented with $10 \mathrm{~mm}$ long electrical resistance strain gages at various locations. In case of a crack happening close to any of these gages, a sudden increase would be observed in the strain.

The RC panels were also equipped with Linear Variable Differential Transformer (LVDT) displacement transducers on top and side surfaces of the RC panel. Each LVDT measured 


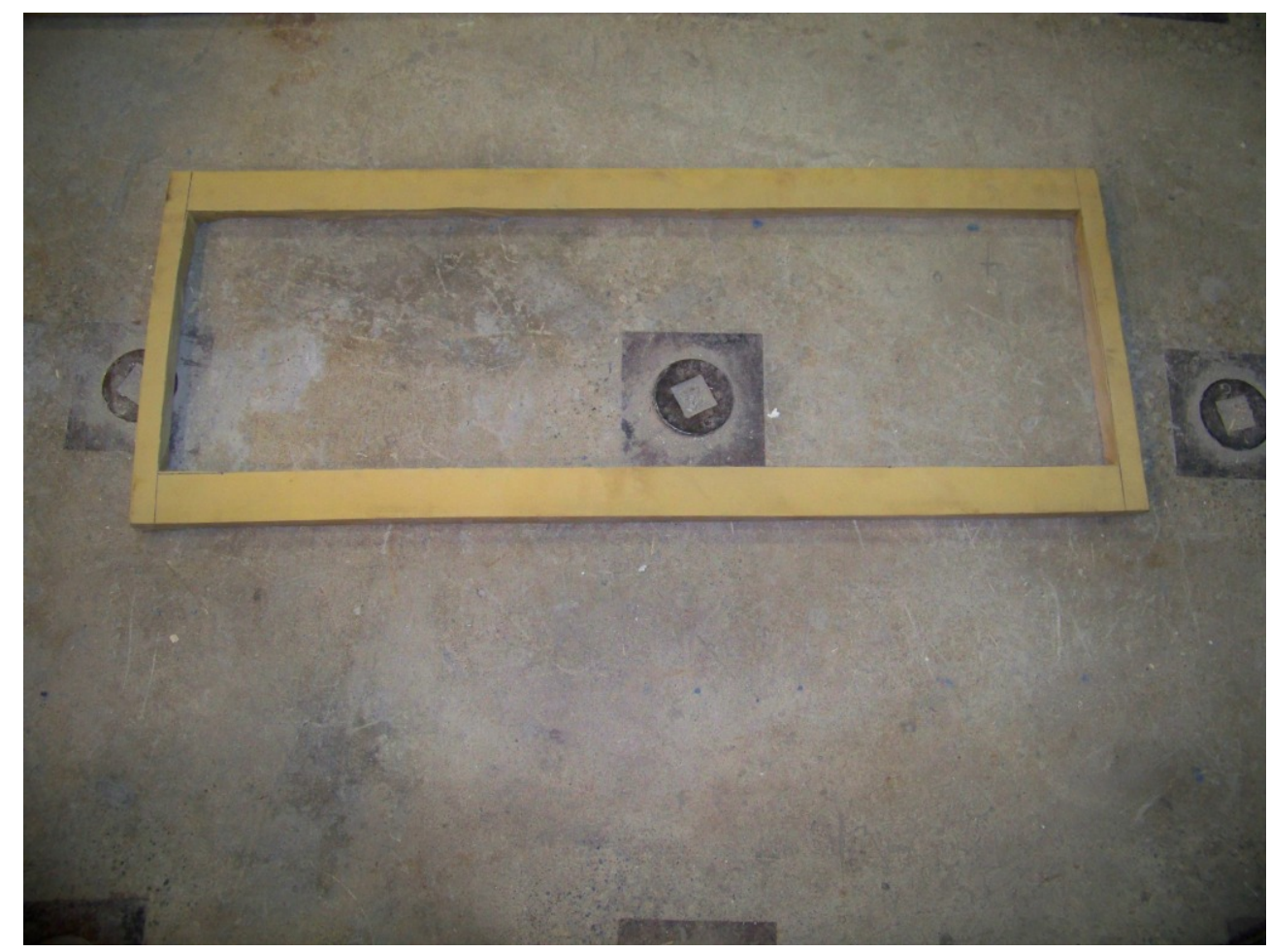

Figure 3.14: Gum Rubber used between the chamber and concrete surface

the displacement over the length that it was installed on. The displacement of the surface of concrete was very small prior to formation of a crack in comparison with the width of a major crack formed by the external load. Each LVDT was attached to a wooden board and placed on a roller to freely slide in the axis of direct tension force. The wooden board was fixed on the surface by heavy duty construction adhesive at its end. The LVDT's needle was pushed inside and kept in that position by an L-shaped steel angel. The LVDT sensors covered the whole length of the RC panel as shown in Fig 3.15a. This configuration, as shown in Fig. 3.15b, allowed the recording of any cracks passing any section covered by the LVDT.

After the first crack was observed the width of the crack was measured at various locations along the crack, using a crackscope with a precision of $0.05 \mathrm{~mm}$ and a magnification of $25 \mathrm{X}$. The hydraulic jacks were then released and the specimens were unloaded for installation of crack gauges. The remaining crack width was measured by the crackscope at various points along the crack to be compared with values gained from LVDTs.

\section{Phase II}




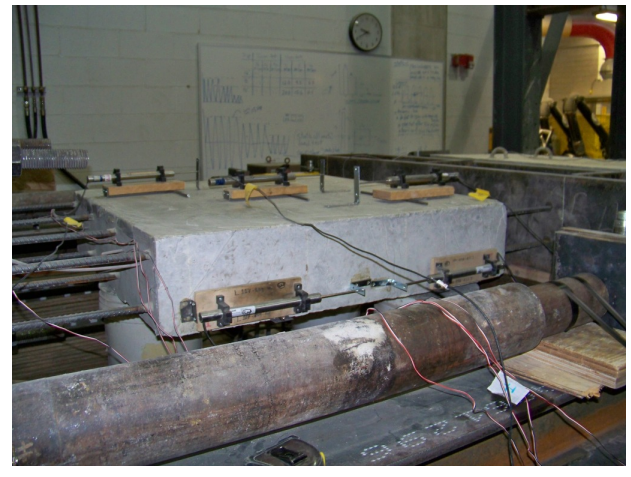

(a) LVDT's Arrangement

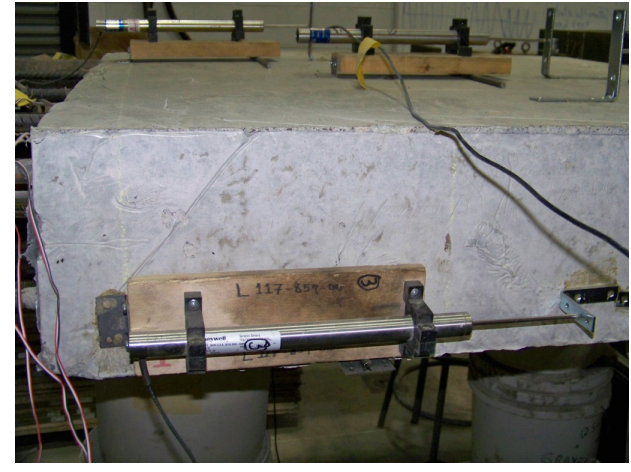

(b) LVDT Setup

Figure 3.15: Phase I, Surface LVDTs

Two types of crack displacement transducers were used to automatically measure the crack width, namely PI-2-50 and KG-5A. PI-2-50 gauges, with the sensitivity of 2000 micro-strain/mm, were used on the top surface. Water resistant KG-5A crack gauges, with the sensitivity of 800 micro-strain/mm, were used both on top and bottom surfaces. The gauges were installed at different locations on the crack to measure the crack width both at top and bottom surfaces. LVDTs, with the same setup as described in PhaseI, were also used at some locations on top and side surfaces of the specimen to measure the crack width automatically.

The RC panel was gradually reloaded using the hydraulic jacks. This was done in multiple stages, making it possible to also measure the crack width manually by the crackscope. For certain levels of external load, the crack width was measured at various locations along the crack to be compared with crack gauge measurements. The cracked RC panel was loaded about $80 \%-85 \%$ of the cracking load to find the relationship between the external load and the crack width. The loads were released at the end of this phase and residual crack widths were measured by the crackscope.

\section{Phase III}

All measuring gadgets were removed from the top surface but the bottom crack gauges were kept at their position. The pressure chamber was installed on the crack as described in $\$ 3.2 .4$ to perform the leakage test. It was required to measure the crack width during the leakage test in order to relate it to the rate of leakage. With the pressure chamber installed on the top surface, it was not possible to have any gauges on the crack opening. KG-5A crack gauges were used at the bottom surface to measure the crack width. The recorded bottom crack width and steel 


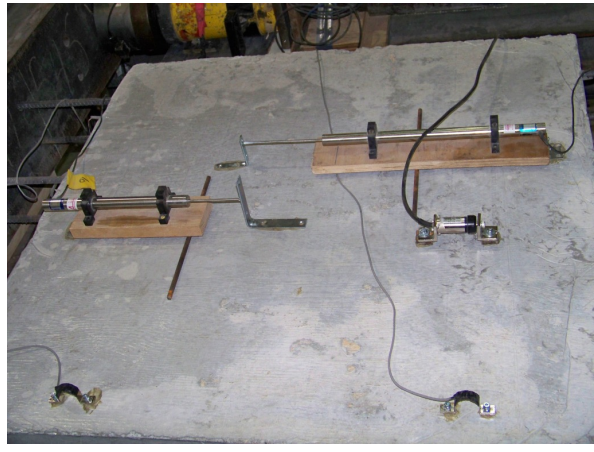

(a) Top PI \& Crack Gauges and LVDTs

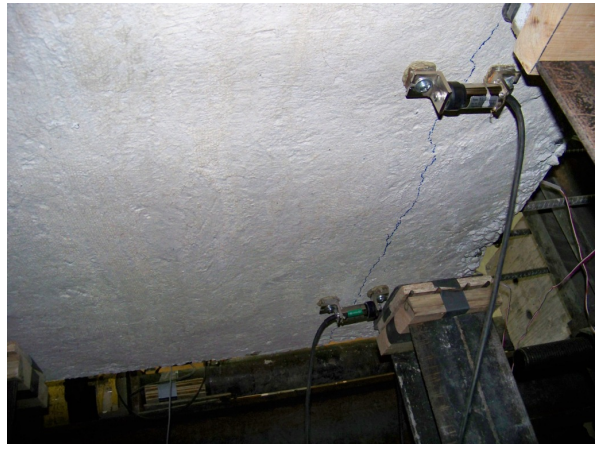

(b) Bottom Crack Gauge

Figure 3.16: Phase II, Crack Width Measurement Devices

strains were compared with those from PhaseII in order to estimate the top crack width during the leakage test.

The leakage test was carried out on a range of crack widths, starting from the residual crack with up to the crack width at cracking load. The direct tension force was increased by increments of $10 \%$ of the cracking load to change the crack width. Each crack width was subjected to water pressures of $0.023,0.046$ and $0.069 \mathrm{MPa}$. These pressures are equal to about 3.33, 6.66 and 10 Psi and water heads of 2.34, 4.84 and 7.18 meters. The pressure regualtor was adjusted so that the pressure gauge (located on the highest level of the chamber) showed 10/3,20/3 and $10 P s i$. These pressures in addition to the height of the chamber which is about $150 \mathrm{~mm}$ will be equal to the mentioned water heads. Each pressure was kept constant for two hours and monitored using a pressure gage as shown in Fig. 3.17. The leaked water was gathered in a container on a digital scale with the sensivity of $1 \mathrm{~g}$. Fig. 3.18 shows the leakage test setup. The weight of the leaked water was measured over this period of time. Each crack widh was also subjected to non-pressurized water to examine the tightness of the cracks against leakage of rain/snow water ponded on rooftops. For this purpose. after filling the chamber with water, the inlet and outlet valves were kept close for a period of 12 hours. 


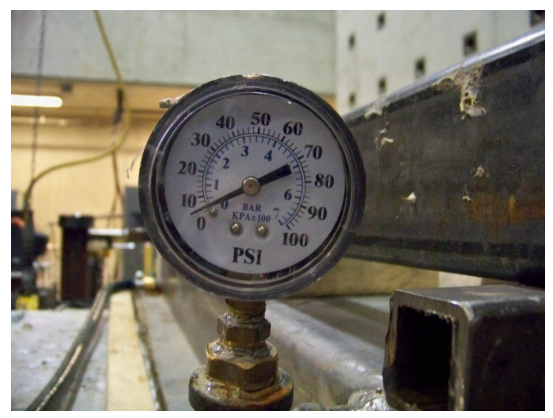

Figure 3.17: Pressure Gauge

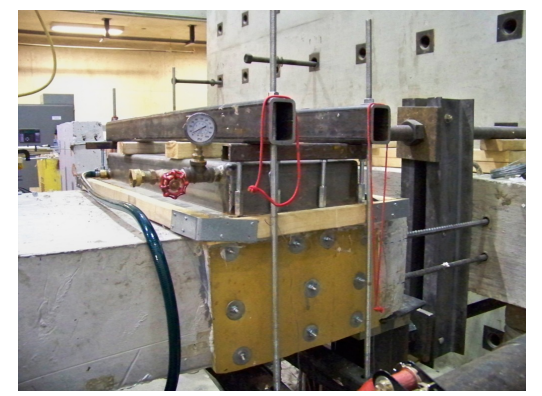

(a) Pressurize Water Chamber

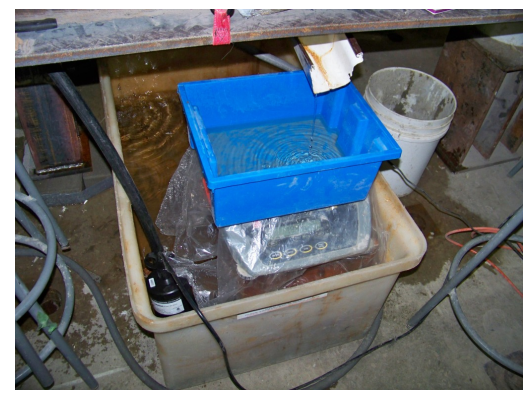

(c) Digital Scale

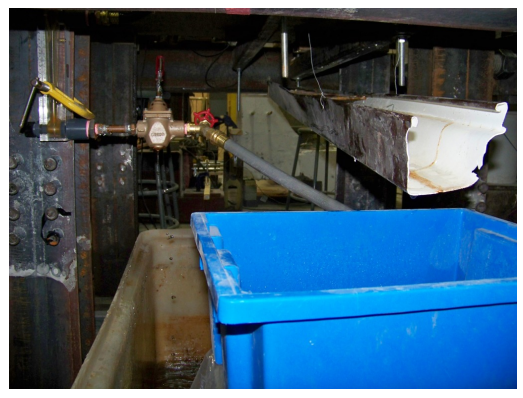

(b) Pressure Regulator and Rainspout chanel

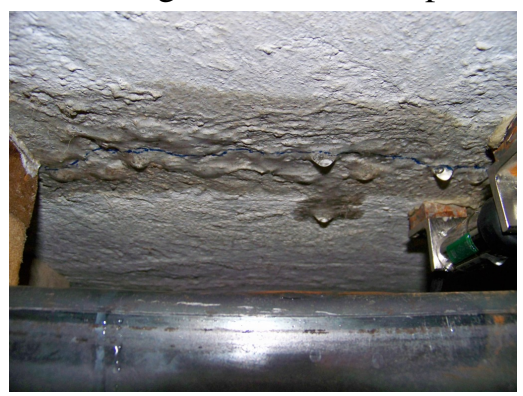

(d) Leakage From the Crack

Figure 3.18: Leakage Test 



\section{Chapter 4}

\section{Test Results and Discussion}

\subsection{General}

The collected data from the experiments are presented in this chapter with more focus on the leakage tests. Steel reinforcement strains, cracking loads, crack widths and the rate of leakage through cracks are reported. The data is analyzed and compared with theoretical models. New findings are discussed in this chapter as well. The data obtained from different phases of the experiment are introduced for the three test specimens followed by analysis and interpretation of the data from Phase III.

\subsection{Phase I}

Concrete cracks as soon as the tensile stress at a section reaches the tensile strength of concrete. In this experiment RC panels were subjected to uniaxial tensile load in order to generate a major crack. The main purpose of phase I was to determine the location of the first major crack for later installation of the water pressure chamber. The load was increased incrementally up to the formation of the first crack. Knowing the tensile capacity of concrete, the tensile cracking load of the RC panel section can be predicted. For this purpose the transformed sectional properties can be used:

$$
\sigma_{c t}=\frac{P_{c r}}{A_{e}}=\frac{P_{c r}}{(n-1) A_{s}+b h}
$$


Where $P_{c r}$ is the tensile load in which the specimen cracks, $n=\frac{E_{s}}{E_{c}}$ is the modular ratio, $A_{s}$ is the area of the steel reinforcement and $b$ and $h$ are depth and width of the section respectively. Modulus of elasticity of concrete and steel are taken as calculated in \$3.2.3: $E_{c}=30850.5 \mathrm{MPa}$, $E_{s}=200000 \mathrm{MPa}$. The tensile strength of the concrete is taken as $\sigma_{c t}=3.315 \mathrm{MPa}$ from the splitting test. The cracking load is calculated for specimen S150 in detail. Table 4.1 summarizes the theoretical values calculated for the cracking load of each specimen.

$$
P_{c r}=\sigma_{c t} *\left[(n-1) A_{s}+b h\right]=2.27 *\left[\left(\frac{200000}{32517}-1\right) * 4 * 300+150 * 1000\right]=354 \quad k N
$$

Table 4.1: Theoretical Cracking Load

\begin{tabular}{|c|c|c|c|}
\hline RC panel & S150 & S200 & S250 \\
\hline $\mathbf{h}(\mathbf{m m})$ & 150 & 200 & 250 \\
\hline$\rho(\boldsymbol{\%})$ & 0.8 & 0.8 & 0.64 \\
\hline$P_{c r}(\mathbf{k N})$ & 354 & 472 & 586 \\
\hline$P_{\text {yield }}(\mathbf{k N})$ & 480 & 640 & 640 \\
\hline
\end{tabular}

\subsubsection{Specimen S150}

The load was increased by two hydraulic jacks established symmetrically on the two sides of the specimen. Each jack was loaded in increments of $10 \mathrm{kN}$. As shown in Fig. 4.1, the first cracks on this specimen appeared around the steel rebars at the corners of specimen while the load was about $100 \mathrm{kN}$. These cracks seemed to have developed due to insufficient side cover of concrete around the rebars resulting in loss of bond between reinforcement and concrete at the corners. The clear side cover for the outer $20 \mathrm{M}$ rebars in this specimen was $40 \mathrm{~mm}$. This implied concrete breakout or splitting failure of the specimen. It was decided to unload the specimen, cut off the outer rebars and reload the specimen with the two middle rebars only. The specimen did not crack even when the stress in the reinforcement became close to the yielding stress. Therefore, the test was stopped and the second and third phases were not performed on specimen S150. 


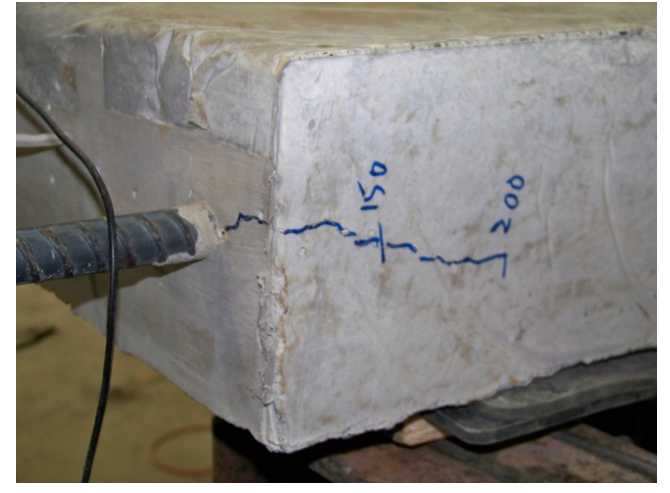

(a)

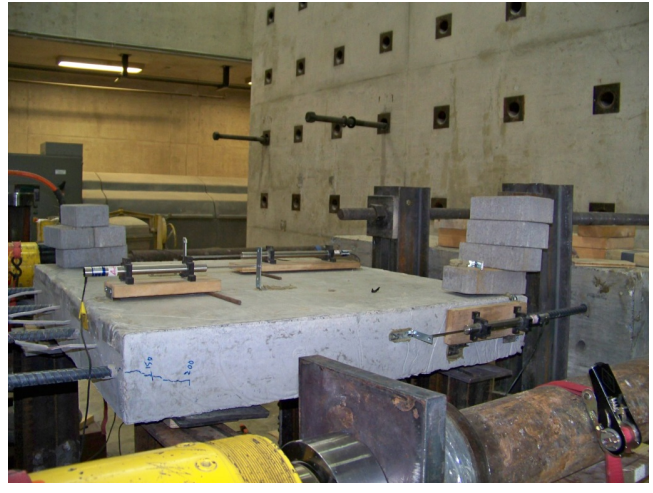

(b)

Figure 4.1: Sample S150 Corner Cracks

\subsubsection{Specimen S250}

The cracking load of $586 \mathrm{kN}$ was calculated for this specimen. Both hydraulic jacks were loaded at the same time. Each hydraulic jack was loaded by increments of $10 \mathrm{kN}$. The first crack was observed at the load of $420 \mathrm{kN}$. As shown in Fig. 4.2 this crack did not cross any of the strain gages. However, as shown in Fig. 4.3, SG5 and SG7 showed a linear increase in the rebar strain before cracking. Sudden increase of the strain indicated cracking of the concrete since the load was suddenly transfered to the rebars. The rate of increase was more than that calculated theoretically. This can be justified according to the CEB-FIP MC90 model as described in Chapter 2. Strain gages SG5 and SG7 were located close to the south edge of the specimen on the top layer of the reinforcement, i.e, they were in the transition length. As a result, they showed a linear increase in the strain prior to cracking, with a larger rate than that of a composite section where the stresses were fully developed through the bond. At the cracked section all of the stresses were carried by the reinforcement and thus, the strain gages showed a value close to the strain of a bare rebar for the applied load.

The first crack did not penetrate through the entire depth of the section. The specimen cracked on the top surface and the crack continued on both sides close to the bottom surface. But no crack was observed on the bottom surface. Furthermore, the crack width on the top was larger than the side crack width. This could be because of one or a combination of the following reasons:

- Lack of uniform distribution of tensile forces on the section because of the possible 


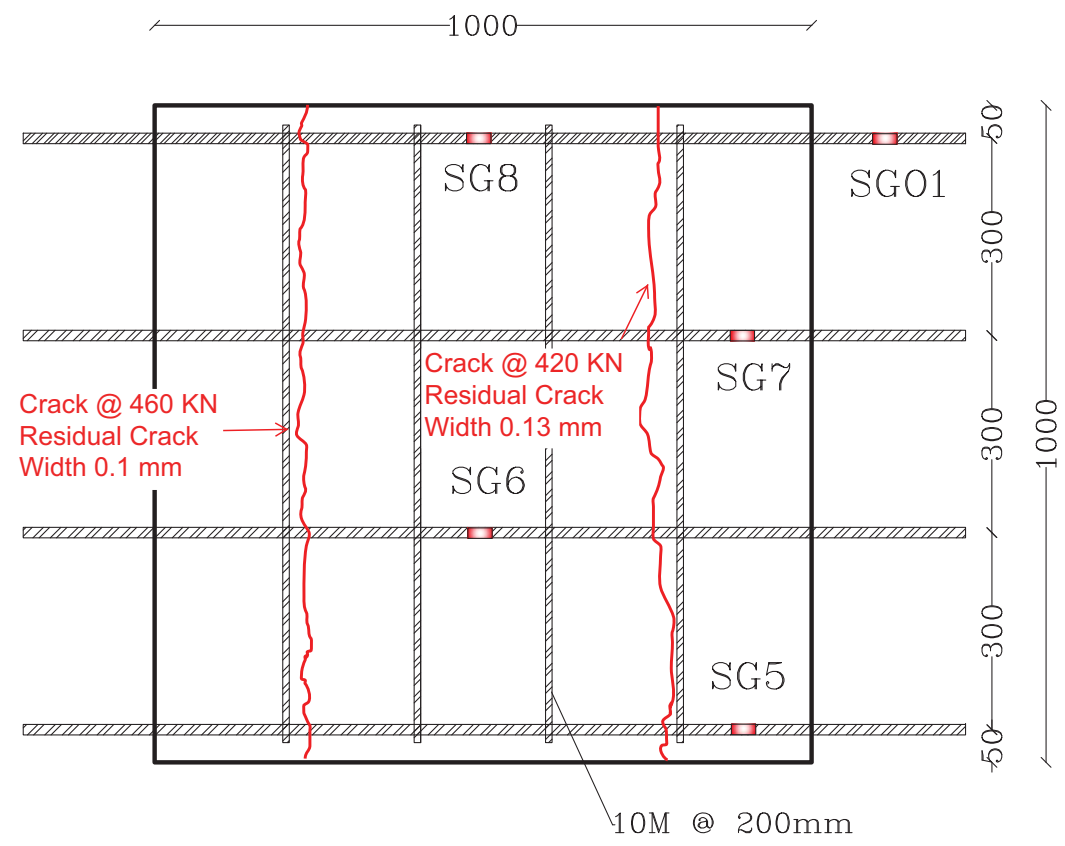

(a) Bottom Layer

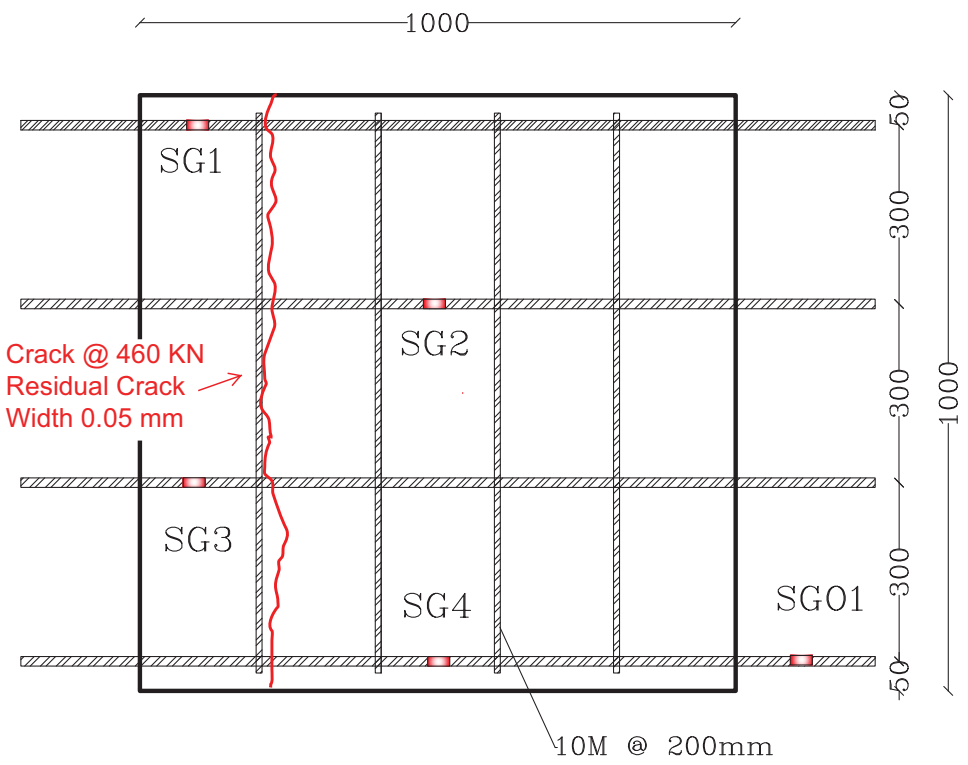

(b) Top Layer

Figure 4.2: Schematic Figure of Cracks on Specimen S250 


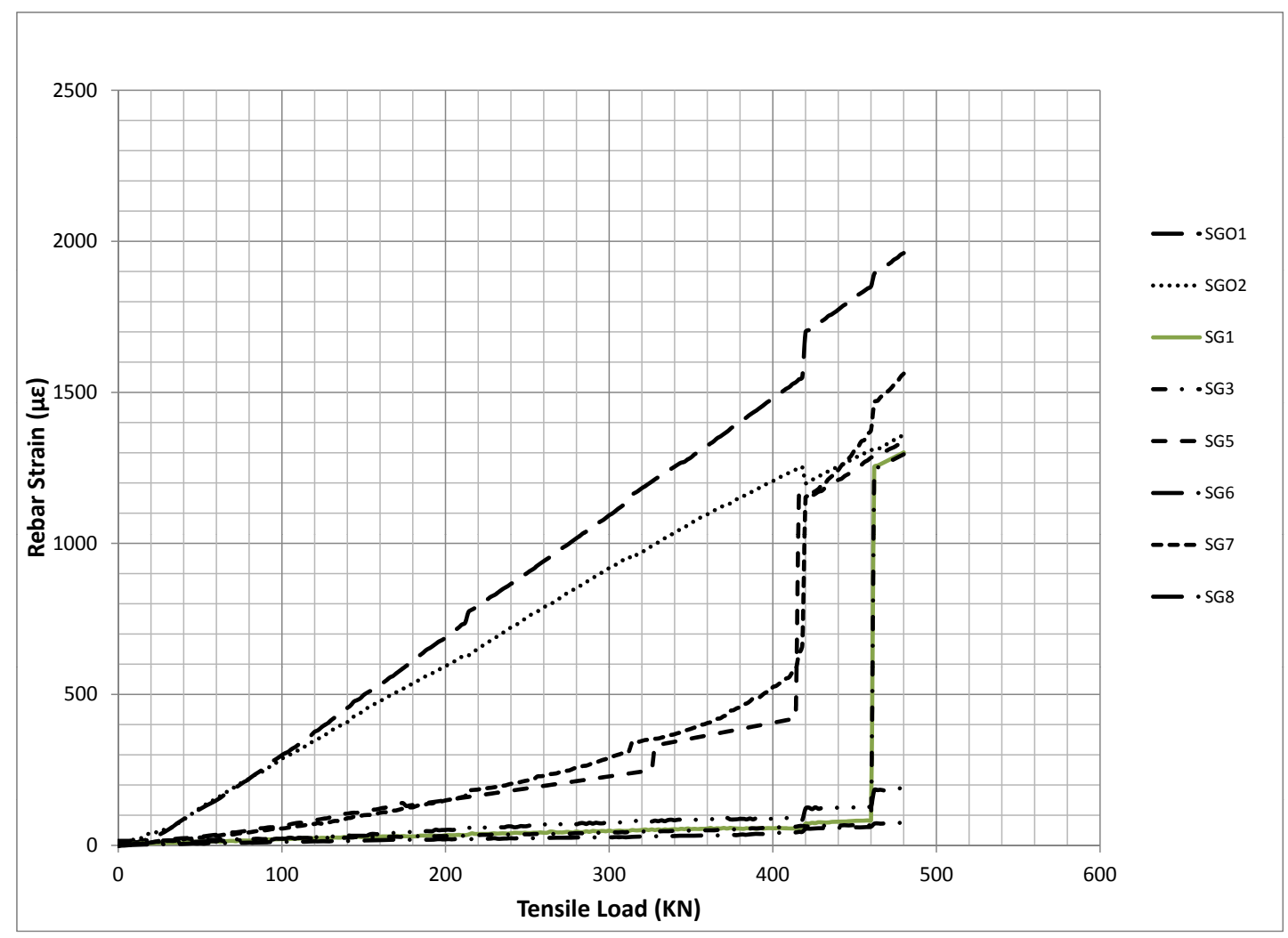

Figure 4.3: Rebar Strain-Tensile Load, S250, Phase I

eccentricity of the longitudinal reinforcement.

- Due to uneven distribution of the forces because of the eccentricity of the hydraulic jacks from the center line between the two layers of reinforcement.

- Friction at the roller supports located at the four corners of the specimen causing the lower levels of the specimen to have lower tensile stresses.

- Deformation of the two end surfaces of the distribution RC beams as a result of previous tests since they were not perfectly level. This might have caused uneven distribution of the tensile force in rebars.

The load was then increased in order to allow the crack penetrate the entire depth of the section. At the load of $460 \mathrm{kN}$ the second crack appeared on the north side of the specimen, 
almost symmetric to the first one. The crack at the load of $460 \mathrm{kN}$ penetrated the entire depth of the section and was best recorded by SG1 and SG3. Both cracks were also recorded by LVDTs attached to the top and side surfaces of the specimen. Each LVDT measured the displacement over the length that it was installed on. No significant change was observed in the LVDT readings prior to cracking. At the cracking loads a sudden increase in the surface displacement was recorded by the LVDTs, equal to the crack opening at the LVDT location. LVDTs TS and TN recorded the top crack width for the first and second cracks respectively. LVDTs SS and $\mathrm{SN}$ recorded the side crack widths of the cracks. Fig. 4.4 shows the displacements recorded by LVDTs. Crackscope readings also showed a more uniform crack width along the top and bottom surfaces in comparison with crack widths through the depth of the section. The top crack widths ranged between $0.29 \mathrm{~mm}$ and $0.33 \mathrm{~mm}$ while the bottom crack widths were in the range of $0.1 \mathrm{~mm}$ to $0.12 \mathrm{~mm}$. A noticeable crack width gradient was observed between the top and bottom crack widths which was due to uneven distribution of the forces in the section.

The sample was then unloaded and the residual crack widths were measured using the crackscope in addition to the LVDT readings. The crackscope readings were in a good agreement with the LVDT measurements for the top and side crack widths. The residual crack width on top surface was $0.12 \mathrm{~mm}$ and $0.1 \mathrm{~mm}$ for first and second crack respectively. An average residual bottom crack width of $0.05 \mathrm{~mm}$ was measured using the crackscope along the crack at the bottom surface. Figs. 4.5 and 4.6 show the LVDT readings for loading/unloading cycle versus the tensile load.

\subsubsection{Specimen S200}

Some of the strain gages in this specimen were damaged or showed a high fluctuation at the beginning of the test. The predicted cracking load for specimen S200 was $472 \mathrm{kN}$. The tensile load was increased increments of $10 \mathrm{kN}$ for each jack. The first crack was observed at the load of $316 \mathrm{kN}$ as shown schematically on Fig. 4.7. This crack did not penetrate through the full depth of the section. The large difference between theoretical and experimental values can be due to possible eccentricity in the specimen or setup causing a bending moment in addition to the tensile forces. The load was then increased and at the load of $342 \mathrm{kN}$ the second crack appeared almost symmetric to the first one. This crack penetrated the full depth of the section. The LVDTs also recorded both cracks as shown in Fig. 4.8. The sudden increase in the LVDT readings indicated cracking of the concrete at the location of the LVDT. The corresponding 


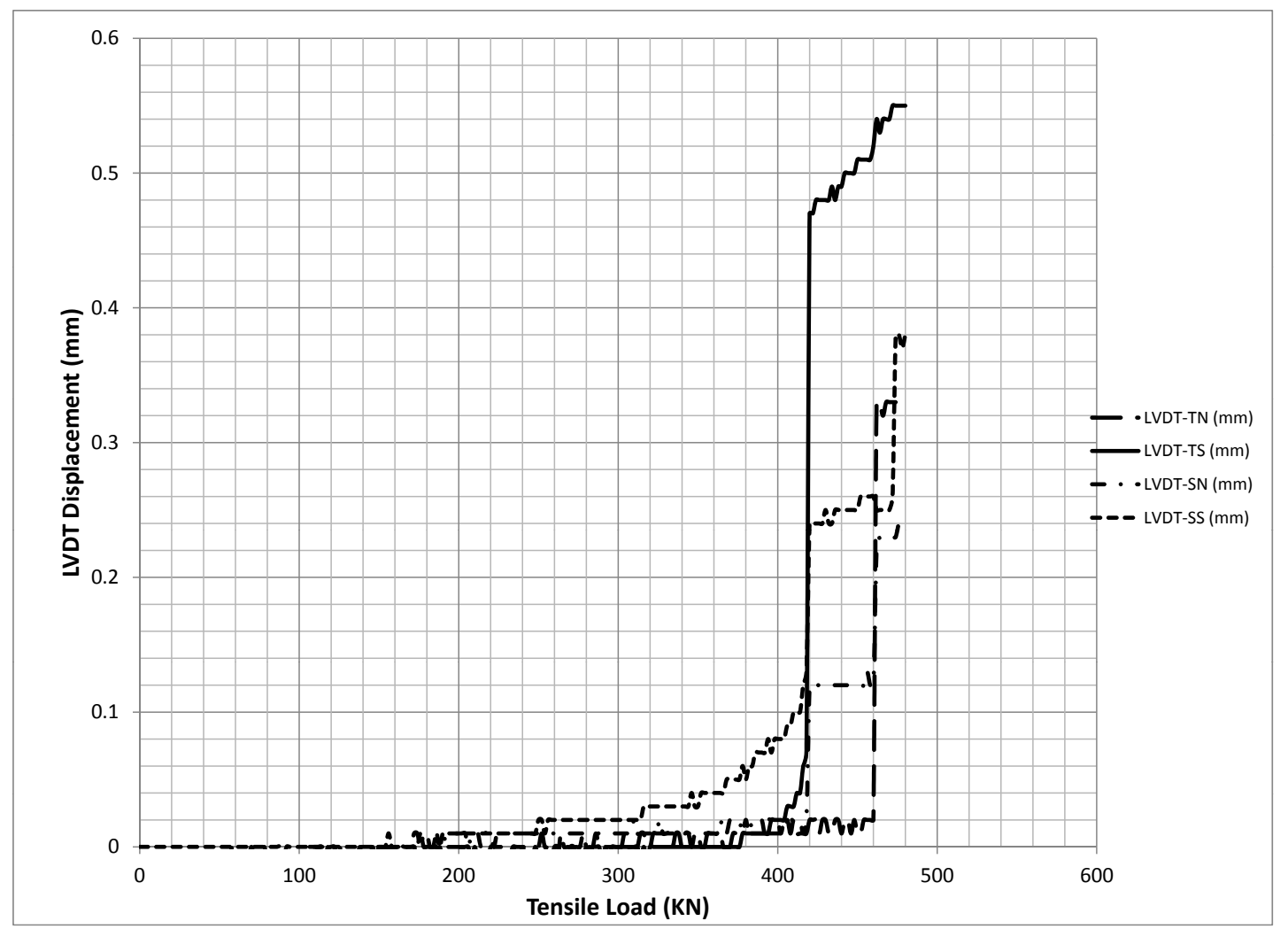

Figure 4.4: Crack widths recorded by LVDTs, S250, Phase I

strains for this stage are shown in Fig. 4.9.

The crack widths were measured using the crackscope at multiple locations along the crack length both on top and bottom surfaces of the specimen. These measurements were in good agreement with the LVDT readings for the top surface cracks. The specimen was then unloaded and the residual crack widths were measured using the crackscope. The average of various readings along the length of the crack suggested residual crack widths of $0.06 \mathrm{~mm}$ on the top surface and $0.05 \mathrm{~mm}$ at the bottom surface for the crack fully developed through the depth of the specimen. 


\subsection{PHASE I}

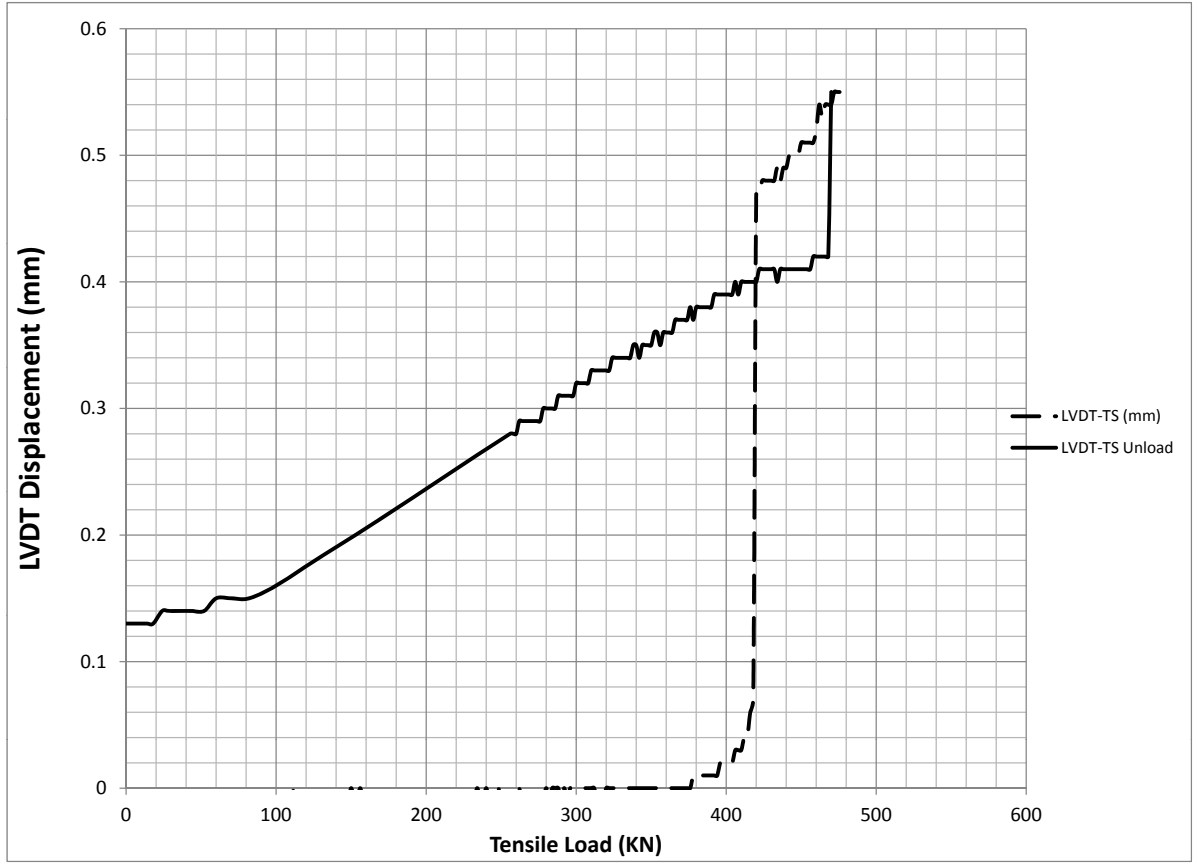

(a) LVDT TS

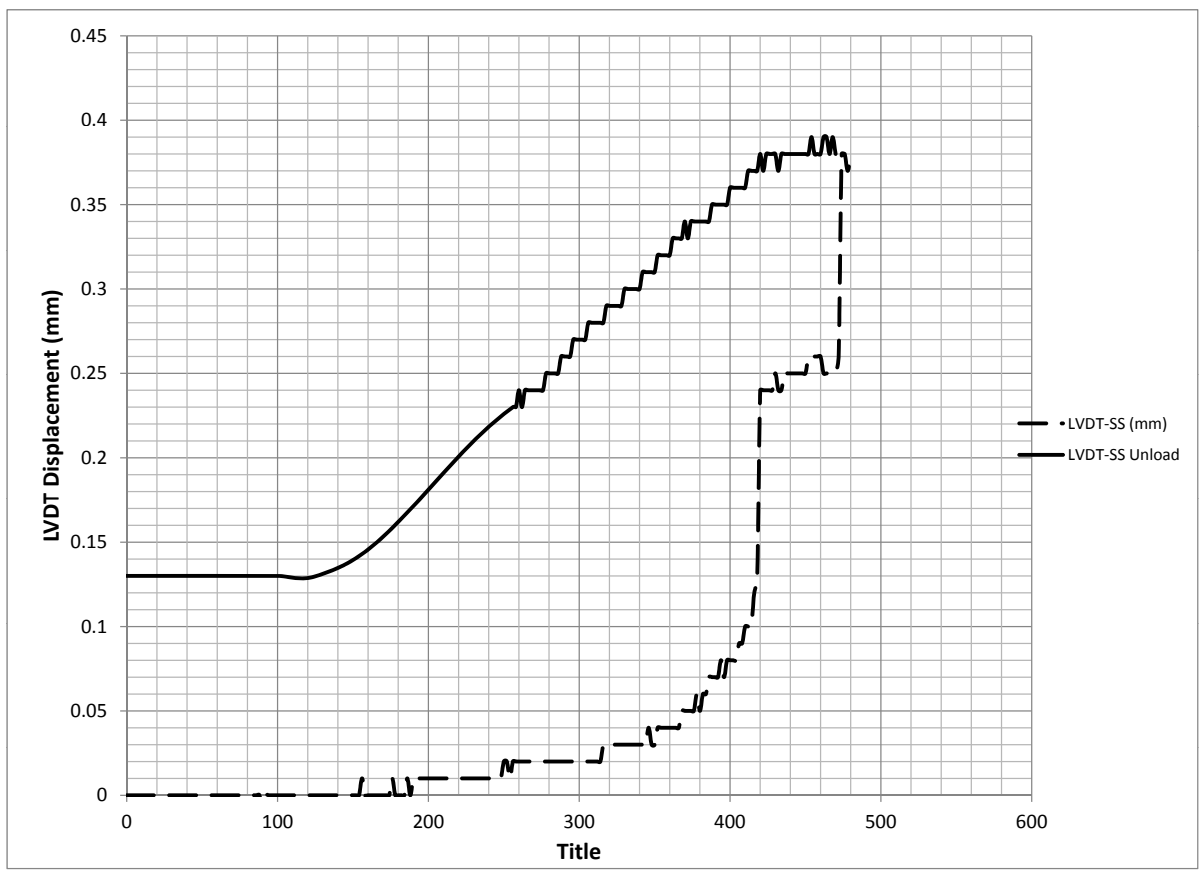

(b) LVDT SS

Figure 4.5: LVDT Readings, S250,Phase I 


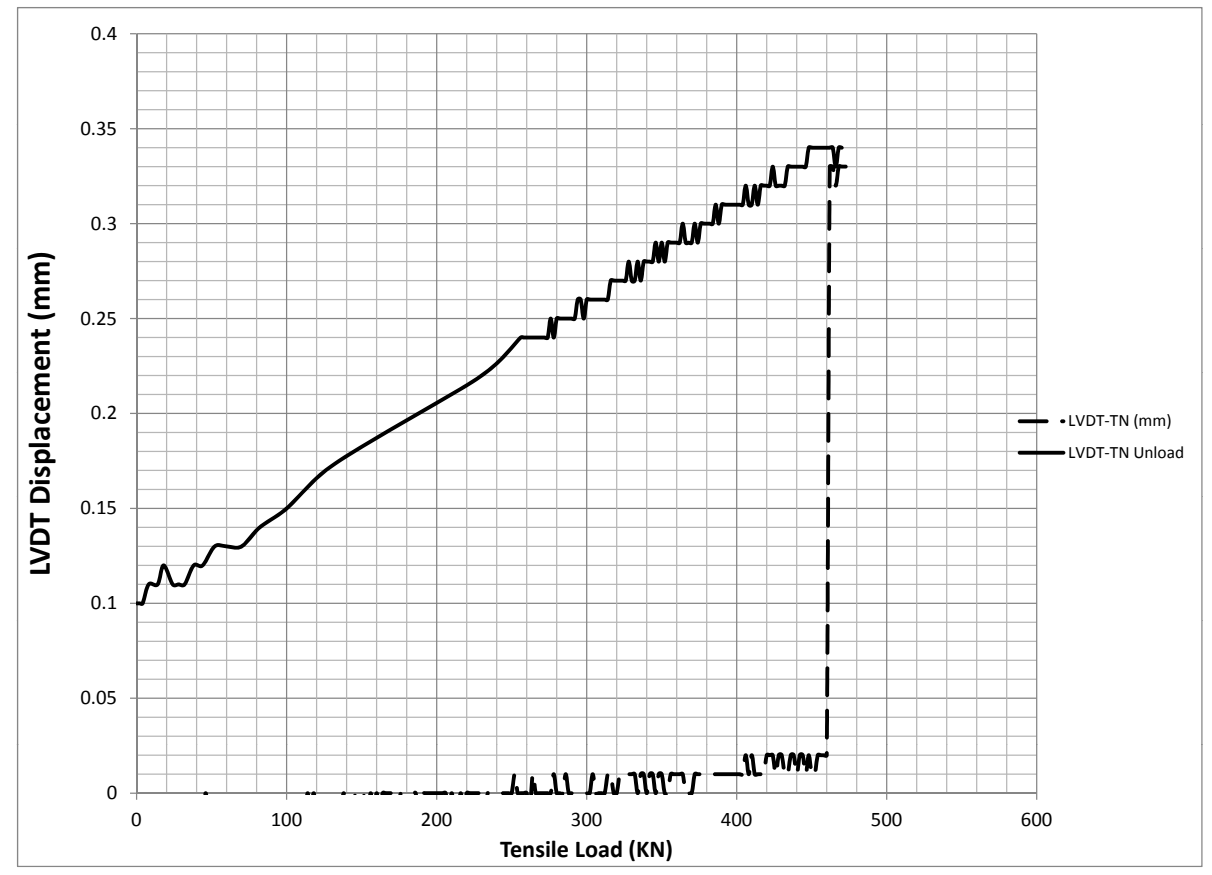

(a) LVDT TN

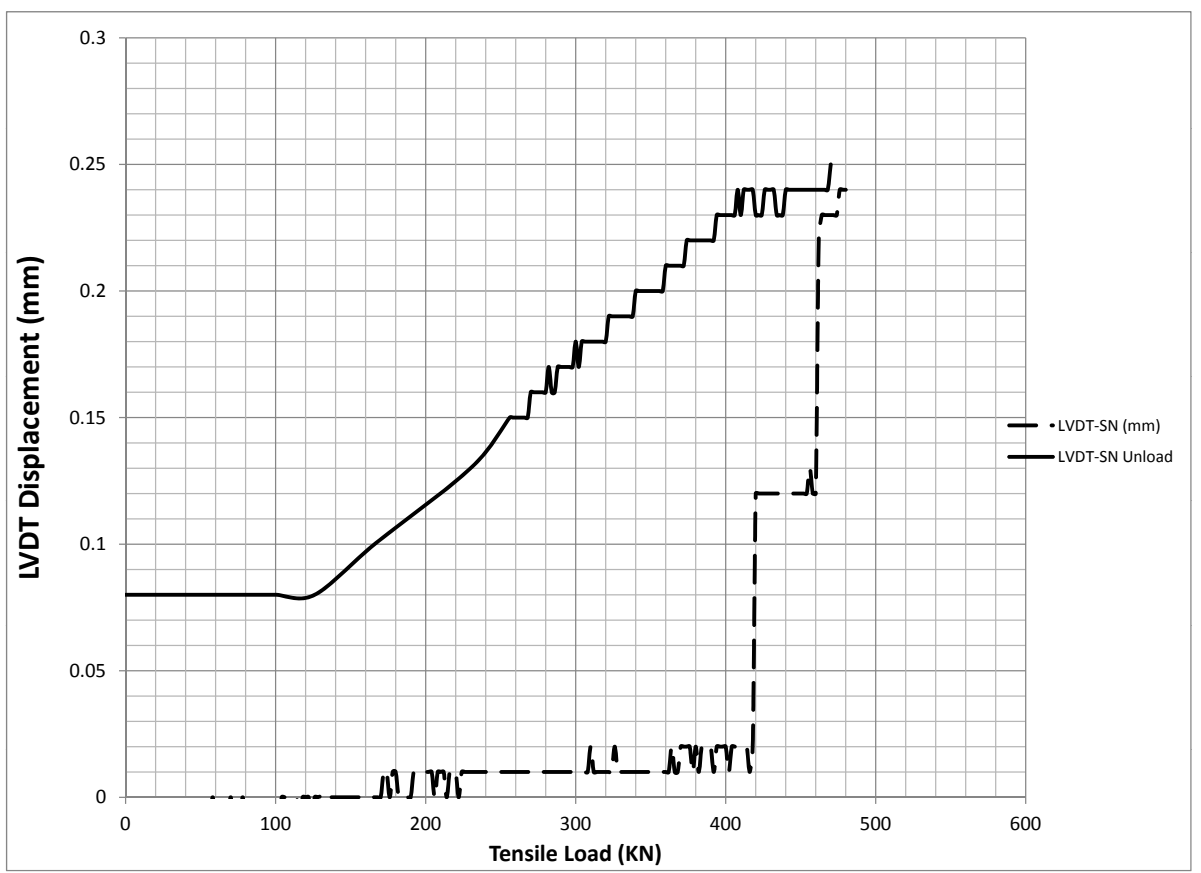

(b) LVDT SN

Figure 4.6: LVDT Readings, S250, Phase I 


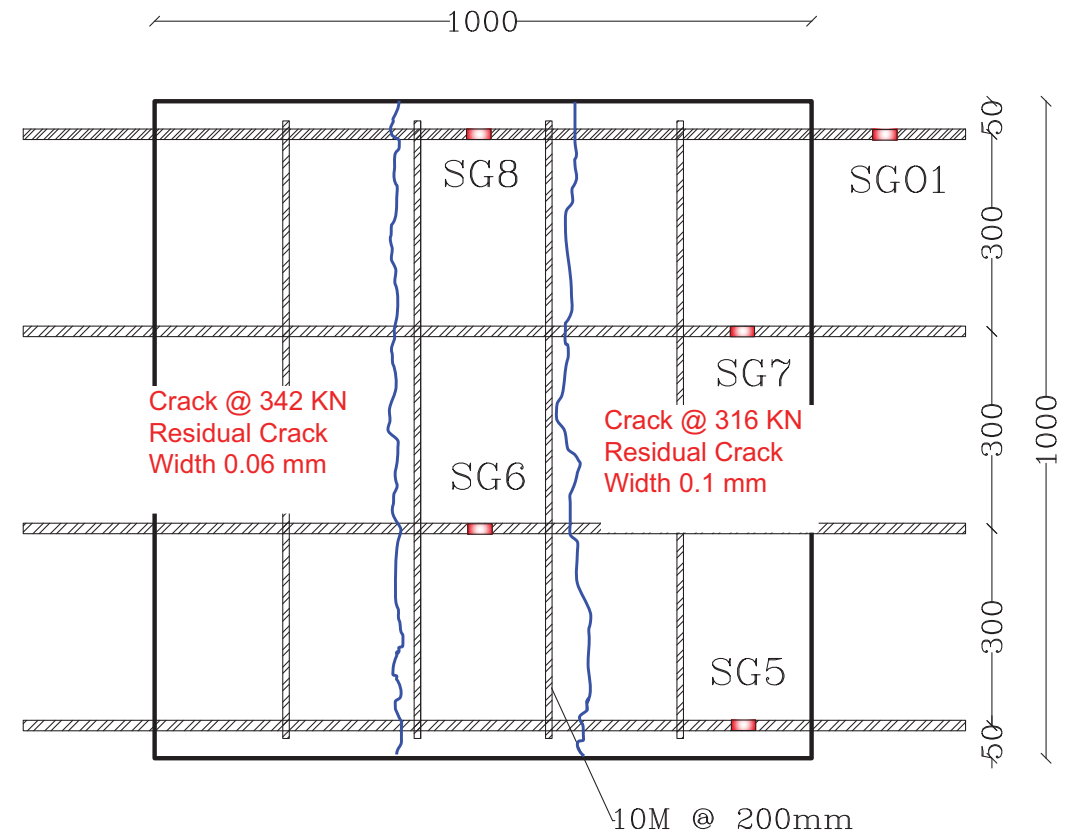

(a) Bottom Layer

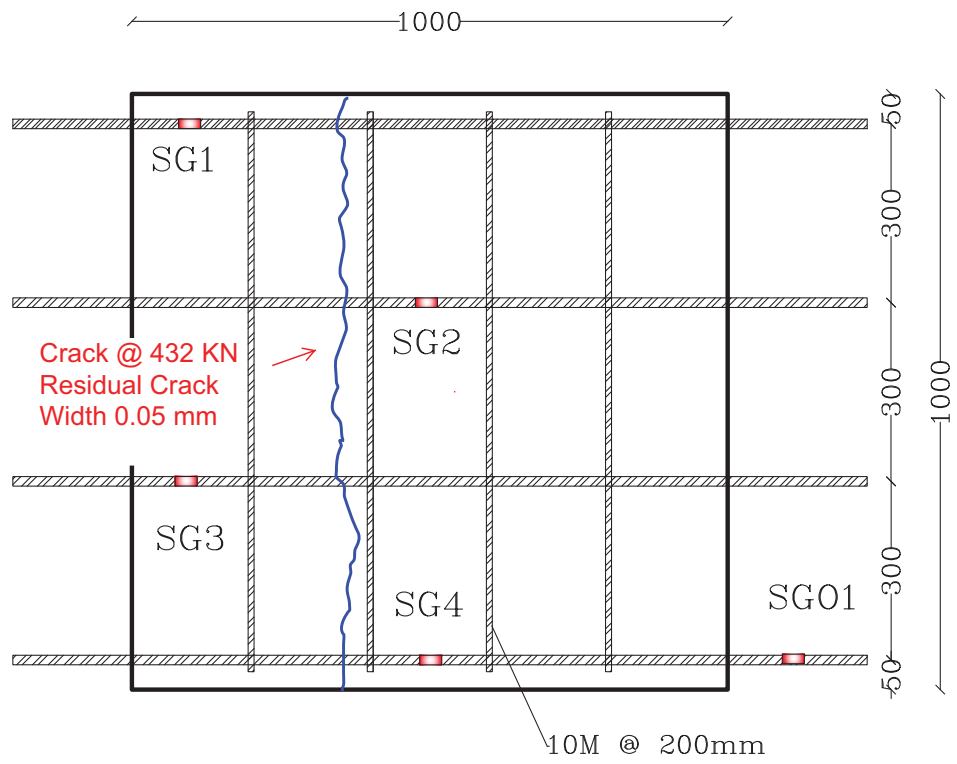

(b) Top Layer

Figure 4.7: Schematic Figure of Cracks on Specimen S200 


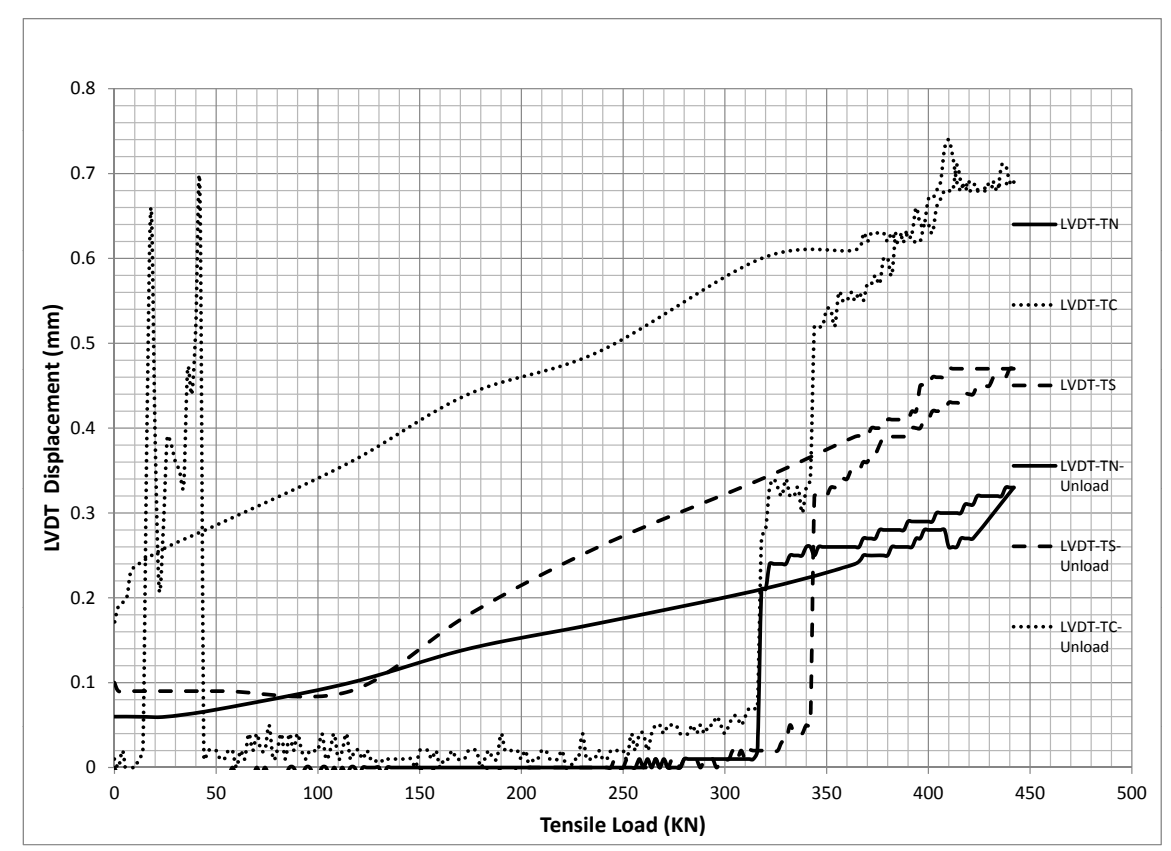

Figure 4.8: LVDT Readings, S200, Phase I

\subsection{Phase II}

The two Specimens were successfully cracked in Phase I. During Phase II the specimens were reloaded to measure the crack widths for different levels of the tensile load. PI gauges and crack gauges installed at fixed locations on the crack made it possible to obtain continuous readings of crack width at their locations. The LVDTs were kept at their original location as in Phase I. The measured residual crack widths from Phase I were taken into account for this phase of the test. The load was increased incrementally and after each step of increase the crack widths were measured along the crack length using the crackscope.

The output format of PI-2-50 and KG-5A sensors was the strain at the concrete surface measured within the sensor's length. PI and KG crack gauges measure the strain over their lengths. The strain at the surface of uncracked concrete at the two sides of the cracks is negligible in comparison with the crack widths. Hence the PI and $\mathrm{KG}$ readings can be taken as the crack width. The displacement, equal to the crack width, was calculated form the output strains of the gauges. 


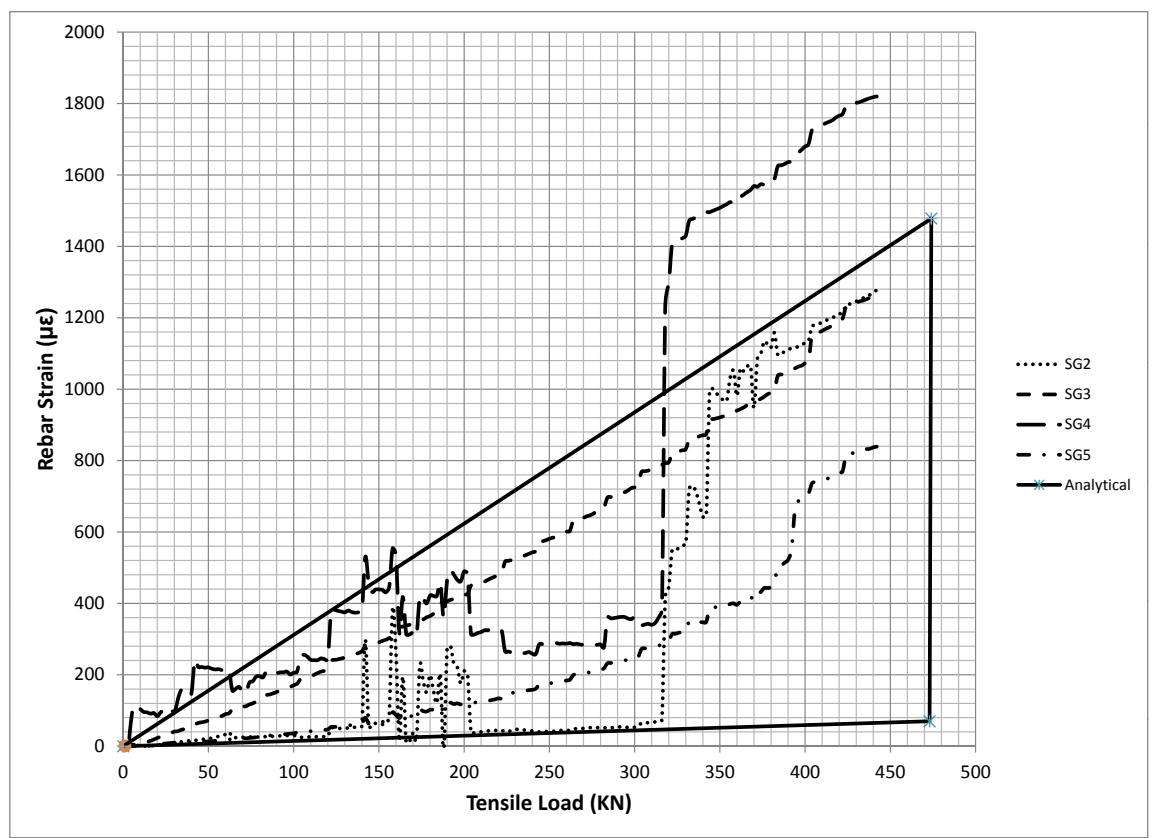

Figure 4.9: Rebar Strain-Tensile Load, S200, Phase I

\subsubsection{Specimen S250}

Fig. 4.10 shows the crack widths measured by different sensors versus the applied load. LVDT SS, LVDT TS and PI68 were installed on the first crack which had not penetrated through the full depth of the section. PI69, CG52, LVDT SN and LVDT TN measured the top crack width on the second crack and the bottom crack width was measured by CG53 and CG54. Although the load was increasing, no significant crack width increase was measured up to the range of 50-70 $\mathrm{kN}$ of tensile load and the crack widths remained almost constant. However, as shown in Fig. 4.11, the strain gages recorded a linear increase in strain. In other words, the applied load was transfered to the reinforcement, but it did not cause any increase of crack widths. This could be because of a number of reasons including slippage of reinforcement at the cracked section or the mechanism of load transfer through the bond. 


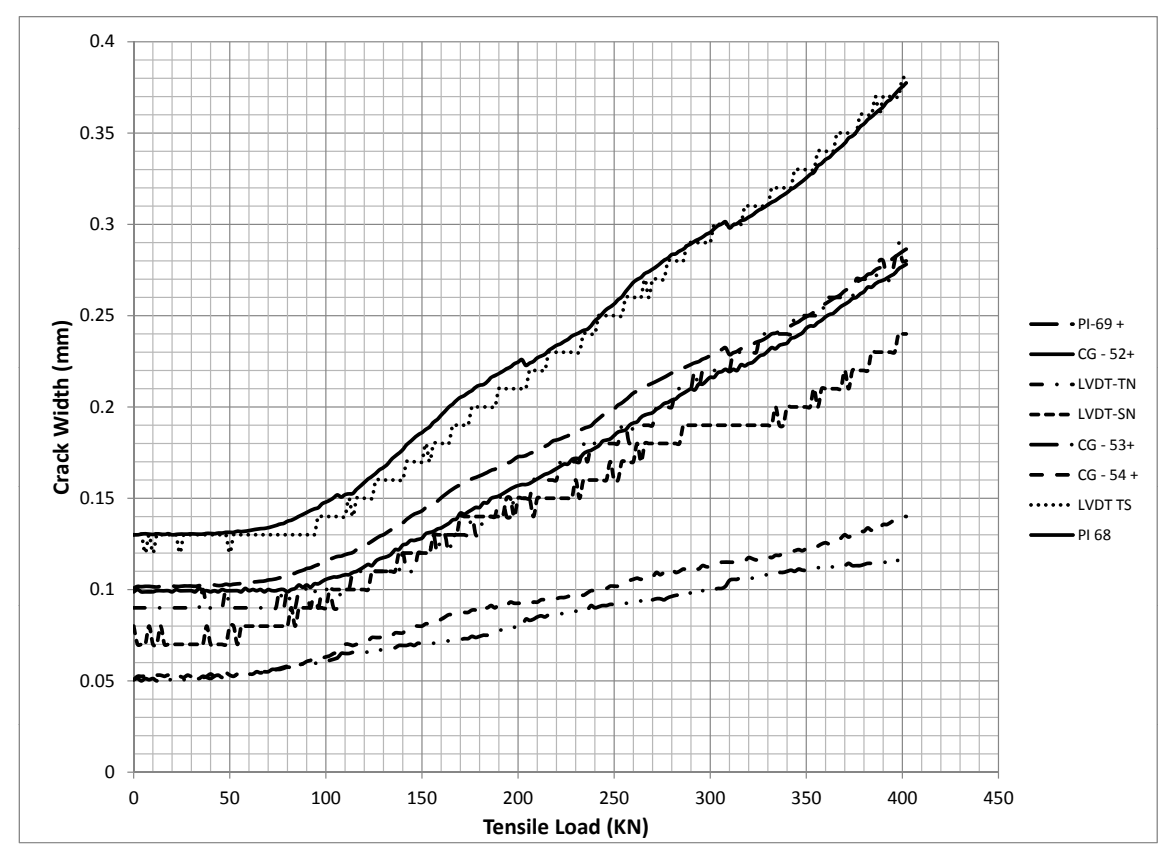

Figure 4.10: Crack Width, S250, Phase II

By increasing the load, the crack width was increased linearly. Although the jacks and load cells configuration was checked at the beginning of this phase, difference rate of increase between bottom and top crack widths was noticeable. The residual bottom crack width of $0.05 \mathrm{~mm}$ was increased to about $0.12 \mathrm{~mm}$ at $400 \mathrm{kN}$ while the top residual crack width of 0.1 $\mathrm{mm}$ was changed to $0.27 \mathrm{~mm}$ at that load. The specimen was then unloaded and the residual crack widths were once again measured along the cracks using the crackscope. No significant difference was observed between the residual crack widths at the end of Phase II in comparison with Phase I. The unloaded crack had residual widths of $0.1 \mathrm{~mm}$ on top and $0.05 \mathrm{~mm}$ at the bottom surface. 


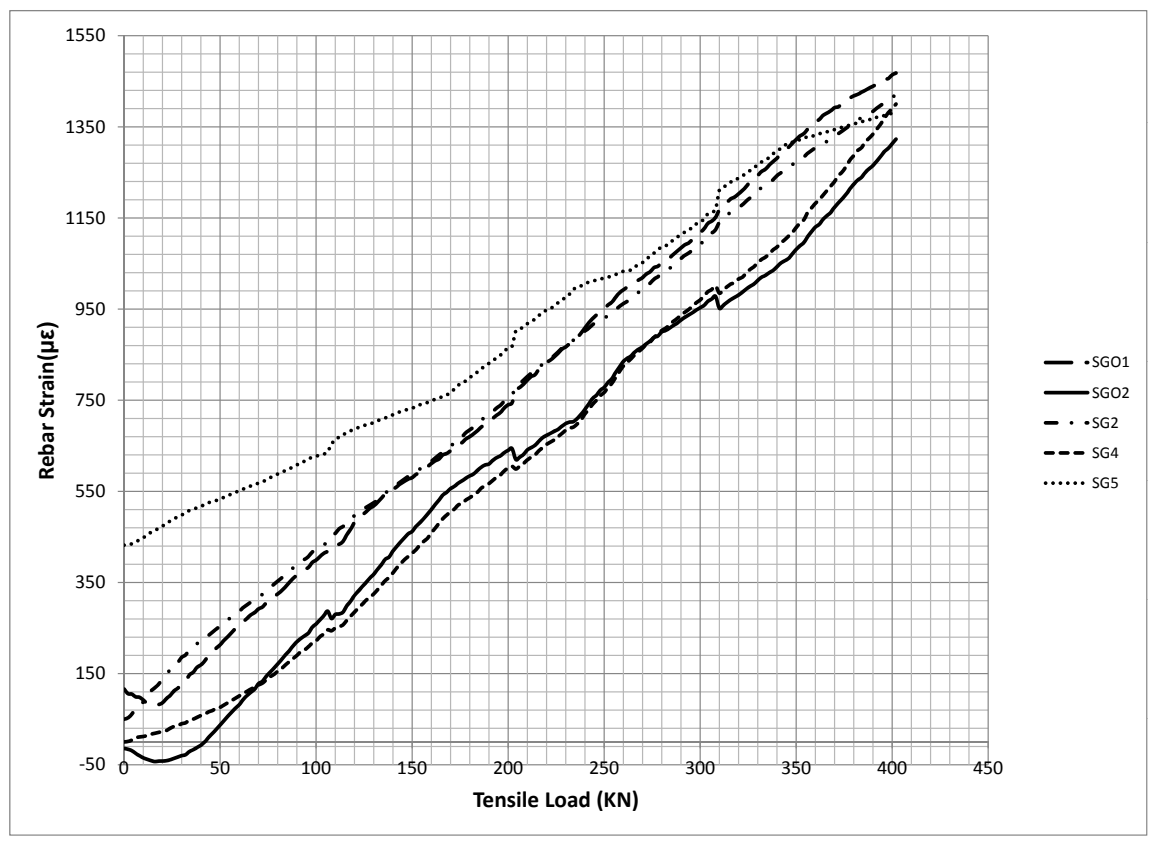

Figure 4.11: Rebar Strains, S250, Phase II

\subsubsection{Specimen S200}

Fig. 4.12 shows the data recorded by the sensors for specimen S200 during Phase II of the test. A larger rate of increase was monitored for the top crack widths in this specimen as well. The same behavior, as in specimen S250, was observed in case of the relationship between the crack width and the tensile load. The crack widths did not increase for the first $50 \mathrm{kN}$ of tensile load and then increased linearly. Fig. 4.13 shows the strain in rebars for the reloading phase. 


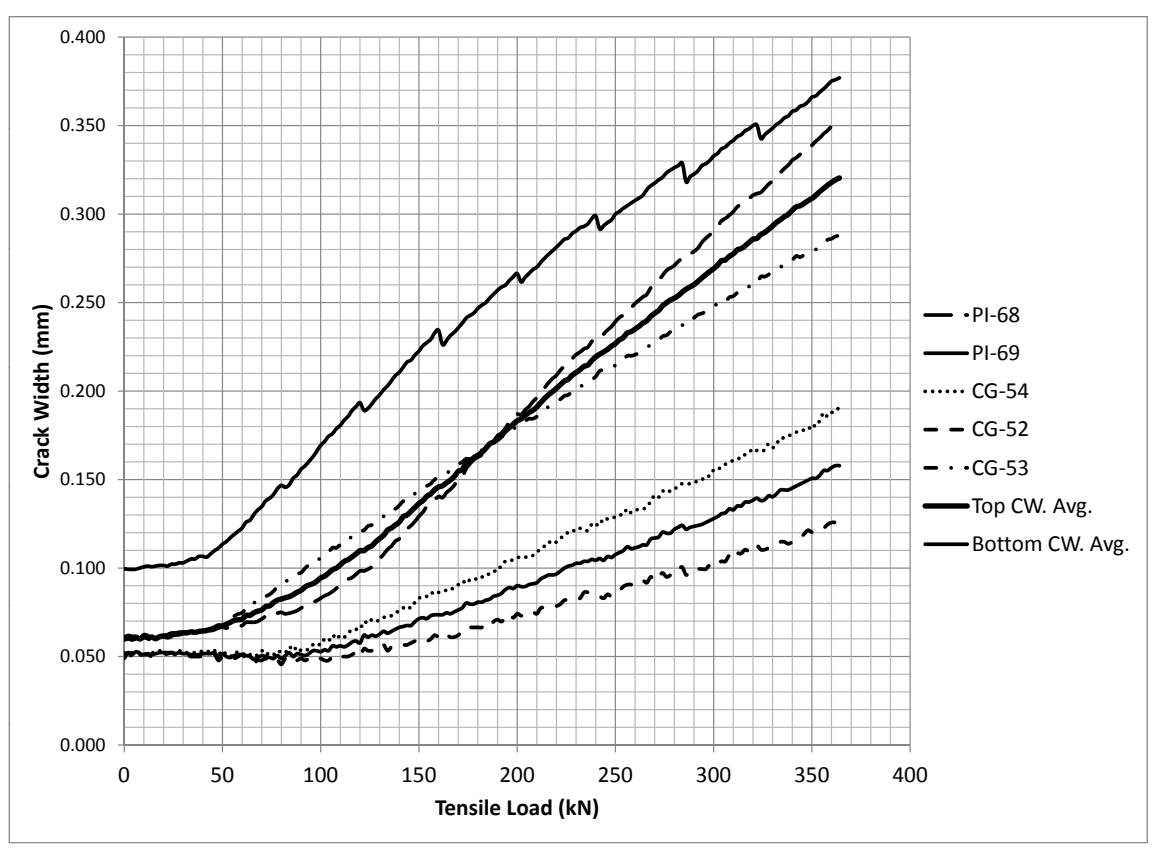

Figure 4.12: Crack Width, S200, Phase II

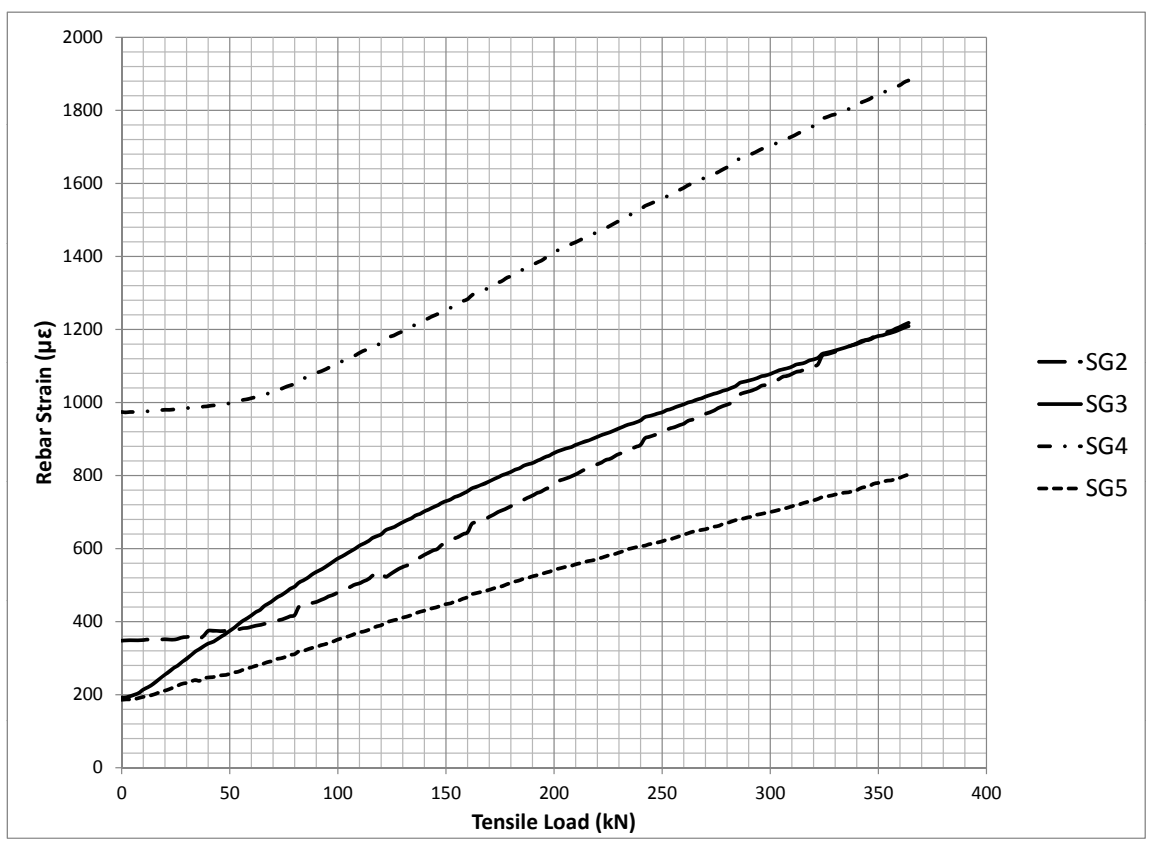

Figure 4.13: Strain-Tensile Load, S200, Phase II 


\subsection{Phase III}

The main focus of this experimental study was to measure the leakage of pressurized water through a fully developed direct tension crack in the RC panels. Specimens were cracked in Phase I and the relationship between tensile load and the crack widths was found in Phase II. In Phase III the water pressure chamber was installed on the RC panel's top surface on the crack as described in Chapter 3. It was not possible to measure the top crack width since it was located inside the pressure chamber. The bottom crack width was measured by water proof KG-5A gauges. In both specimens another crack existed only on the top surface outside of the chamber. The width of this crack was also measured during Phase III. Measured crack widths during the leakage test were compared to those of Phase II in order to find the top crack width which could not be measured. The strains of the rebars were also used to validate the results between the two phases.

\subsubsection{Specimen S250}

Fig. 4.14 and 4.15 show the recorded crack widths for the third phase of the test together with the results of Phase II. The tensile load-crack width relationship for the two phases of the test were shown in the same graph in order to allow for comparison of crack widths. Measured crack widths in Phase III are in same range as those measured in Phase II. The rebar strains were also plotted together for the last two phases of the test in Fig. 4.16. Each strain gage had recorded similar strains for the two phases of the test. Since similar crack widths and strains were recorded for Phase II and Phase III, it was concluded that the top crack width for the crack located inside the water chamber was equal to the crack width measured in Phase II.

Fig. 4.17 shows the crack widths against the tensile load in Phase III. The tensile loads and the corresponding crack widths that were used for the leakage test are summarized in Table. 4.2. The selected crack widths,ranging from the residual crack width to the crack width at cracking load $(450 \mathrm{kN})$, were subjected to three different water pressures of $p_{1}=0.023$, $p_{2}=0.046$ and $p_{3}=0.069 \mathrm{MPa}(2.34 \mathrm{~m}, 4.48 \mathrm{~m}$ and $=7.18 \mathrm{~m}$ of water head $)$. The corresponding measured leakage flow due to these pressures, $Q_{p 1} Q_{p 2} Q_{p 3}$, is presented in Table. 4.3. The measured flow is also plotted separately for both top and bottom crack widths in Fig. 4.18 and Fig. 4.19 respectively. 


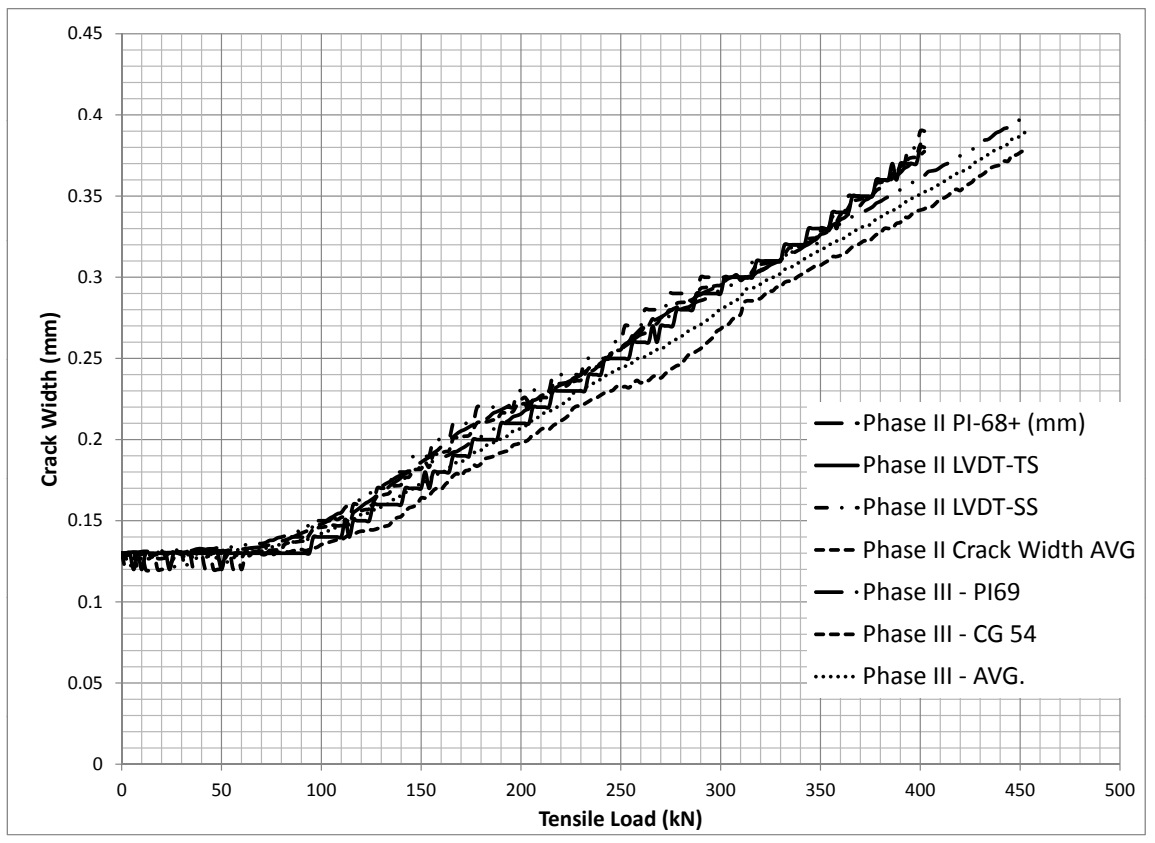

Figure 4.14: Top Crack Width (Outside of the Chamber),S250, Phases II and III

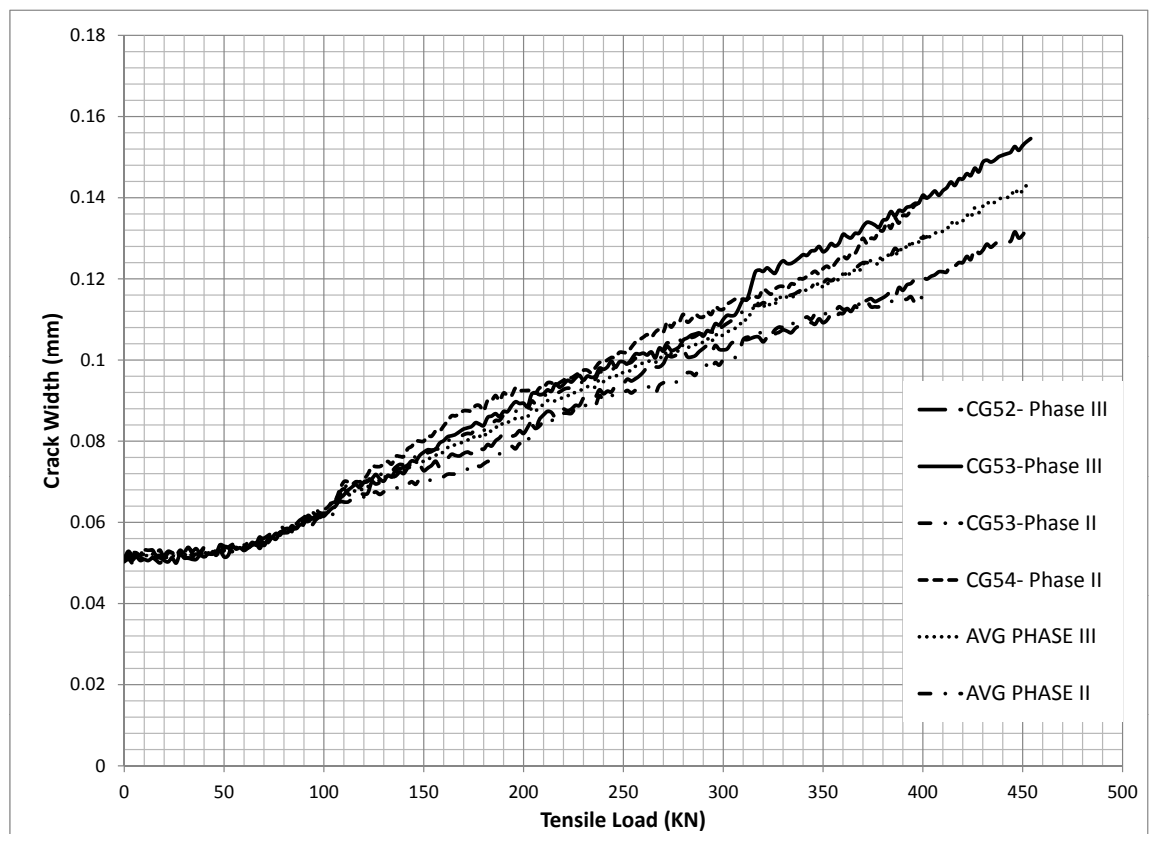

Figure 4.15: Bottom Crack Width, S250, Phases II and III 


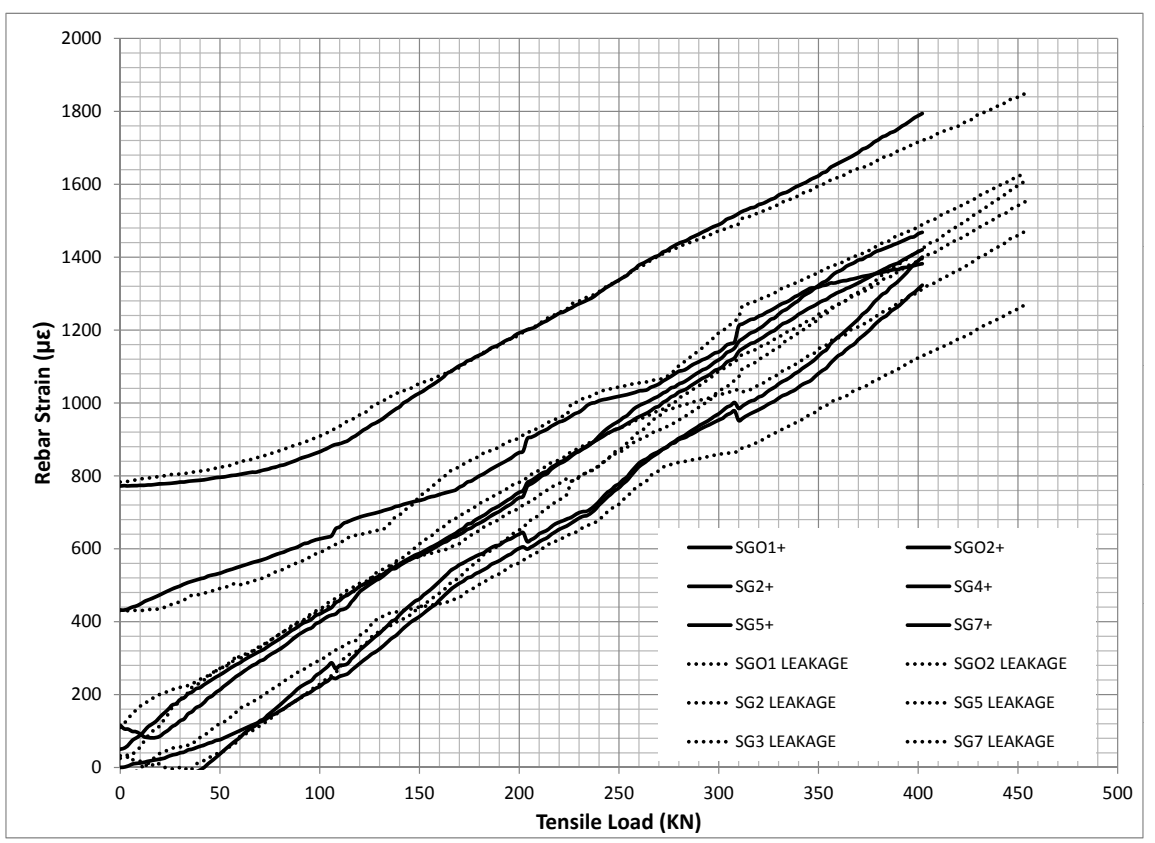

Figure 4.16: Rebar Strains, S250, Phase II and Phase III

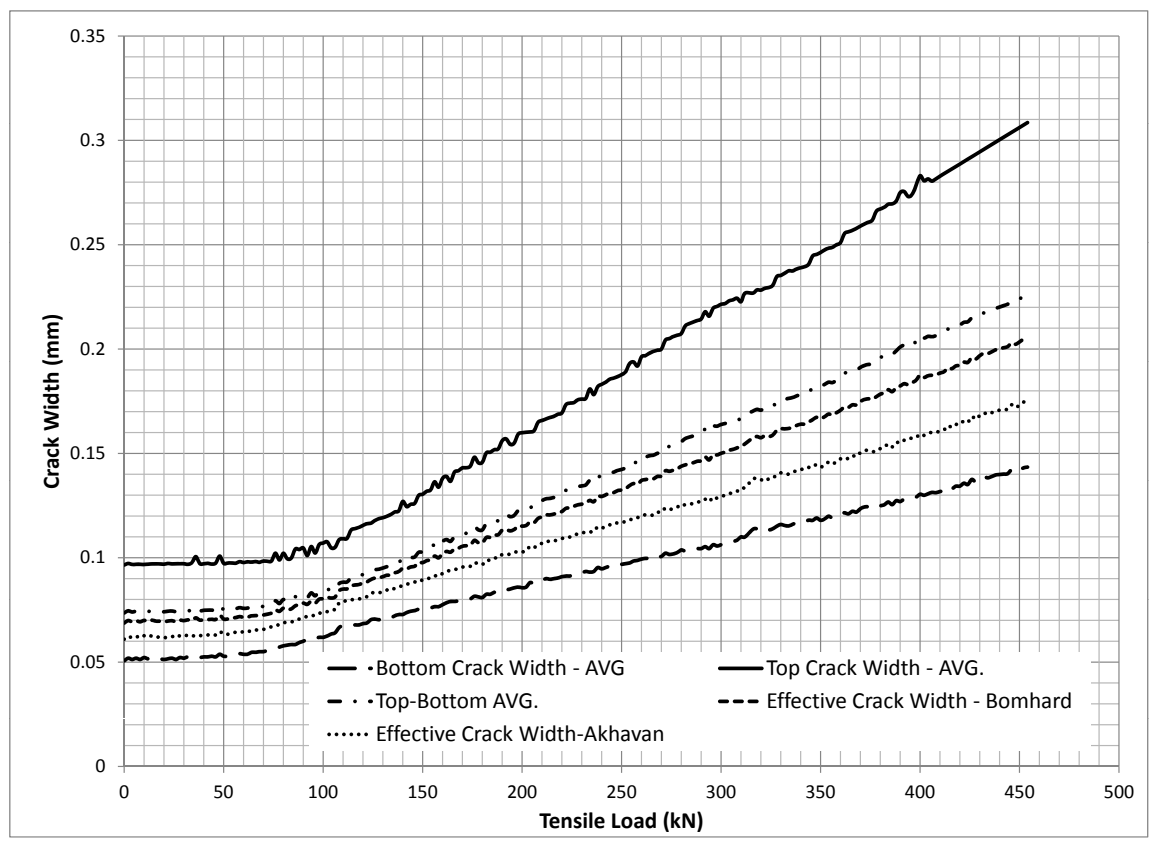

Figure 4.17: Crack Widths vs. Tensile Load, S250, Phase III 
Table 4.2: Leakage Test Crack Widths (mm), S250

\begin{tabular}{|c|c|c|c|c|c|}
\hline Tensile Load (kN) & $W_{\text {Bottom }}$ & $W_{\text {Top }}$ & $W_{\text {Avg. }}$ & $W_{\text {eff. }}$ (Bomhard) & $W_{\text {eff. }}$ (Akhavan) \\
\hline 0 & 0.051 & 0.097 & 0.074 & 0.069 & 0.061 \\
\hline 50 & 0.053 & 0.097 & 0.075 & 0.071 & 0.063 \\
\hline 100 & 0.062 & 0.107 & 0.084 & 0.080 & 0.073 \\
\hline 150 & 0.075 & 0.130 & 0.103 & 0.098 & 0.089 \\
\hline 200 & 0.086 & 0.160 & 0.123 & 0.115 & 0.103 \\
\hline 250 & 0.097 & 0.188 & 0.142 & 0.132 & 0.117 \\
\hline 300 & 0.106 & 0.221 & 0.164 & 0.150 & 0.129 \\
\hline 350 & 0.118 & 0.246 & 0.182 & 0.167 & 0.144 \\
\hline 400 & 0.130 & 0.283 & 0.207 & 0.188 & 0.159 \\
\hline 450 & 0.142 & 0.310 & 0.226 & 0.205 & 0.173 \\
\hline
\end{tabular}

Table 4.3: Measured Leakage for Different Crack Widths, S250

\begin{tabular}{|c|c|c|c|c|}
\hline$W_{\text {Bottom }}(\mathbf{m m})$ & $W_{\text {Top }}(\mathbf{m m})$ & $Q_{P 1}(\mathbf{L i t} / \mathbf{m i n})$ & $Q_{P 2}(\mathbf{L i t} / \mathbf{m i n})$ & $Q_{P 3}(\mathbf{L i t} / \mathbf{m i n})$ \\
\hline 0.051 & 0.097 & 0.010 & 0.010 & 0.010 \\
\hline 0.062 & 0.107 & 0.020 & 0.034 & 0.047 \\
\hline 0.075 & 0.130 & 0.080 & 0.110 & 0.140 \\
\hline 0.086 & 0.160 & 0.190 & 0.256 & 0.321 \\
\hline 0.097 & 0.188 & 0.330 & 0.400 & 0.540 \\
\hline 0.106 & 0.221 & 0.540 & 0.652 & 0.805 \\
\hline 0.118 & 0.246 & 0.850 & 1.030 & 1.130 \\
\hline 0.130 & 0.283 & 1.194 & 1.377 & 1.560 \\
\hline 0.142 & 0.306 & 1.600 & 1.710 & 1.901 \\
\hline
\end{tabular}




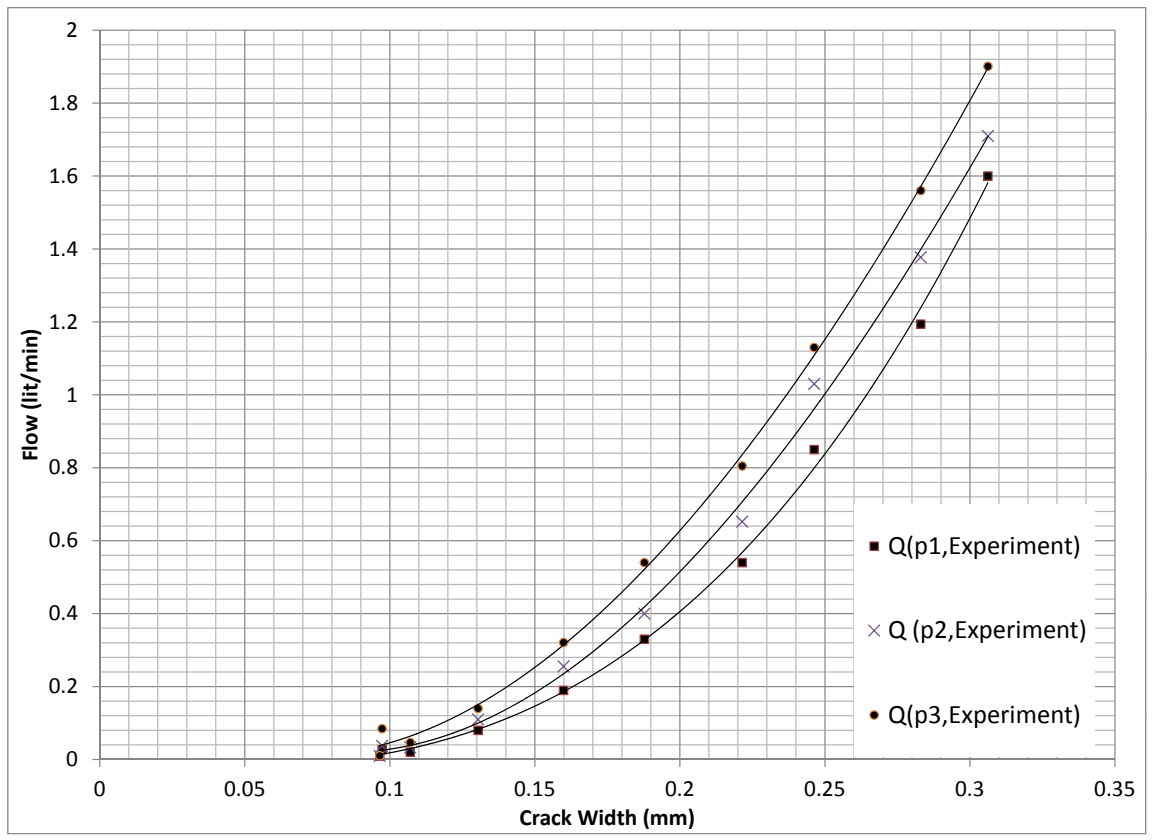

Figure 4.18: Leakage Flow vs. Top Crack Width, S250

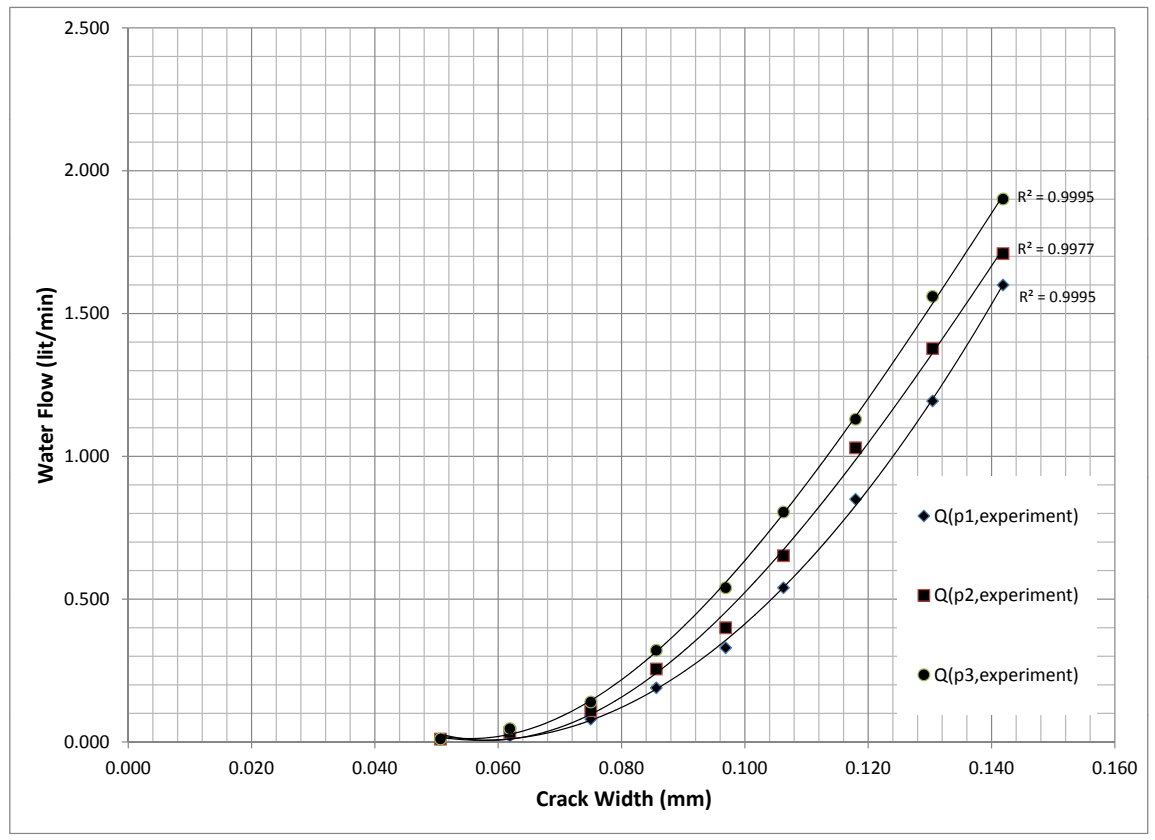

Figure 4.19: Leakage Flow vs. Bottom Crack Width, S250 


\subsubsection{Specimen S200}

A similar procedure to specimen S250 was employed to make a decision about the top crack width since it was not possible to measure it inside the chamber. The bottom crack widths measured by the crack gauges and also the rebar strains were in the same range as measured in phase II.

In Fig. 4.20 the relationship between the tensile load and top and bottom crack widths is presented. The crack widths used for the leakage test are presented in Table. 4.4. The water leakage is related to the top and bottom crack widths in Fig. 4.21 and 4.22. The measured leakage is a function of the cube of the crack width. In a same manner as in specimen S250, the experimental values of flow are much lower than the theoretical values due to the roughness of the inner walls of the crack. The roughness factor can be calculated by deviding the

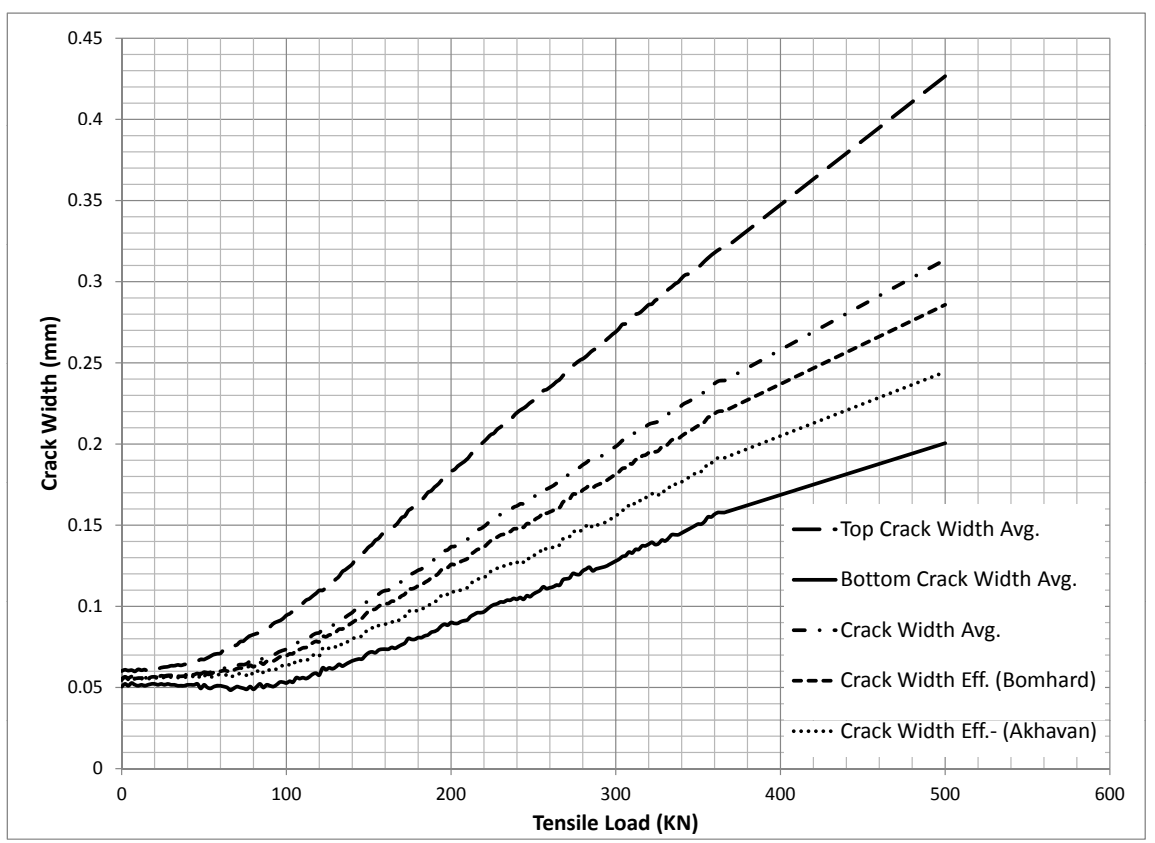

Figure 4.20: Crack Widths, S200, Phase III 
Table 4.4: Measured Leakage for Different Crack Widths, S200

\begin{tabular}{|c|c|c|c|c|}
\hline$W_{\text {Top }}(\mathbf{m m})$ & $W_{\text {Bottom }}(\mathbf{m m})$ & $Q_{P 1}(\mathbf{L i t} / \mathbf{m i n})$ & $Q_{P 2}(\mathbf{L i t} / \mathbf{m i n})$ & $Q_{P 3}(\mathbf{L i t} / \mathbf{m i n})$ \\
\hline 0.060 & 0.051 & 0.008 & 0.014 & 0.020 \\
\hline 0.113 & 0.062 & 0.023 & 0.025 & 0.028 \\
\hline 0.227 & 0.108 & 0.067 & 0.119 & 0.180 \\
\hline 0.328 & 0.161 & 0.312 & 0.428 & 0.636 \\
\hline 0.427 & 0.201 & 0.832 & 0.886 & 1.243 \\
\hline
\end{tabular}

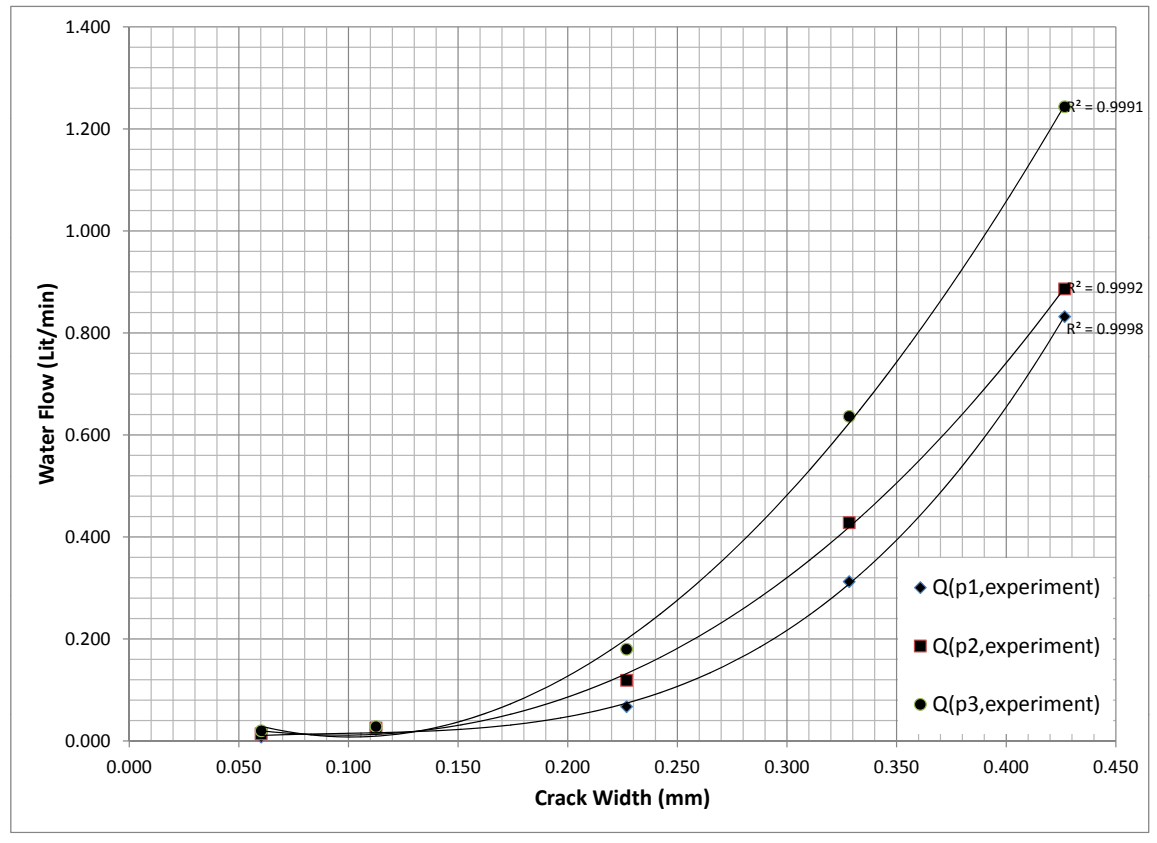

Figure 4.21: Leakage Flow vs. Top Crack Width, S200 


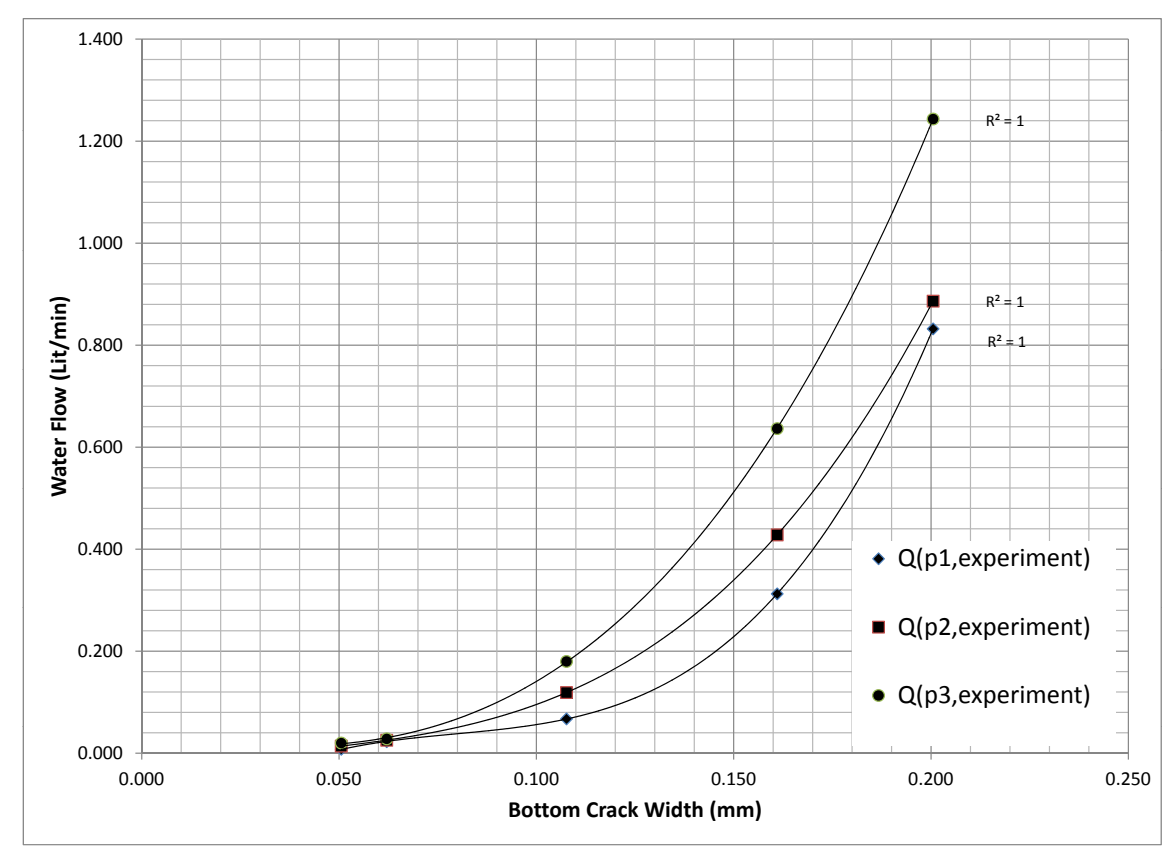

Figure 4.22: Leakage Flow vs. Bottom Crack Width, S200

\subsection{Leakage Test Results Analysis}

As discussed in Chapter 2, permeability of cracked concrete depends on the crack width. According to the Poisseulle flow (Eq. 2.8) the volumetric flow of water through the crack is related to the cube of crack width. The best fit curves in Fig. 4.18, 4.19, 4.21 and 4.22 strongly confirm the validity of the cubic law as the flow of water through the crack is related to the cube of top or bottom crack width. In case of variable crack widths through the depth of specimen, a unique value of crack width must be chosen in way that results in the same flow as in the original crack having width gradient. This unique crack width is known as the effective crack width as introduced in $\$ 2.3 .5$. In this study both models of Bomhard (1986) and Akhavan and Rajabipour (2012) are employed. These effective crack widths are then used to calculate the flow reduction factor. The final results are compared with results from previous studies. 


\subsubsection{Specimen S250}

The effective crack widths for specimen S250 are summarized in Table 4.2. According to the crackscope measurements the crack width was almost uniform along its length on each surface of the specimen and equal to the measurements with other devices. In contrast, the crack width varied through the thickness of the specimen and a noticeable gradient was recorded between the top and bottom crack width. Effective crack widths are calculated using the two top and bottom crack widths as $w_{1}$ and $w_{2}$ in Eq. 2.17 and Eq. 2.26:

Akhavan effective crack width: $w_{\text {eff }}=\sqrt[3]{\frac{m}{\sum_{i=1}^{m=2}\left(\frac{1}{\left.w_{i}\right)^{3}}\right.}}=\sqrt[3]{2 \frac{\left(w_{1} w_{2}\right)^{3}}{w_{1}^{3}+w_{2}^{3}}}$

Bomhard effective crack width: $w_{e f f}=\sqrt[3]{2 \frac{\left(w_{1} w_{2}\right)^{2}}{w_{1} w_{2}}}$

The theoretical flow was calculated by Eq. 2.6 based on the assumption of a crack with parallel smooth walls using the effective crack widths. The crack length was also measured equal to $1.11 \mathrm{~m}$. Fig. 4.23 and 4.24 show the theoretical values of the flow together with the results from the experiment. It can be seen that the experimental flow is much less than the theoretical values. This is because of the roughness of the inner surface of the crack which the Poiseuille flow does not account for. Thus, the theoretical values must be reduced using the reduction (roughness) factor:

$$
Q_{\text {Rough }}=\xi Q_{S \text { mooth }}
$$

This reduction factor was calculated by dividing the theoretical flow by the experimental flow for each effective crack width. The roughness factors are plotted on Fig. 4.26 for the two sets of effective crack widths. These graphs suggest that the roughness factor depends on the crack width. The roughness factors increase as the crack gets wider. In other words, the effect of roughness decreases as the crack opens and the Poisseulle's flow becomes more valid. In the crack width range of $0.05-0.12 \mathrm{~mm}$, the roughness factor increases in a greater rate in comparison to the crack widths larger than $0.15 \mathrm{~mm}$. 


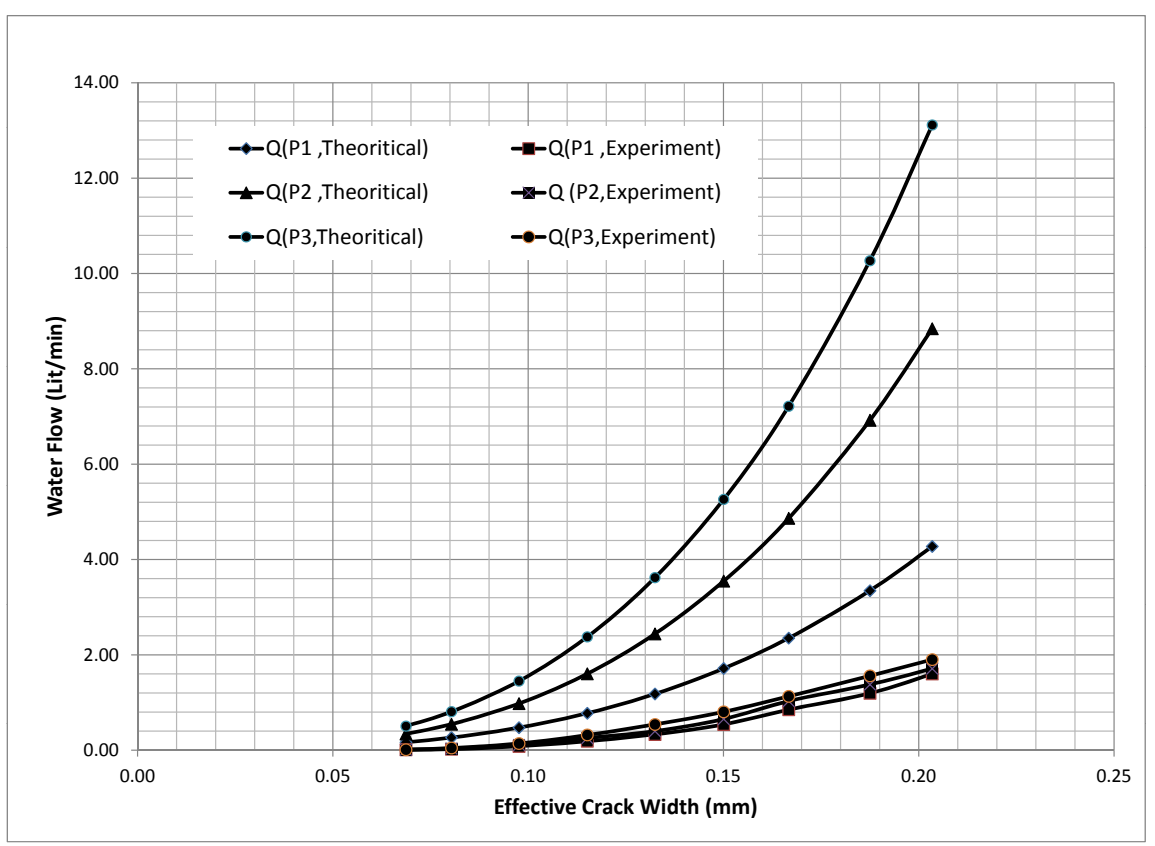

Figure 4.23: Leakage vs. Bomhard Effective Crack Width, S250

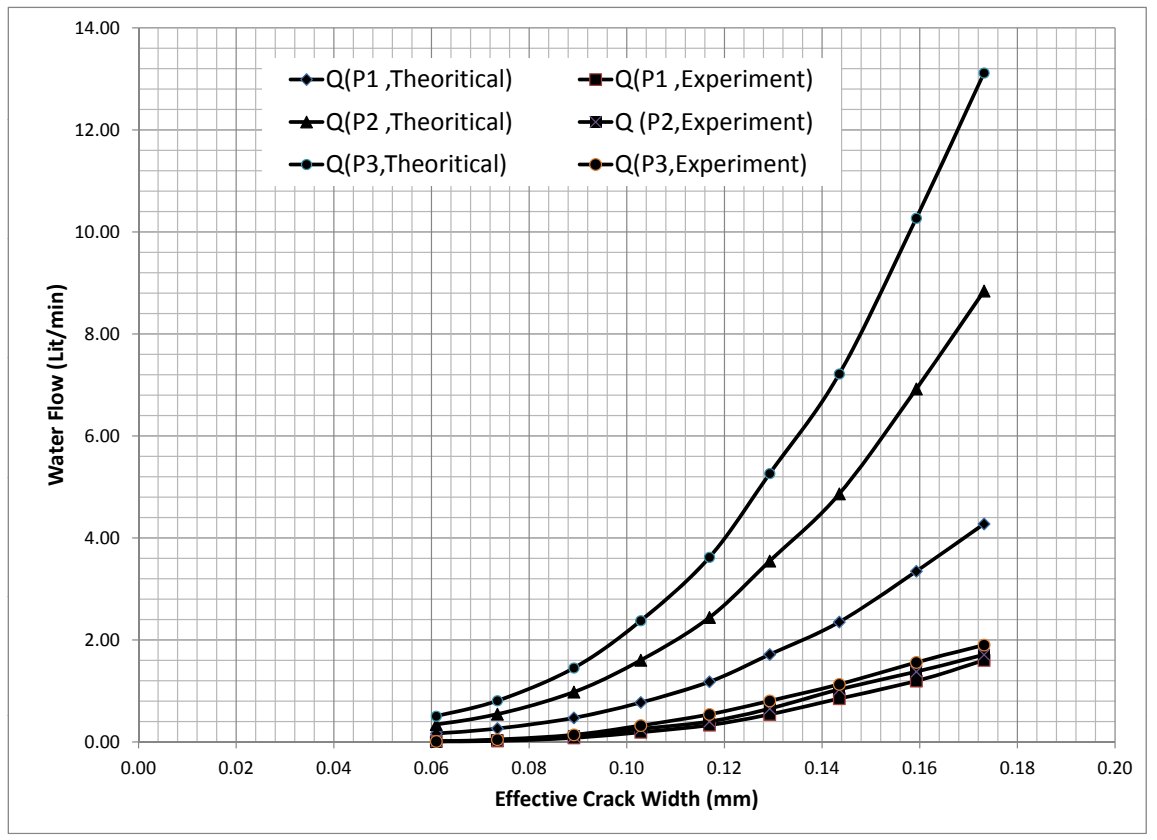

Figure 4.24: Leakage vs. Akhavan Effective Crack Width, S250 
The reduction factors calculated for specimen S250 vary with the pressure gradient. For the same crack width, the roughness factor is larger for smaller pressure gradients. This variation implies that the roughness factor depends on the pressure gradient between the two ends of the crack. This phenomenon is in good agreement with the Darcy friction factor qualitatively. Darcy's friction factor accounts for the friction losses in pipe or open channel flow.

$$
f=\frac{8 \tau_{w}}{\rho V^{2}}
$$

Where $\tau_{w}$ is the shear stress between the fluid and the inner surface of the channel, $\rho$ is the fluid density and $V$ is the velocity of the fluid. Darcy's friction factor is related to the inverse of fluid velocity square. The friction between the fluid and the solid surface is larger in higher velocities. The volumetric flux can be written as the product of velocity and area of the crack. Higher water pressures result is higher velocity of water and leakage. Meanwhile, the effect of friction is also increased. The same conclusion can be made by comparing the experimental values of leakage through a single crack width subjected to three different water heads of $2.34 \mathrm{~m}, 4.48 \mathrm{~m}$ and $7.18 \mathrm{~m}$. The flow through the crack can be calculated using the following equation.

$$
Q=\xi \frac{g l}{12 v} \frac{\Delta h}{h} w_{e f f}^{3}
$$

The term $\xi$ in Eq. 4.4 is the roughness factor and known to be a function of crack width. According to this equation, there is a linear relationship between the flow and water head. Hence, the leakage due to water head of $7.18 \mathrm{~m}$ will be three times larger than the leakage due to water head of $2.34 \mathrm{~m}$. However, the experimental results do not show such an increase in the leakage. For instance, Fig. 4.25 shows both theoretical and experimental values of leakage for effective crack width of $0.15 \mathrm{~mm}$ versus water head.

The roughness factors calculated for specimen S250 were almost in the same range as previously reported factors as summarized in $\$ 2.5$. Akhavan's model conservatively related the measured flows to smaller effective crack widths in comparison with Bomhard's suggestion and as a result, the roughness factors ranged from 0.02 to 0.37 . This range was 0.03-0.61 if the Bomhard effective crack widths were used. As shown in Fig. 4.26, while the roughness factors for the smaller crack widths are in the same range for both models, a higher variation is observed for wider cracks. 


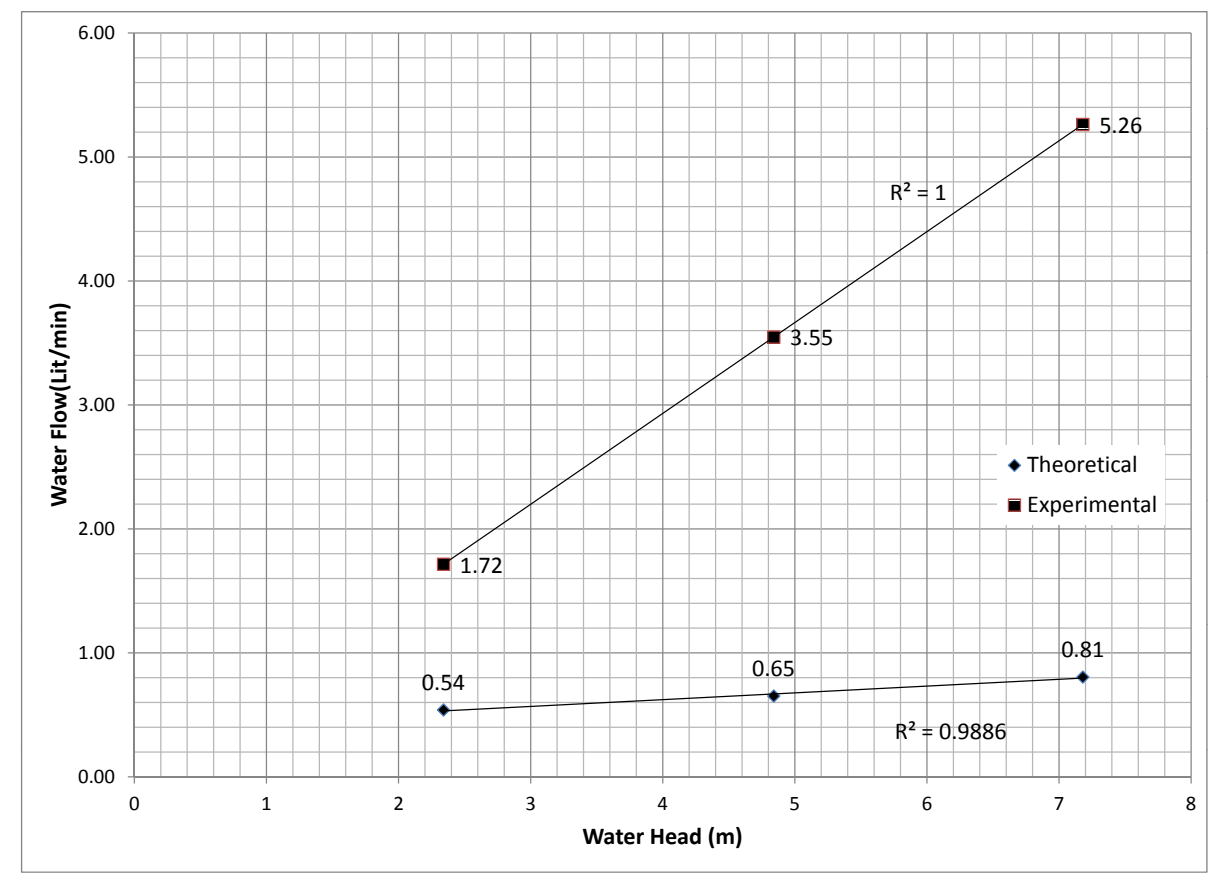

Figure 4.25: Leakage vs. Water Head, S250, Crack Width of $0.15 \mathrm{~mm}$

\subsubsection{Specimen S200}

The crack width gradient existed through the thickness of the specimen and the crack was uniform along its length on top or bottom surfaces. Table 4.5 shows the effective crack widths used for the leakage test. The theoretical flow was calculated by Eq. 2.6 using the effective crack widths and the assumption of a crack with parallel smooth walls. The crack length was also measured equal to $1.06 \mathrm{~m}$. Fig. 4.27 shows the theoretical values of the flow together with the results from the experiment. The leakage per meter length of the crack is also shown in Tables 4.6 and 4.7 .

The roughness factor was computed in the same manner as for specimen S250, by dividing the experimental value of the flow by the theoretical value. These roughness factors are presented in Fig. 4.28. The variation of the roughness factor for this specimen is much lower than specimen S250 and will be discussed later. The roughness factor is smaller than 0.1 for most of the crack widths. Similar to specimen S250, the roughness factors from tests with higher water pressures indicate lower roughness factor, i.e., the stronger effect of friction in higher 


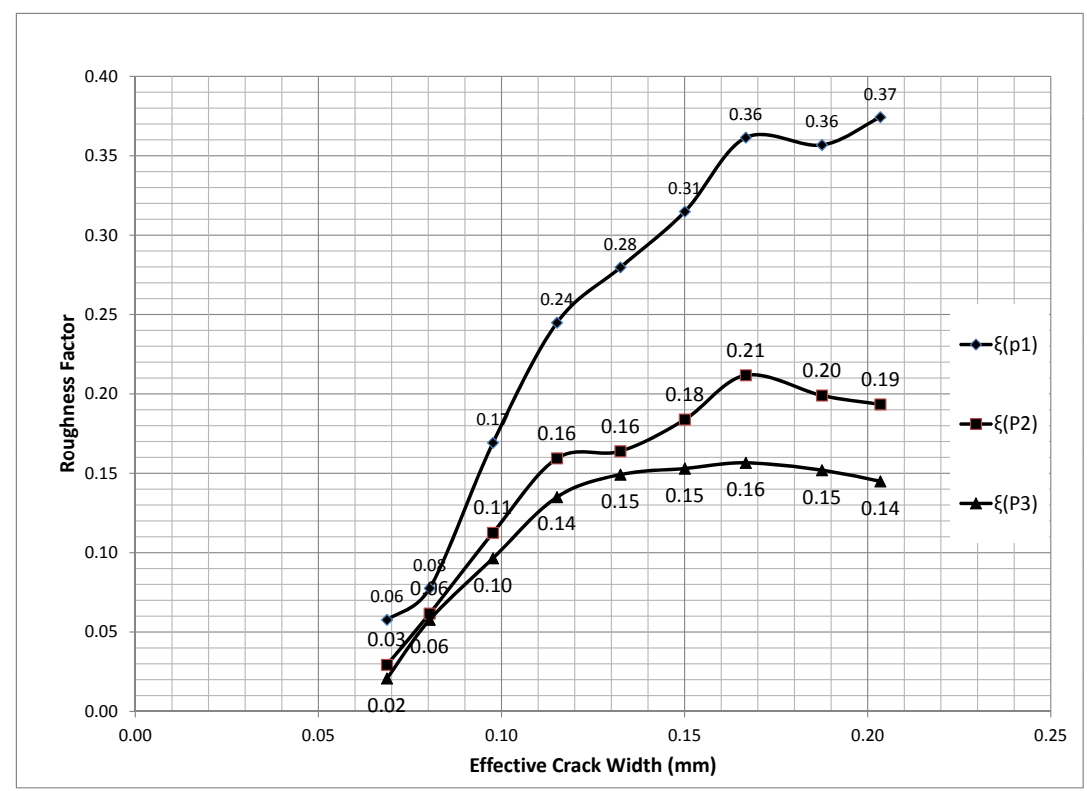

(a) Bomhard Effective Crack Width

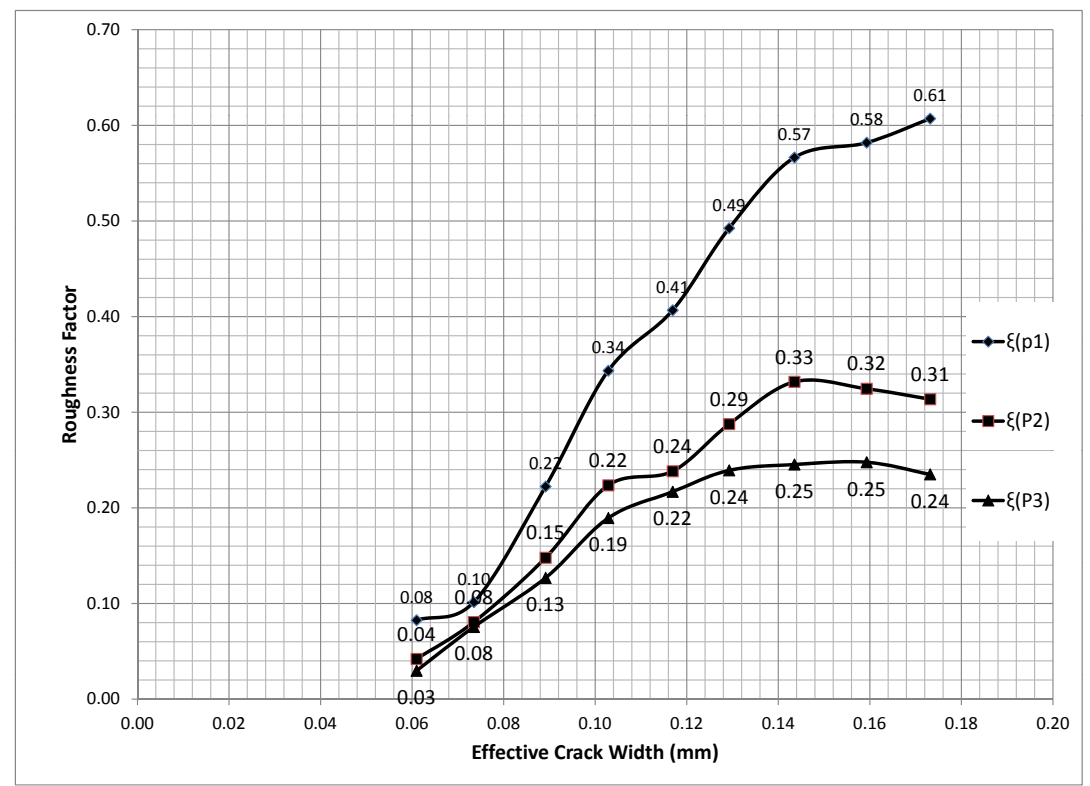

(b) Akhavan Effective Crack Width

Figure 4.26: Roughness Factor, S250 


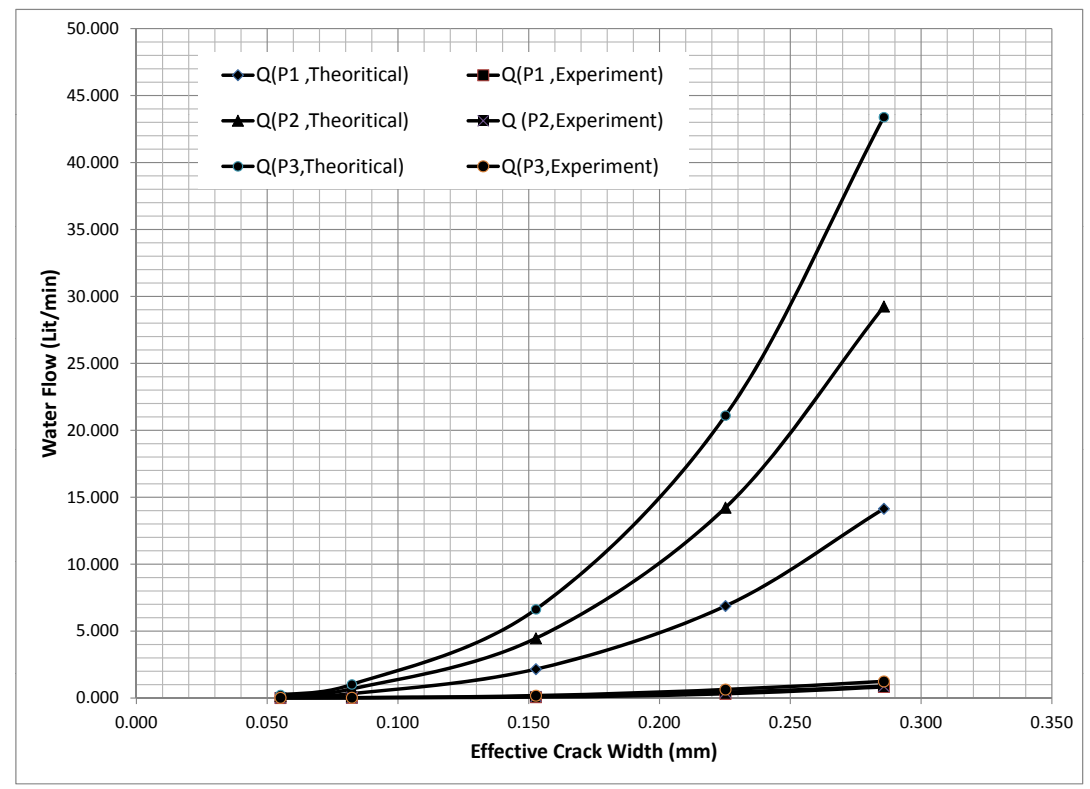

(a) Bomhard Effective Crack Width

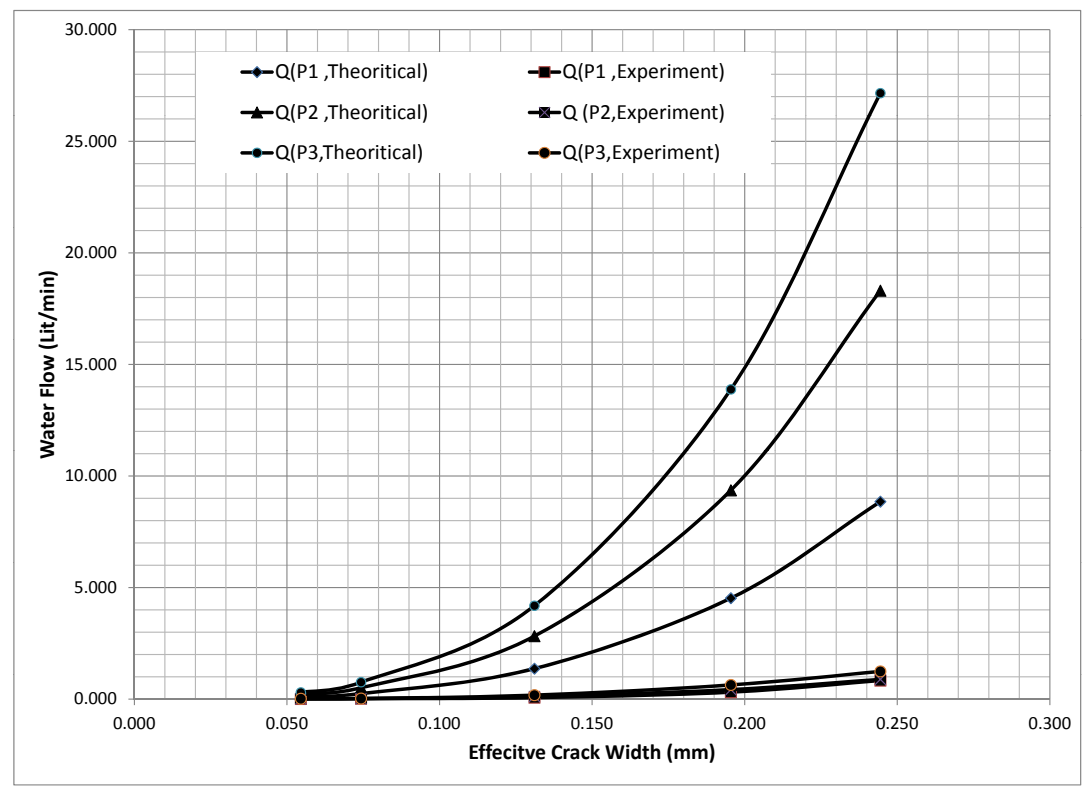

(b) Akhavan Effective Crack Width

Figure 4.27: Leakage vs. Effective Crack Width, S200 
Table 4.5: Crack Widths used for Leakage Test in millimeter, S200

\begin{tabular}{|c|c|c|c|c|c|}
\hline Tensile Load (kN) & $W_{\text {Top }}$ & $W_{\text {Bottom }}$ & $W_{\text {Avg. }}$ & $W_{\text {eff. }}$ (Bomhard) & $W_{\text {eff. }}$ (Akhavan) \\
\hline 0 & 0.060 & 0.051 & 0.055 & 0.055 & 0.055 \\
\hline 126 & 0.113 & 0.062 & 0.087 & 0.082 & 0.074 \\
\hline 250 & 0.227 & 0.108 & 0.167 & 0.153 & 0.131 \\
\hline 376 & 0.328 & 0.161 & 0.245 & 0.225 & 0.195 \\
\hline 500 & 0.427 & 0.201 & 0.314 & 0.286 & 0.244 \\
\hline
\end{tabular}

pressures.

The roughness factors decrease from about 0.1 to 0.03 while the effective crack width increases form $0.1 \mathrm{~mm}$ to $0.15 \mathrm{~mm}$. The roughness factors remain almost constant for pressures $P_{2}$ and $P_{3}$ and slightly increase for $P_{1}$. These results are in contrast with results from similar tests that suggest more validity of the Poiseuille flow with crack width increase.

As mentioned before the roughness factors calculated for specimen S200 were smaller than that calculated for specimen S250. A noticeable difference between specimens S200 and S250 was observed in the ratio between the bottom and top crack widths. Fig. 4.29 shows this ratio for both specimens.

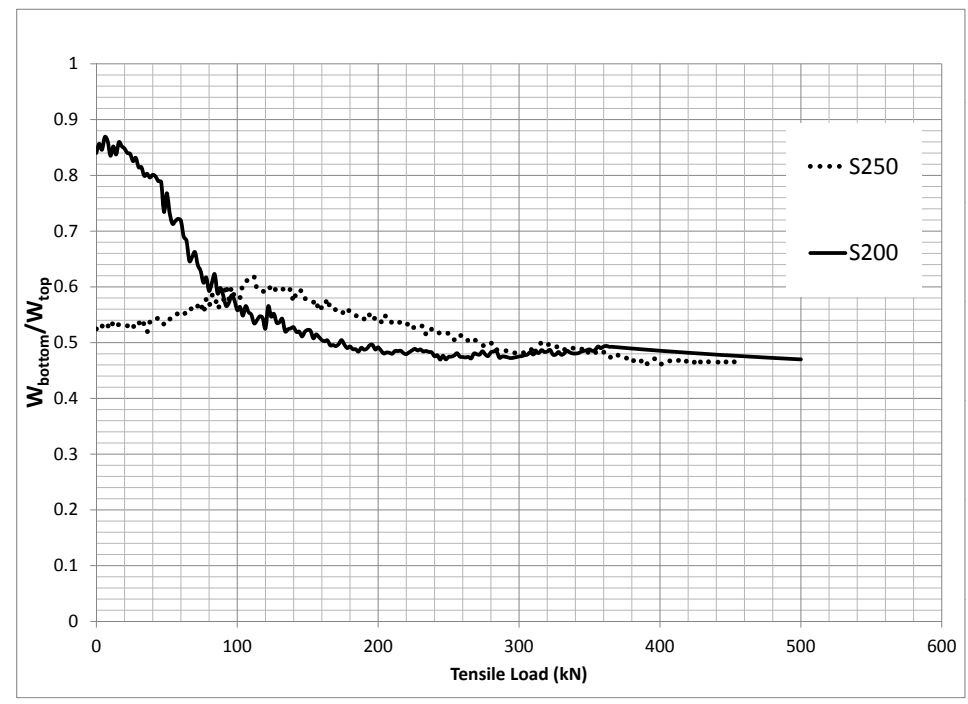

Figure 4.29: Crack Width Ratio 


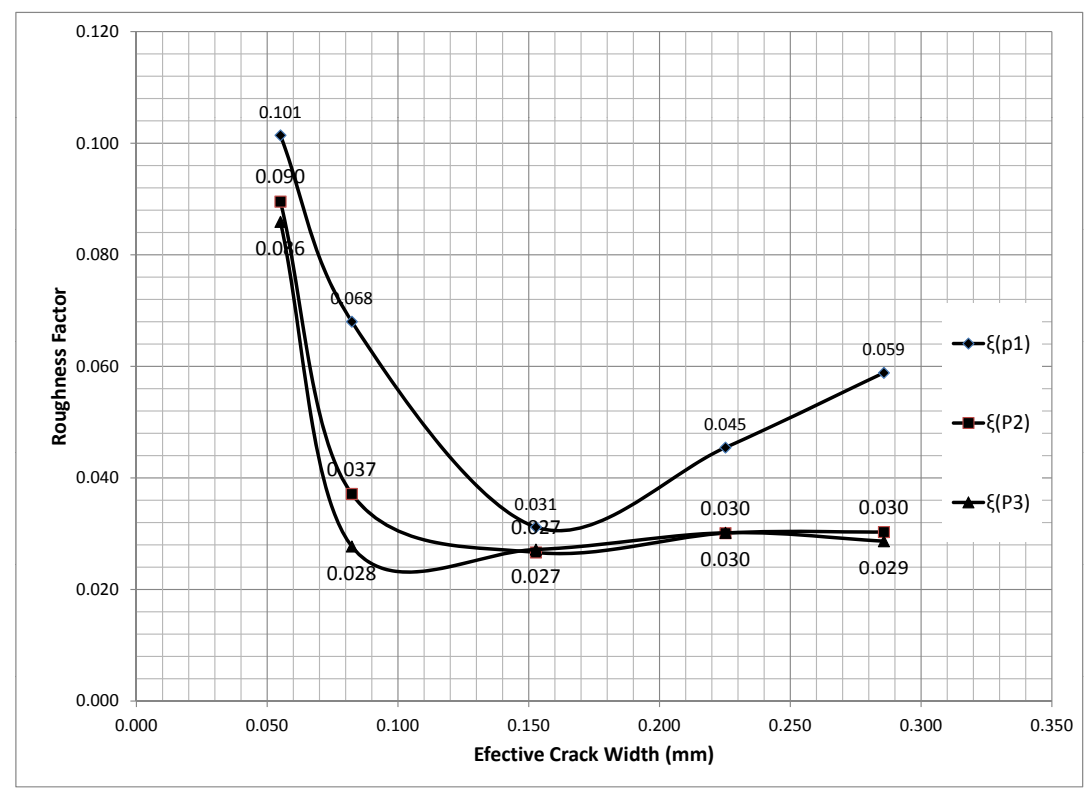

(a) Bomhard Effective Crack Width

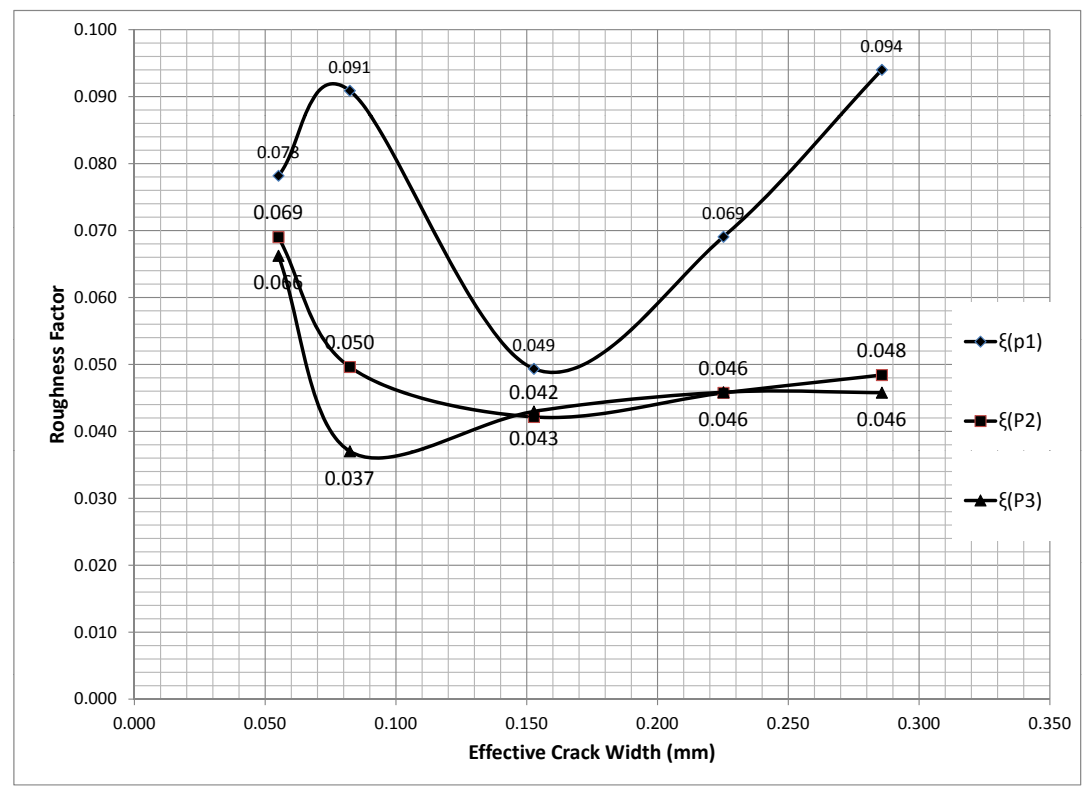

(b) Akhavan Effective Crack Width

Figure 4.28: Roughness Factor, S200 
- In Specimen S200 for the range of 0-120 kN of tensile load, although the crack is getting wider both on top and bottom, the rate of increase is larger for the top crack width. This implies a larger angle between the walls of the crack and the flow direction, resulting in more resistance of the crack against the flow. The mentioned tensile load range matches the effective crack width of $0.05-0.08 \mathrm{~mm}$. The experiment results suggest a decrease in the roughness factors for this range of crack widths.

- In specimen S250 for the range of 0-110 kN of tensile load, the crack width ratio between the top and bottom increases. In other words the bottom crack width increases more that the top crack width. The rate of increase is about one-third of this rate in specimen S200 and shows no significant effect on the roughness factor.

Table 4.6: Leakage per meter length, S250

\begin{tabular}{|c|c|c|c|c|}
\hline$w_{\text {eff }}($ Akhavan $)(\mathrm{mm})$ & $w_{\text {eff }}($ Bomhard $)(\mathrm{mm})$ & $Q_{p 1}[\mathrm{lit} / \mathrm{h} / \mathrm{m}]$ & $Q_{p 2}[\mathrm{lit} / \mathrm{h} / \mathrm{m}]$ & $Q_{p 3}[\mathrm{lit} / \mathrm{h} / \mathrm{m}]$ \\
\hline 0.07 & 0.08 & 1.12 & 1.83 & 2.55 \\
\hline 0.09 & 0.10 & 4.36 & 6.00 & 7.64 \\
\hline 0.10 & 0.12 & 10.35 & 13.94 & 17.51 \\
\hline 0.12 & 0.13 & 18.00 & 21.82 & 29.45 \\
\hline 0.13 & 0.15 & 29.45 & 35.58 & 43.91 \\
\hline 0.14 & 0.17 & 46.36 & 56.18 & 61.64 \\
\hline 0.16 & 0.19 & 65.13 & 75.13 & 85.09 \\
\hline 0.17 & 0.20 & 87.27 & 93.27 & 103.69 \\
\hline
\end{tabular}

Table 4.7: Leakage per meter length, S200

\begin{tabular}{|c|c|c|c|c|}
\hline$w_{\text {eff }}($ Akhavan $)(\mathrm{mm})$ & $w_{\text {eff }}($ Bomhard $)(\mathrm{mm})$ & $Q_{p 1}[\mathrm{lit} / \mathrm{h} / \mathrm{m}]$ & $Q_{p 2}[\mathrm{lit} / \mathrm{h} / \mathrm{m}]$ & $Q_{p 3}[\mathrm{lit} / \mathrm{h} / \mathrm{m}]$ \\
\hline 0.055 & 0.055 & 0.43 & 0.79 & 1.13 \\
\hline 0.074 & 0.082 & 1.28 & 1.44 & 1.60 \\
\hline 0.131 & 0.153 & 3.81 & 6.73 & 10.19 \\
\hline 0.195 & 0.225 & 17.69 & 24.23 & 36.03 \\
\hline 0.244 & 0.286 & 47.10 & 50.17 & 70.38 \\
\hline
\end{tabular}




\section{Chapter 5}

\section{Conclusions}

\subsection{Summary}

An experimental study on the leakage of pressurized water through direct tension cracks was carried out. The main purpose of this research was to measure the flow of water through a fully developed crack in an RC panel of real-life scale. The results of this study can assist to set appropriate values of crack width for LCS since tests of this kind are rare and have not been reported in the literature. In case of a tank with a circular basis, the tank wall will go under tensile stresses due to the hydrostatic pressure of the liquid inside the container. The cracks induced under such loading conditions are more vulnerable to leakage of liquid in comparison with flexural cracks. This study was dedicated to examination of water leakage through these cracks.

With this intension an experimental program was designed and examined under three phases. In phaseI, direct tensile forces were applied to RC panels, each representing a segment of a reinforced concrete tank wall, in order to create a major crack. The specimens were unloaded after formation of a crack which was fully developed through specimen's thickness. During PhaseII, the cracked specimens were reloaded and the crack widths were measured for different magnitudes of tensile load. The specimens were unloaded again at the end of this phase. In phaseIII, a pressure vessel, particularly designed for this test, was installed on the induced crack. The specimens were reloaded incrementally. The leakage test was performed at three different water heads of $2.34 \mathrm{~m}, 4.84 \mathrm{~m}$ and $7.18 \mathrm{~m}$ for crack widths at certain loads. The water flow through the crack was measured over time. 
ACI 350 (2001) recommends crack widths of $0.23 \mathrm{~mm}$ and $0.27 \mathrm{~mm}$ for flexural cracks in severe and normal conditions respectively. But no suggestions are available for cracks induced in pure tension. Crack widths must be limited to $0.1 \mathrm{~mm}$ in LCS according to ACI 224R-01. The results of this experiment indicate a leakage of 0.14 lit/min for a crack in the specimen with thickness of $250 \mathrm{~mm}$ subjected to more than 7 meters of water head. The relative crack widths for the mentioned leakage rate was $0.13 \mathrm{~mm}$ on top and $0.07 \mathrm{~mm}$ at the bottom, resulting in an effective crack width of $0.1 \mathrm{~mm}$.

\subsection{Conclusions}

Several conclusions reached in the leakage test can be summarized as follows:

- The measured flow strongly depends on the cube of the crack width which is in good agreement with the Poiseuille flow model.

- The roughness factors $(\xi)$ calculated in this study are in the similar range of those previously reported in the literature. The results of this experiment suggest a scattered range of 0.03-0.61 for this factor.

- The results confirm that the roughness factor is a function of the crack width. For constant top to bottom crack width ratio, the roughness factor increases as the crack width becomes larger. In other words, the effect of roughness decreases as the crack opens and the Poiseuille flow becomes more valid.

- Results from both test specimens suggest that for a single effective crack width, the roughness factor varies with pressure gradient. Higher pressures result in smaller values of the roughness factor. The effect of pressure gradient on roughness is reduced as the water pressure increases.

- Test results suggest that in case of crack width gradients, the ratio between the top and bottom crack widths may have an effect on the amount of leakage. Such conditions requires further study.

- No water leakage was observed during this test for cracks subjected to unpressurized water (15 cm of water head). This simulated the behavior of cracks on roof tops where 
there might be a possibility of ponding water due to rain and snow. The maximum effective crack width reached in this study was $0.29 \mathrm{~mm}$.

- For the maximum crack width of $0.1 \mathrm{~mm}$ (ACI 224R recommendation), subjected to 7.2 $m$ of water head, a leakage flow of $2.55 \mathrm{lit} / \mathrm{h} / \mathrm{m}$ was measured. This rate was $17.5 \mathrm{lit} / \mathrm{h} / \mathrm{m}$ for effective crack width of $0.1 \mathrm{~mm}(0.16 \mathrm{~mm}$ on top, $0.09 \mathrm{~mm}$ at the bottom).

\subsection{Recommendations for Future Research}

This experimental study aimed to investigate the leakage of water through cracked RC sections. Some new findings during this study require further investigation. The following are some suggestions for future study based on the outcomes of this research:

- The process of applying a uniform tensile load to the one meter strip specimen and also sealing the chamber on the specimen were extremely time consuming. It was not possible to reach water heads higher than about $7 \mathrm{~m}$ with the proposed setup because of the long contact length between the specimen and the chamber which had to be sealed. Instead of the one meter strip sample, a single rebar with the effective concrete area around it can be used for similar tests.

- Leakage test can be conducted with pressure range of $10 \mathrm{~m}$ to $15 \mathrm{~m}$ of water head. In addition to the leakage data at this pressure range, this will allow for better understanding of the relationship between the roughness factor and pressure gradient.

- Different concrete mixes can be used for similar experiments.

- An experimental study can be dedicated to examination of the effect of crack width gradients and the ratio of crack widths at the two sides of the crack.

- Self healing of the cracks can be examined for water heads greater than $10 \mathrm{~m}$. Meanwhile, the effect of leakage on corrosion of the steel reinforcement can be of interest. 



\section{References}

ACI 209R (2008). Prediction of Creep, Shrinkage and Temperature Effects in Concrete Structures, (ACI 209R-92). American Concrete Institute: Farmington Hills, Mich.

ACI 224 (2001). Control of Cracking in Concrete Structures. American Concrete Institute: Farmington Hills, Mich.

ACI 318 (2008). Building Code Requirements for Structural Concrete ((ACI 318-08)) and commentary (ACI 318R-9). American Concrete Institute: Farmington Hills, Mich.

ACI 350 (2006). Code Requirements for Environmental Engineering Concrete Structures and Commentary. American Concrete Institute: Farmington Hills, Mich.

Akhavan, A., S. S. and F. Rajabipour (2012). Quantifying the effects of crack width, tortuosity, and roughness on water permeability of cracked mortars. Cement and Concrete Research 42, 313-320.

Archambault G., Rouleau, A. and B. Ladanyi (1992). Comportement anisotrope de la dformabilit-dilatance permabilit des massifs rocheux fractures. In Gomatriaux Coll. Ren Houpert, Str. Comp. Mca.

ASTM C39/C39M (2005). Standard Test Method for Compressive Strength of Cylindrical Concrete Specimens. Annual Book of ASTM Standards: Philadelphia.

ASTM C496/C496M (2004). Standard Test Method for Splitting Tensile Strength of Cylindrical Concrete Specimens. Annual Book of ASTM Standards: Philadelphia.

Batchelor, G. . K. (1967). An Introduction to Fluid Dynamics. Cambridge and New York: Cambridge University Press. 
Bomhard, H. (1986). Concrete Tanks for Water Storage- A Conceptional Approach. In Proceedings of the Tenth International Congress of the FIP, pp. 55-77.

Breysse, D., G. B. and M. Lasne (1994). An Experimental Device to Study Cracking and Deterioration of Concrete. In 3rd CANMET/ACI Int. Conf. on Durability of Concrete.

Breysse D., Grard B., L. M. (1997). Cracking Of Concrete Relevance and effects, Tightness of Concrete with Respect to Fluids. RILEM TC-146 TCF State-of-the-Art Report.

Dietrich, P., H. R. S. M. H. H. K. J. and G. Teutsch (2005). Flow and Transport in Fractured Porous Media. Berlin, Germany: Springer.

Edvardsen, C. (1996). Chloride Penetration into Cracked Concrete. RILEM International Workshop on chloride penetration into concrete, St. Remy-lesChevreuses.

Edvardsen, C. (1999). Water Permeability and Autogenous Healing of Cracks in Concrete. ACI Materials Journal 96(4), 448-454.

Hearn, N. and M. C.T. (1997). Self-Sealing Property of Concrete Experimental Evidence. Materials and Structures 30.

Imhof-Zeitler, C. (1996). Fliessverhalten von Flüssigkeiten in durchgehend gerissenen Betonkonstruktionen. Berlin: Deutscher Ausschuss Für Stahlbeton Heft 460.

Jaeger, J. C. Cook, N. and R. W. Zimmerman (2007). Fundamentals of Rock Mechanics, 4th Edition. Blackwell Publishing Ltd.

Kermani, A. (1991). Permeability of stressed concrete. Building Research and Information 19(16), 360-366.

Marchal, J. and B. M. (1992). Transfert diphasique experimental sur une paroi paisse de bton soumise a une elevation rapide de pression et de temperature. Ann. ITBTP 506.

Park, R. and T. Paulay (1975). Reinforced Concrete Structures. New York: John Wiley \& Sons, Inc.

Phillips, O. . M. (1991). Flow and Reactions in Permeable Rocks. Cambridge and New York: Cambridge University Press.

Reinhardt, H. and M. Joos (2003). Permeability and Self-healing of Cracked Concrete as a Function of Temperature and Crack Width. Cement and Concrete Research 33(7), 981985. 
Tsukamoto, M.and Wörmer, J. (1991). Permeability of Cracked Fiber-reinforced Concrete. Darmstad Concrete, Ann. J. Concr. and Concr. Str. 6.

Wang, K., J. D. S. S. and A. Karr (1997). Permeability Study of Cracked Concrete. Cement and Concrete Research 27(3), 381-393.

Ziari, A. and M. R. Kianoush (2009a). Investigation of Direct Tension Cracking and Leakage in RC Elements. Engineering Structures 31(2), 466-474.

Ziari, A. and M. R. Kianoush (2009b). Investigation of Flexural Cracking and Leakage in RC Liquid Containing Structures. Engineering Structures 31(5), 1056-1067. 



\section{REFERENCES}


